NBSIR 73.402

\title{
NBS Materials Science and Manufacturing in Space Research
}

E. Passaglia, R. L. Parker

Institute for Materials Research

Metallurgy Division

National Bureau of Standards

Washington, D. C. 20234

\section{November 1973}

Final Report

For the Period 1 November 1972 - 31 October 1973

Annual Report, NASA Contract W-13,475 No. 1

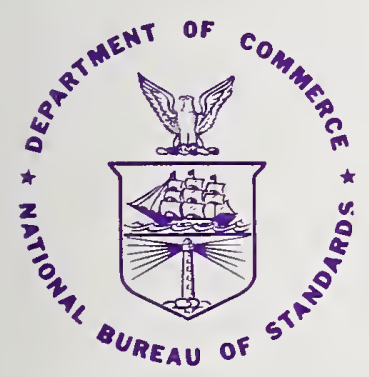

\section{U. S. DEPARTMENT OF COMMERCE}

NATIONAL BUREAU OF STANDARDS 
NBSIR 73-402

\section{NBS MATERIALS SCIENCE AND \\ MANUFACTURING IN SPACE RESEARCH}

E. Passaglia, R. L. Parker

Institute for Materials Research

Meta!lurgy Division

National Bureau of Standards

Washington, D. C. 20234

November 1973

Final Report

For the Period

1 November 1972 - 31 October 1973

Annual Report, NASA Contract W-13,475 No. 1

This report was prepared by the National Bureau of Standards under contract W-13,475 No. 1 - NBS Materials Science and Manufacturing in Space Research, for the Advanced Missions Program of The National Aeronautics and Space Administration.

U. S. DEPARTMENT OF COMMERCE, Frederick B. Dent, Secretary NATIONAL BUREAU OF STANDARDS, Richard W. Roberts, Director 
Table of Contents

Page

Summary. • . . . . . . . . . . . . . . . . . . . . 1-2

Task 1 - EFFECTS OF CONVECTION ON CRYSTAL PERFECTION IN CZOCHRALSKI CRYSTAL GROWTH by M. Kuriyama,

J. G. Early and H. E. Burdette. . . . . . . . . . 3-24

Task 2 - VAPOR TRANSPORT SYNTHESIS AND CRYSTAL GROWTH OF OXIDES by H. S. Parker. . . . . . . . . . . . 25-32

Task 3 - PREPARATION OF ULTRAHIGH PURITY MATERIAL by R. C. Paule . . . . . . . . . . . . . . 33-44

Task 4 - ROLE OF SURFACE TRACTION AND RELATED PHENOMENA IN CHEMICAL PROCESSING IN SPACE by A. L. Dragoo. . . . . 45-56

Task 5 - VACUUM EFFECTS IN THE PREPARATION OF COMPOSITE MATERIALS by H. Yakowitz and D. E. Newbury. . . . . . 57-68

Appendix . . . . . . . . . . . . . . . 69-88

Distribution List. . . . . . . . . . . . . . . . . 89-90 

National Bureau of Standards Materials Science

and

Manufacturing in Space Research

\section{Summary}

This report describes NBS work for NASA in support of NASA's Materials Science and Manufacturing in Space (MS/MS) (now Space Processing) program, covering the period November 1, 1972 to October 31, 1973. The objectives of the NBS program are to perform ground-based studies of those aspects of space that could possibly provide a unique environment for making materials more perfect or more pure. The approach taken deals primarily with experimental and theoretical studies of the possible effects of the absence of gravitational forces on those materials preparation processes where the presence of gravity may be important in reducing perfection or purity. The materials preparation processes studied comprise 5 tasks in the areas of crystal growth, purification and chemical processing, and the preparation of composites.

The results obtained for each task are given in detailed summaries in the body of the report. Briefly, in Task 1 - Effects of Convection on Crystal Perfection in Czochralski Crystal Growth - an intensive study has been performed, and optimum solidification parameters determined for the production of highly perfect copper crystals by the Czochralski growth process, using x-ray topographs and rocking curve measurements of crystal perfection. In Task 2 - Vapor Transport 
Synthesis and Crystal Growth of Oxides - the $\mathrm{ZrO}_{2}-\mathrm{Ta}_{2} \mathrm{O}_{5}$ mixed oxide system was investigated in chemical vapor transport and met severe problems in attack of quartz reaction tubes. In Task 3 - Preparation of Ultrahigh Purity Materials - a calculational procedure involving the use of complex chemical equilibrium was developed and showed that extensive purification can be obtained in evaporative purification. In Task 4 - Role of Surface Traction and Related Phenomena in Chemical Processing in Space - the pattern of thermocapillary convection cells in a liquid drop with an axially symmetric temperature field on the surface was deduced. In Task 5 - Vacuum Effects in the Preparation of Composite Materials - the scanning electron microscope was used to study the effects of strain, surface coatings and specimen tilt in electron channelling patterns.

While it would be premature to draw, at this stage, extensive conclusions from these studies on space processing, it is clear that the role of gravity in materials processing can have significant, and possibly limiting, effects on purity and perfection of materials, and that extensive experimental and theoretical investigations, in ground-based environments, are important base-line information needed for the efficient use of the space environment in materials processing. 


\section{Effects of Convection on Crystal Perfection}

in Czochralski Crystal Growth

M. Kuriyama, J. G. Early and H. E. Burdette

Metallurgy Division

Institute for Materials Research

\section{Summary}

In the absence of gravity, thermal convection, i.e., convection induced by gravity acting on density differences in the melt, would be expected to be negligible. Fluid flow in the melt, including thermal convection, probably affects crystals grown from the melt. At present, the relationship between crystal growth conditions, in particular fluid flow conditions, and the degree of crystal perfection has not been well established for metals. As a continuation and expansion of our previous work (Government Order H-84832A, NASA), an intensive study has been performed and reported here on optimum solidification parameters for the production of highly perfect copper crystals by Czochralski growth. In this research, the crystal perfection has been assessed by non-destructive methods of x-ray diffraction, such as Borrmann anomalous transmission and rocking curve measurements by double crystal diffractometry. The copper single crystals have been grown under various growth conditions where the rotation of the seed and of the melt and the diameter of the bottle-neck are chosen as variables. $\mathrm{X}$-ray topographs have been analysed along with the data obtained from 
rocking curve measurements. Tables of growth conditions and quantitative data of rocking curve widths are presented in this report with the $x-r a y$ topographs. Optimum growth parameters resulting in highly perfect crystals have been determined. Possible mechanisms for obtaining highly perfect crystals have been discussed. 
Although for many years certain semiconducting materials, such as Si and Ge have been grown from the melt phase, free of dislocations, it has not generally been possible to grow sizable metal crystals free of dislocations. The reasons for this are still not entirely clear. The difficulty in growing highly perfect metal crystals may be attributed to their low dislocation energy and high dislocation mobility, compared with those factors for semiconducting crystals. Imperfections can be produced by impurity particles present in the melt which may originate in the container used to hold the melt.

In addition to these defect sources, one certainly cannot neglect sources related to thermal conditions. Among them, the presence of thermal convection and other fluid flow phenomena in the melt may affect solidification processes resulting in the build-up of inhomogeneous strain fields sufficiently large to cause dislocations to multiply. Since thermal convection is induced predominantly by gravity acting on density differences in the melt, it is usually impossible to control completely fluid flow, especially convection, during crystal growth on the earth's surface.

At the present time, the relationship between the crystal growth conditions and the degree of crystal perfection has not been well established for metals. As a continuation and an expansion of our previous work, an intensive study has been performed and reported here on optimum solidification parameters for the production of large, highly perfect metal crystals by Czochralski growth. In this research as well 
as in the previous study, a non-destructive assessment of the crystal perfection of the grown crystals is indispensable. Further development has, therefore, been continued on high resolution $\mathrm{X}$-ray diffraction methods for the characterization of such crystals. Hereafter, our previous work will be referred to as Report $\mathrm{I}^{*}$.

In the present report, emphasis will be placed on studying the resultant crystal perfection from the following aspects:

a. reproducibility of crystal perfection for given growth conditions,

b. "bottle-necking" effects in the processes of crystal growth, c. annealing effects after sample crystals are prepared in a disc form.

In studying crystal perfection as a functional of fluid flow, it is necessary first to establish the fact that there is, indeed, a relation between the crystal perfection and the fluid flow conditions. In Report I, we have discussed such a relation, based on our preliminary experiments. However, it was not conclusive whether or not the variations of crystal perfection are caused by fluid flow conditions, per se, or by other factors, such as the perfection of seed crystals, and the procedures of handling grown crystals. In view of this, it is important to check whether one can reproduce the same degree of crystal perfection for a given fluid flow condition. This check cannot be done without including aspects $b$ and $c$, although analysing the results in aspect a

* Government Order H-84832A, National Aeronautics and Space Administration; NBS Report 10873. 
alone seems sufficient enough to define the optimum fluid flow conditions in the melt for the present purpose.

\section{Experimental Procedures}

The details of the experimental procedures and the principles of $\mathrm{x}$-ray diffraction mechanisms which are required to perform the present work have been described in Report $I$. In the present report, only changes and improvements will be discussed, along with a brief description of the techniques we use.

The schematic diagram of the Czochralski pulling apparatus is shown in Fig. 1, where the principle variables defining growth conditions are denoted by $x$ (pulling speed), y (seed rotation) and $z$ (crucible rotation). The pulling speed is genera11y between $0.013 \mathrm{~cm} / \mathrm{min}$. and $0.1 \mathrm{~cm} / \mathrm{min}$. The speed does not cause as significant a change in diameter, except for crystals having a very small bottle-neck diameter $(\sim 0.05 \mathrm{~cm})$, as does the temperature in the melt. When the crystal initially grows with a very small bottle-neck diameter, the pulling speed affects the diameter of the growing part significantly until the bottle-neck region completely clears the top of the furnace.

Crystal boules were grown by narrowing the diameter at one region of the boule and increasing the diameter for the rest of the boule till the desired crystal diameter $(1.5 \mathrm{~cm} \sim 3.0 \mathrm{~cm})$ is reached. Narrowing the crystal diameter (the bottle-neck) can be produced by increasing the temperature of the melt. Two examples of crystal boules are shown in Fig. 2. Because of extremely narrow bottle-necks, the removal of 
crystal boules from the puller required the following procedures to be adopted to prevent any flexing of the crystal in the neck region which would induce strains and dislocations. When the boule has cooled to room temperature, a mold is placed around the boule, but not touching it. The mold is then filled with molten paraffin (at approximately $40^{\circ} \mathrm{C}$ ). When the wax has cooled, the crystal is released from the puller. The wax supports the neck while the crystal is mounted on an acid saw.

At least three slices of sample crystals were cut from different regions of each boule. One of the slices was annealed at $1000^{\circ} \mathrm{C}$ for three days in a hydrogen (dew point $=-90^{\circ} \mathrm{F}$ ) flow furnace. The thicknesses of the slices were determined by use of the Borrmann (anomalous transmission) effect of $x$-ray diffraction. Fig. 3 illustrates schematically the experimental arrangement and the derivation of the thickness equation $\mathrm{D}=\left(\mathrm{L}_{0}-\mathrm{L}_{\mathrm{S}}\right) / \tan \theta$.

In the present work, the slit placed in the $\mathrm{x}$-ray beam before the crystal is $0.01 \mathrm{~cm}$ wide. A photograph of a nuclear plate used for the determination of thickness is shown in Fig. 4, where the (111) Bragg diffraction was used with $\mathrm{Cu} \mathrm{K} \alpha_{1}$ radiation.

For the characterization of the perfection of sample crystals, we have used two different $\mathrm{x}$-ray optical alignments, namely an asymmetrical topographic camera and a high resolution double crystal spectrometer. The former, which will be called ATC hereafter, was designed in order to enable us to survey a large number of sample crystals effectively in a shorter time period than that required for ordinary topography. Although this was accomplished at the expense of high resolution, the 
quality of topographs from the ATC remained just as good as in ordinary x-ray topography. (It was one of the requirements for this design to maintain such high quality in the topographs.)

In the ATC, the first crystal is a silicon crystal whose surface makes an angle of $13.5^{\circ}$ with the (111) diffracting plane. The incident $x$-ray beam falls on the crystal surface almost parallel to it, and the (111) diffracted beam appears with a size of $1.7 \mathrm{~cm} \times 2.5 \mathrm{~cm}$, being sufficiently large enough to cover the entire area of sample crystals. Care must be taken with the first crystal so that it would not superimpose its own surface structure on topographs of the structure of the sample crystal. This requirement of ten induces an unavoidable lack of ideal high resolution in the ATC. The schematic diagram of the ATC is shown in Fig. 5. Topographs are taken from the sample crystal (Cu) both in transmission geometry, where the (111) diffraction of copper is used, and in reflection geometry, where the (220) diffraction is used.

To obtain diffraction rocking curves and high resolution topographs at various locations on the sample crystals, the high resolution double crystal spectrometer (hereafter called the spectrometer) has been used with a scanning stage mounted on it. The schematic diagram of the spectrometer is shown in Fig. 6, where the first crystal is only shown in reflection geometry. A photograph of the spectrometer in operation is shown in Fig. 7. A silicon crystal of disc shape whose surface is a (110) crystallographic plane has been chosen as the first crystal to obtain a well collimated monochromatic beam from the (220) Bragg diffraction both in reflection and transmission geometry. Between the x-ray 
source of a point focus x-ray tube and the first crystal, a horizontal slit of $6 \mathrm{~mm}$ and a vertical slit of $0.3 \mathrm{~mm}$ have been inserted. When the first crystal is in reflection geometry, two vertical slits of $0.15 \mathrm{~mm}$ and $0.10 \mathrm{~mm}$, respectively, are placed a distance of $3 \mathrm{~cm}$ apart from each other before the second crystal. When the first crystal is in transmission geometry, no slits are inserted.

The quality of the beam was checked by measuring the rocking curves of a dislocation free germanium crystal which was placed at the second crystal position. The full width at half maximum (FWHM) of the rocking curve from the (220) germanium diffraction was determined to be 12.8 seconds of arc in the $\mathrm{Si}$ (220) surface/Ge (220) surface mode and 15.5 seconds of arc in the Si (220) transmission/Ge (220) surface mode, where $\mathrm{Cu} \mathrm{K} \alpha$ radiation is used throughout.

\section{Experimental Results}

\section{Fluid Flow Conditions}

The fluid flow conditions in the melt during crystal growth are classified into groups by different sets of values of the principle variables, angular velocity of crucible and seed rotation, as listed in Table I. By interchanging the values of $y$ and $z$, we obtain $\Delta$ with opposite signs. Based on the results in Report I and the results in the present work, there appears to be no significant difference in the resultant crystal perfection due to the difference in the sign of $\Delta$. Therefore, we do not discriminate fluid flow conditions from each other when the sign of $\Delta$ is changed by exchanging the values of $y$ and $z$. 
In addition, we have introduced another parameter indicating the diameter of the bottle-necks grown during the crystal growth process. There are always at least two different bottle-neck diameters chosen in each group; one is very narrow, usually less than $1 \mathrm{~mm}$ and the other between $2 \mathrm{~mm}$ and $4 \mathrm{~mm}$.

\section{Spectroscopic Data}

In Table II, we list the values of rocking curve widths (FWHM) observed in both transmission and surface reflection geometry for all the growth conditions, including annealing. The crystal is considered to be more perfect, the smaller the observed width. The crystals are ranked, as shown in the eighth and ninth columns, in increasing order of their widths. The annealed crystals are ranked separately with the letter A accompanied by their rank. The ranks based on the transmission data should be judged along with the values of $\mu \mathrm{L}$, because, even with the same degree of perfection, thicker crystals show narrower widths.

In most crystais, the perfection is not uniform throughout the crystal. Rocking curves taken at different locations from the same crystal are shown in Fig. 8, where the (220) diffraction is set in reflection geometry. Other examples of local rocking curves are shown in Fig. 9, where the (111) diffraction is set in transmission geometry $(\mu \mathrm{L} \sim 25)$. In this figure, the horizontal axis represents a decreasing glancing angle to the right. The little humps on the right side of the individual profiles correspond to the Bragg diffraction due to $\mathrm{Cu} \mathrm{Ka}_{2}$ radiation. The separation of the $\alpha_{1}$ and $\alpha_{2}$ peaks in the $S_{i}$ (220)/Cu (111) 


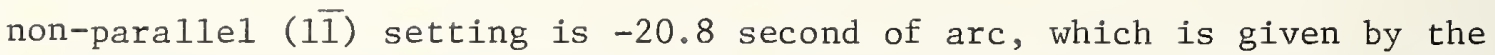
difference between the separation of $\alpha_{1}$ and $\alpha_{2}$ due to Si (220) and that due to the $\mathrm{Cu}$ (111) diffraction.

Typical rocking curve profiles are shown in Fig. 10 and 11 for various crystals. In Fig. 10, the curves were obtained in both transmission and surface reflection geometry of the copper crystal with the first crystal, Si (220), in transmission geometry. The horizontal axis represents an increasing glancing angle to the right. The smaller peaks correspond to the $\alpha_{2}$ diffraction: the separation in the reflection geometry is calculated to be +163.0 seconds of arc. Fig. 11 shows the rocking curve profiles from a crystal of good quality (非037303) and a typical rocking cúrve from a crystal of poor perfection (非35302). The latter crystal did not produce observable anomalous transmission.

\section{X-Ray Topographs of the Grown Crystals}

As mentioned previously, diffraction topographs were taken by two different $x$-ray alignments, the ATC and the scanning spectrometer. The topographs taken by the ATC usually gave the entire view of the sample crystals, unless the crystal size was larger than the size of the $x-r a y$ beam. Examples of the topographs ${ }^{*}$ are shown in Figs. 12a, b and 13a, b in both the reflection and the transmission geometry from as grown crystals. Since for lack of space we cannot show all the topographs here, we shall describe the qualities of the crystals as-grown in various growth conditions, based on their topographs.

* Many of the enlargements of the topographs are formed as composite photographs as a result of limitations of the microscope used in the enlargement technique. 
The crystals grown in Growth Condition I with a narrow neck generally produced surface topographs (obtained by a surface Bragg diffraction) almost as good as those shown in Figs. 12a and 13a, but with a continuous distribution of darkness (excess intensity) areas which we call "strain contours". The transmission topographs (taken in transmission geometry) indicated, however, much poorer quality in those crystals, showing the anomalous transmission only in about $50 \%$ of the total area.

In contrast, the crystals grown in Growth Condition I with a wider neck showed much poorer quality in their surface topographs, in which not only the strain contours, but many lines of imperfections appeared. These crystals usually did not produce good transmission topographs.

The crystals grown in Growth Condition II were of a quality similar to those grown in Growth Condition I with larger necks. The surface topographs showed many strain contours and often the topograph images did not cover the entire exposed area of the crystals. The transmission topographs were broken up into many areas, indicating that the perfect crystal areas were very much limited within small local regions. These results were consistent in this growth condition, regardless of their bottle neck diameters.

The crystals grown in Growth Condition III with a narrow neck generally displayed the best quality of perfection. Fig. 12a, b and Fig. 13a, b are examples of the topographs from the crystals grown in this condition. The surface topographs showed much fewer crater-type 
images than those taken from the crystals grown under other growth conditions. The number of visible dislocations in the surface topographs are found to range between 11 and 100 dislocations per $\mathrm{cm}^{2}$ for the crystals as-grown in this condition. The transmission topographs, however, reveal more imperfections in the interior of the crystals, as shown in Fig. $12 \mathrm{~b}$ and $13 \mathrm{~b}$. One of the common features in the transmission topographs from these crystals is shown in Fig. 13b, although this crystal happened to show this feature in a somewhat exaggerated fashion. In this topograph, many lines runs normal to the <111> direction. The Bragg diffraction in this case is (111). Also, additional lines, though less visible, run normal to the $\overline{l 1} 1\rangle$ direction. In addition, there appear black and white bands parallel to the <110> direction. Those lines are caused by extended dislocations associated with a stacking fault, running almost parallel to the $\langle 10 \overline{1}\rangle$ direction. The lines probably represent Lomer-Cottrell locking of the interacting dislocations.

The crystals grown in this condition but with a large neck diameter generally produced topographs of almost the same quality of perfection as the crystals grown in Growth Condition I with a large bottle-neck. The transmission topographs consisted of several regions, indicating that there were few highly perfect regions throughout the crystals.

The crystals grown in Group Condition IV could not be investigated by $x$-ray topography, as they were not single crystals.

Under Growth Condition V, regardless of the bottle-neck diameter, the crystals displayed typical mosaic structures, as shown in Fig. 14 . No transmission topographs were produced. 
Now we turn to the annealing effects. As indicated in Table II, at least one crystal from the boules in each growth condition was annealed. As shown in Fig. 14b, the surface topograph from an annealed crystal of Growth Condition V is just as bad as Fig. 14a, indicating that the mosaic structure was not at all affected by annealing. The annealed crystals of Growth Condition II showed polygonization, which usually resulted in the formation of several subgrains.

All the topographs taken from the annealed crystals in Growth Conditions I and III showed an equally high degree of perfection in both surface and transmission geometry. The resultant degree of perfection was almost independent of the bottle-neck diameters. Examples of the surface and transmission topographs are shown in Fig. 15a, b and Fig. 16a, b, respectively of Growth Condition I and Growth Condition III. As seen in the transmission topographs, the Lomer-Cottrell locks of dislocations disappeared and dislocations net works appeared rather randomly.

The number of dislocations counted on the surface topographs for these annealed crystals was less than 23 dislocations per $\mathrm{cm}^{2}$, the smallest number observed was $7 \mathrm{dis} 1 . / \mathrm{cm}^{2}$. The dislocation densities can be obtained from the transmission topographs which show all the dislocations in the interior of the crystals. In this case, the dislocation density is equal to the number of dislocations multiplied by the length of each dislocation divided by the volume where the dislocations are counted. The average number of dislocations thus obtained was 15 dislocations per $\mathrm{cm}^{2}$. The smallest number was 12.8 dislocations per $\mathrm{cm}^{2}$. In these 
annealed crystals, there were always subgrain boundaries observed, which were, of course, considered to be piled-up dislocations, but were not included in the count of individual dislocations. These subgrain boundaries would have eventually been driven out of the crystals, if we had annealed the crystals for a longer period of time.

In Fig. 17a and $\mathrm{b}$, we show the composite topographs taken from the same crystal as in Fig. 15a and b by the scanning spectrometer. The resolution is much higher in Fig. 17 than Fig. 15. The striation-1ike background which is seen in Fig. 15 is not present in Fig. 17. This background was caused by the image structure due to the asymmetrical silicon crystal. In the transmission topograph of the scanning spectrometer, the details of the dislocation networks are clearly visible. A few examples of enlarged topographs taken by the spectrometer are shown in Fig. 18a, b and c, representing a highly perfect region, an intermediate region and a highly dislocated region, respectively.

\section{Conclusion and Discussion}

Before concluding this annual report, we would like to emphasize one of our principles followed in conducting the present work. At present, many people believe that growing perfect crystals is still an art where personal skills play significant roles. Although we do not object to this view, and often agree with this view based on our experience, we have attempted to eliminate such an art from the present work. This attitude probably resulted in producing crystals less 
perfect than they could be. However, we see significance in establishing reproducibility of the resultant crystal perfection as a functional of growth conditions, rather than a functional of the "art" part of crystal growth technology. In the present work, we grew crystals as routinely as possible, with the least effort of human control. Once the variables were set, we did not attempt to modify these variables in response to local perturbations which occurred from time to time during growth. During the growth process, we were tempted more often than not to correct the diameter by changing temperatures or to increase the pulling or rotation speed when the melt surface started vibrating occassionally. However, we made none of these possible corrections.

In the present work, the spectroscopic data indicated that Growth Condition II generally produced crystals of higher perfection, along with crystals produced under Growth Condition I with narrow necks. These results are in good agreement with the observations of the $x-r a y$ topographs. The topographs obtained by the scanning spectrometer further helped to distinguish the subtle differences in the resultant qualities from conditions I and III. Those topographs indicated that Growth Condition III with narrow bottle-necks usually produced crystals of better quality than Condition I. The other growth conditions are clearly inferior to Conditions I and III. It is, therefore, concluded that Growth Condition III is most optimum for growing a single crystal of high perfection, when the bottle-neck is made less than one millimeter in diameter. 
If one anneals as-grown crystals afterward, Growth Conditions I and III with narrow bottle-necks result in almost the same degree of crystal perfection. However, crystals grown in the other conditions did not show much improvement in quality as a result of annealing. It is, therefore, further concluded that annealing becomes most effective only when the grown crystals are already highly perfect.

In the optimum growth condition, the density of dislocations can be as low as 11 dislocations per cm ${ }^{2}$ for "as-grown" crystals, and as low as 7 dislocations per $\mathrm{cm}^{2}$ for annealed crystals. The lowest dislocation density measured from the transmission topographs was 12.8 dislocations $/ \mathrm{cm}^{2}$ which is in good agreement with the dislocation densities determined from surface topographs.

Apart from the growth conditions that we studied from the viewpoint of fluid flow, it may be worthwhile to mention that gravity can be considered as a driving force to produce slip in the crystals during their growth process, as indicated in the previous section. The weight of the crystal may cause slip when the crystal is being pulled. However, these dislocations interact with each other, forming LomerCottrell locks and becoming immobile. Then the resultant crystal becomes highly perfect. This presumably takes place in Growth Conditions I and III. If wide-spread slip occurs or if many dislocations form randomly, as in the case of the other growth conditions, then the locking would not take place and the dislocations would still be mobile and affect the subsequently grown part of the crystal, resulting in a less perfect crystal. The lack of gravity in space 
my favor the growing of perfect crystals from this point of view, which may be entirely independent of fluid flow conditions.

Because of the lack of time, we could not investigate crystal perfection in Growth Conditions III in more detail by the use of high resolution scanning spectrometry. It is highly desirable to pursue the study of this growth condition combined with "art" part of crystal growth techniques and establish the correlation between the crystal perfection and the fluid flow motion. 
Table 1

\begin{tabular}{|c|c|c|c|c|}
\hline $\begin{array}{c}\text { Group } \\
\text { Number }\end{array}$ & $\begin{array}{c}\text { Crucible } \\
\text { Rotation (Y) }\end{array}$ & $\begin{array}{c}\text { Seed } \\
\text { Rotation }(Z)\end{array}$ & $\begin{array}{c}\text { Difference } \\
(\Delta=Y-Z)\end{array}$ & $\begin{array}{c}\text { Crystal } \\
\text { boules* }\end{array}$ \\
\hline I & $-5.4 \mathrm{rpm}$ & $-6.0 \mathrm{rpm}$ & $+0.6 \mathrm{rpm}$ & $\begin{array}{l}21,22,23,24,25, \\
29,35,36\end{array}$ \\
\hline II & $+6.0 \mathrm{rpm}$ & $+10.0 \mathrm{rpm}$ & $-4.0 \mathrm{rpm}$ & $\begin{array}{l}10,13,16,26,27, \\
38,39\end{array}$ \\
\hline III & $-20.6 \mathrm{rpm}$ & $-20.0 \mathrm{rpm}$ & $-0.6 \mathrm{rpm}$ & $20,28,30,37$ \\
\hline IV & $+30.0 \mathrm{rpm}$ & $+20.0 \mathrm{rpm}$ & $+10.0 \mathrm{rpm}$ & $31,32,33$ \\
\hline $\mathrm{V}$ & $-6.6 \mathrm{rpm}$ & $+6.0 \mathrm{rpm}$ & $-12.6 \mathrm{rpm}$ & $14,15,34$ \\
\hline
\end{tabular}

* Boule number 21, for example, stands for the first three digits 021 of the number of sample crystals. 


\begin{tabular}{|c|c|c|c|c|c|}
\hline 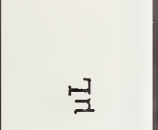 & 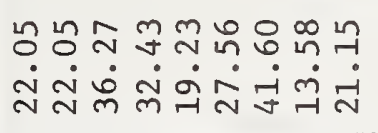 & 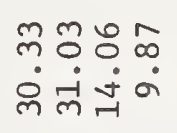 & 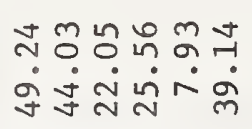 & & \\
\hline \multirow{2}{*}{ 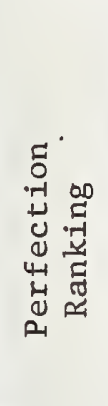 } & 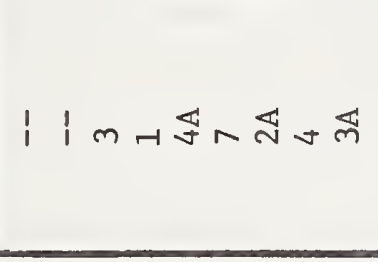 & 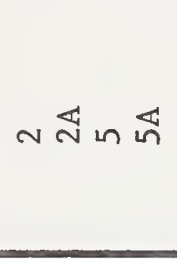 & 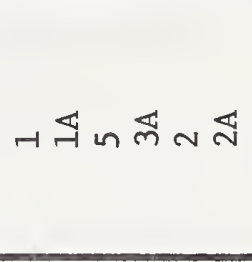 & & \\
\hline & 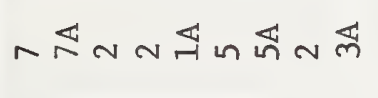 & 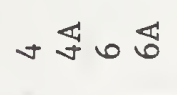 & 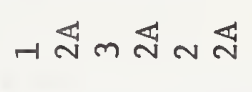 & & \\
\hline 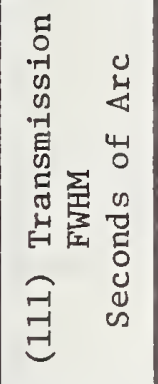 & 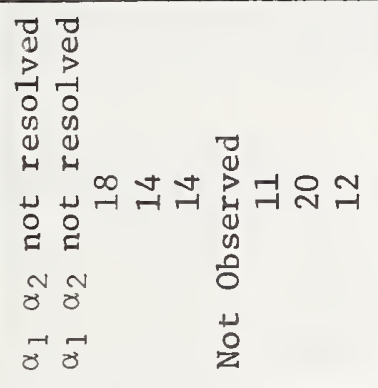 & 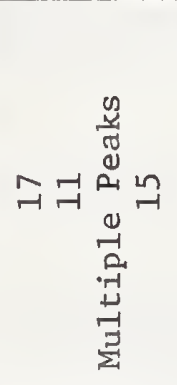 & 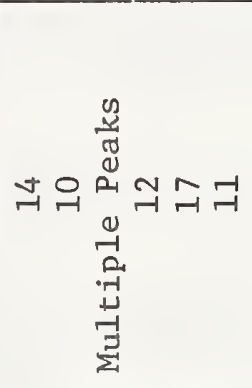 & & \multirow[b]{2}{*}{ 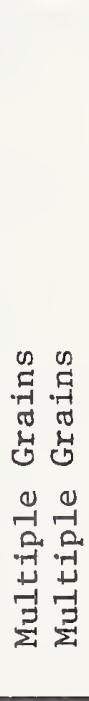 } \\
\hline 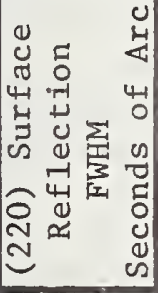 & 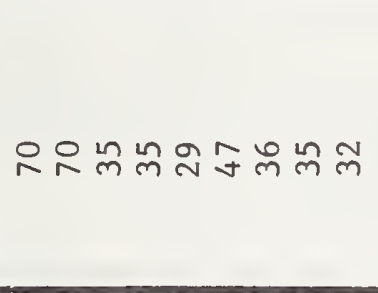 & 의 $\mathrm{m}$ i용ㅇ & लn & & \\
\hline 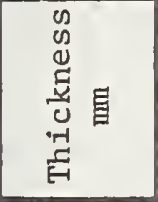 & 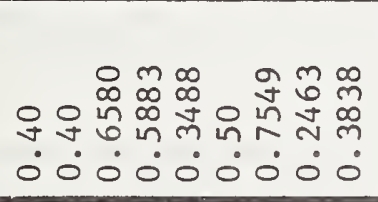 & 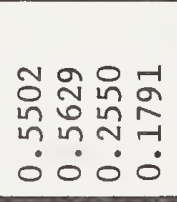 & 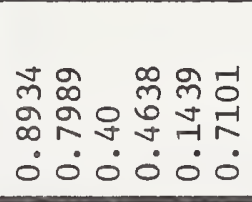 & & 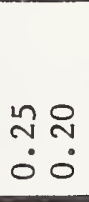 \\
\hline 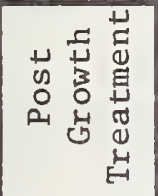 & 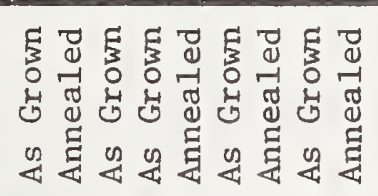 & 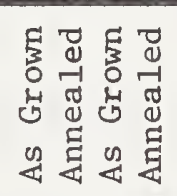 & 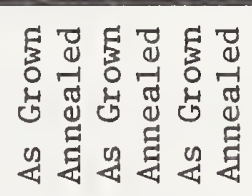 & \multirow{3}{*}{ 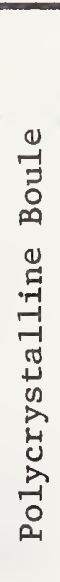 } & 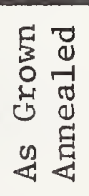 \\
\hline 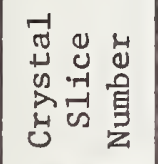 & 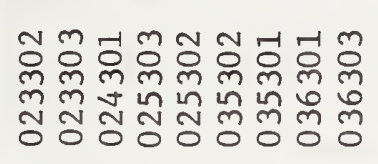 & 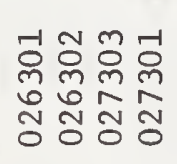 & 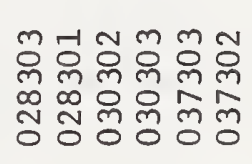 & & 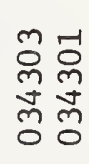 \\
\hline 苍岀 & 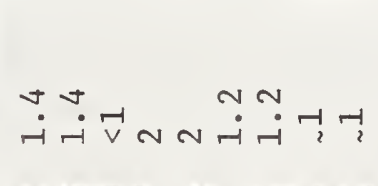 & $H-12 a$ & $\vec{v}-1 \wedge \curvearrowright r_{2}$ & & $m m$ \\
\hline 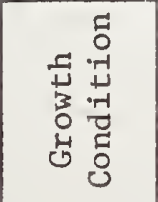 & $\mapsto \mapsto \mapsto \mapsto \mapsto \mapsto$ & 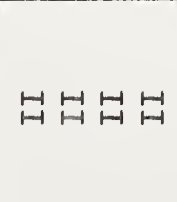 & 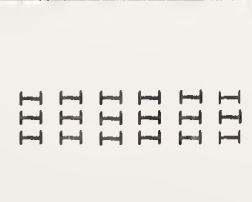 & 羊 & $p>$ \\
\hline
\end{tabular}


Figure 1 Schematic diagram of Czochralski crystal growing apparatus

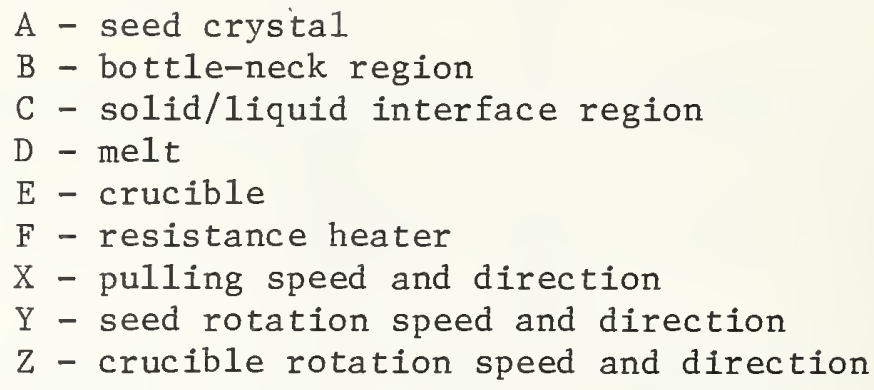

Figure 2 Photograph of crystal boules grown with different bottleneck diameters

a. bottle-neck diameter $=4.7 \mathrm{~mm}$ crystal 1 作20000

b. bottle-neck diameter $=0.675 \mathrm{~mm}$ crystal $\# 024000$

Figure 3 Schematic of experimental procedure used in the determination of the crystal thickness

Figure 4 Photograph of nuclear plate used to dermine the thickness of copper crystal 非 028301

Figure 5 Schematic diagram of the asymetrical topographic camera illustrating both the surface reflection and transmission mode

Figure 6 Schematic diagram of the high resolution double crystal spectrometer with scanning capability illustration both the surface reflection and transmission mode

Figure 7 Photograph of high resolution double crystal spectrometer with scanning stage

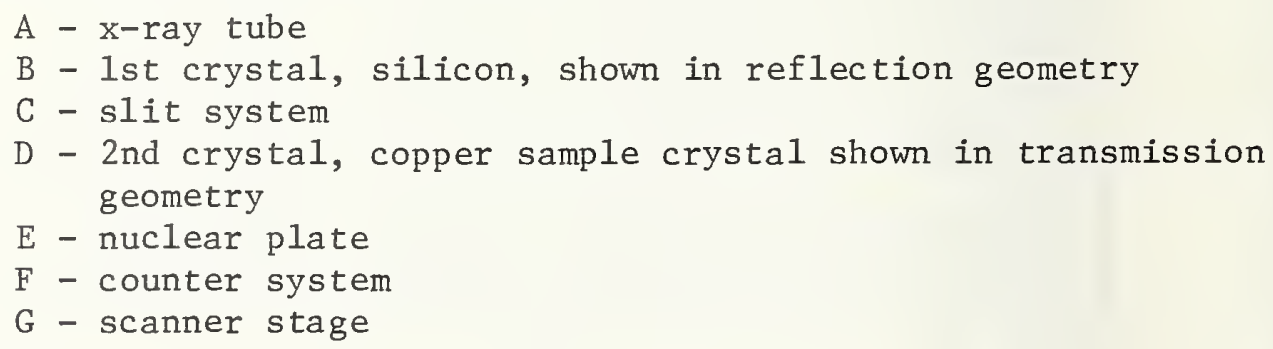

Not shown for clarity is adjustable slit system between $D$ and $E$ which stops direct and transmitted $x$-ray beams from reaching film. 
Figure 8 Diffraction rocking curves taken in the surface reflection geometry for copper crystal 028303 at three different locations on the crystal

Figure 9 Diffraction rocking curves taken in the transmission

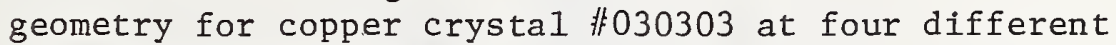
locations on the crystal

Figure 10 Diffraction rocking curve taken in both the surface reflection and transmission geometry for copper crystal 非26302 at one location. For this alignment, both the copper $\mathrm{Ka}$ and $\mathrm{K} \alpha_{2}$ components are present with the smaller peak due to the $\mathrm{K} \alpha_{2}^{2}$ component.

Figure 11 Diffraction rocking curves taken from a typically good copper crystal (非037303) in both surface reflection and transmission geometry and a typically poor copper crystal (\#035302) in surface reflection.

Figure 12 ATC $x$-ray topographs of as-grown copper crystal \#028303, growth condition III
a. (220) surface reflection composite topograph
b. (111) transmission topograph

Figure 13 ATC x-ray topographs of as-grown copper crystal \#037303, growth condition III
a. (220) surface reflection composite topograph
b. (111) transmission topograph

Figure 14 ATC x-ray topographs of copper crystals grown under growth condition $\mathrm{V}$

a. (220) surface relfection composite topograph of asgrown copper crystal \#034303

b. (220) surface reflection composite topograph of annealed copper crystal \#034301

Figure 15 ATC x-ray topographs of annealed copper crystal 非25302, growth condition I
a. (220) surface reflection composite topograph
b. (111) transmission composite topograph 
Figure 16 ATC x-ray topographs of annealed copper crystal \#030303, growth condition III

a. (220) surface reflection composite topograph

b. (111) transmission composite topograph

Figure 17 Scanning spectrometer topograph of annealed copper crystal 非 025302

a. (220) surface reflection composite topograph

b. (111) transmission composite topograph

Figure 18 Enlarged regions of scanner topographs

a. highly perfect region

b. intermediate region

c. highly dislocated region 


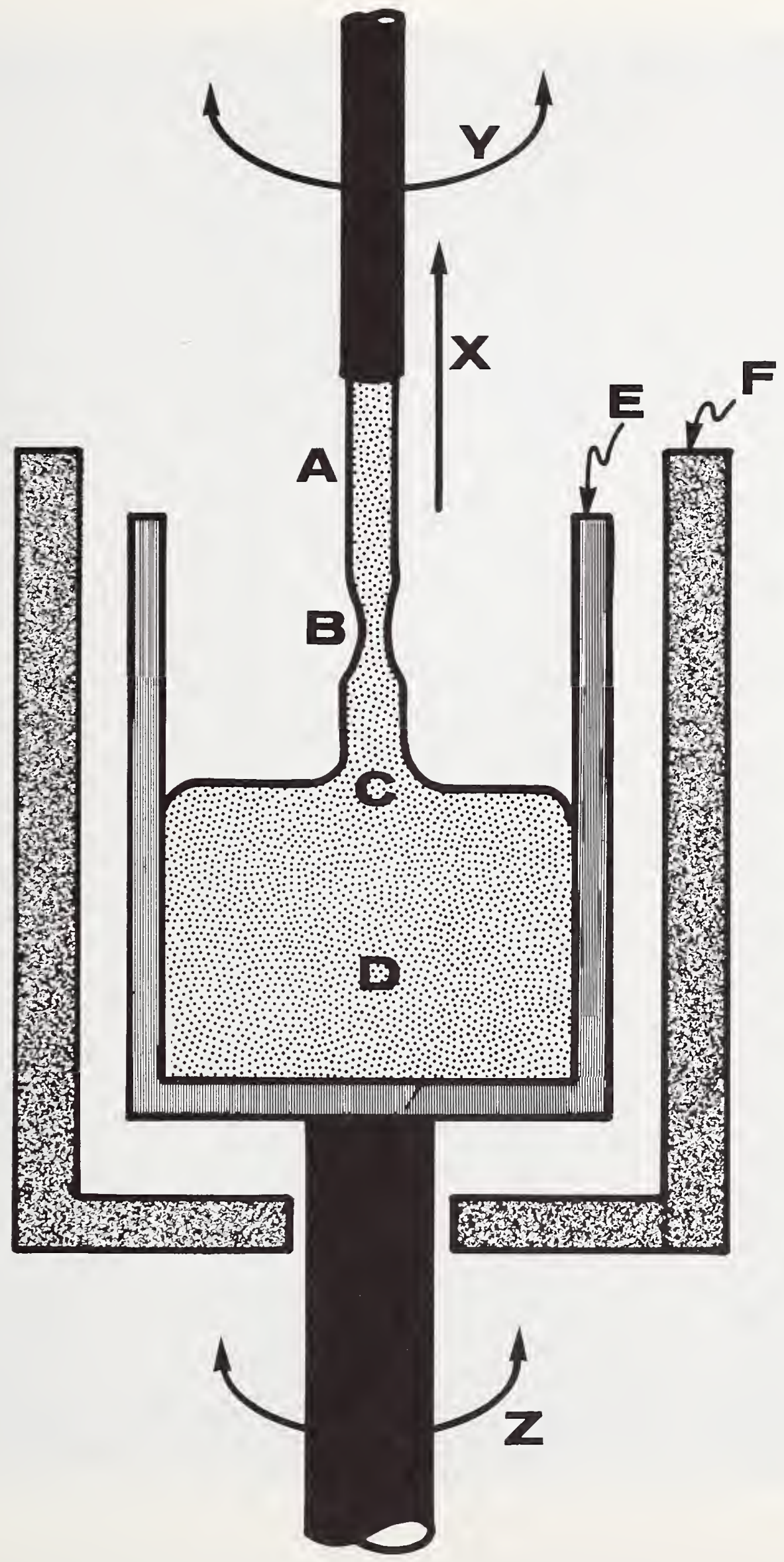





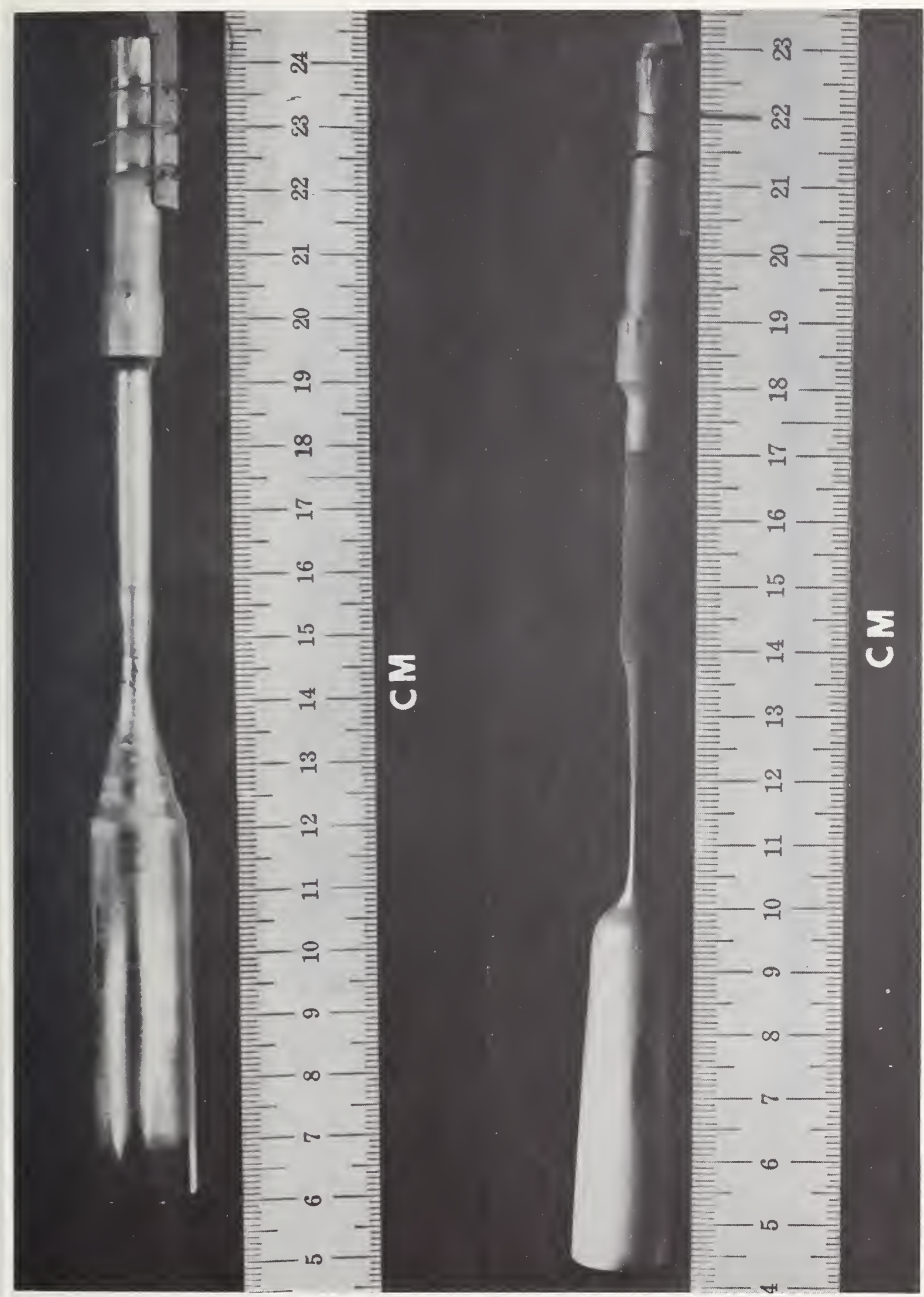

Fig. 2 

SLIT

DIFFRACTING

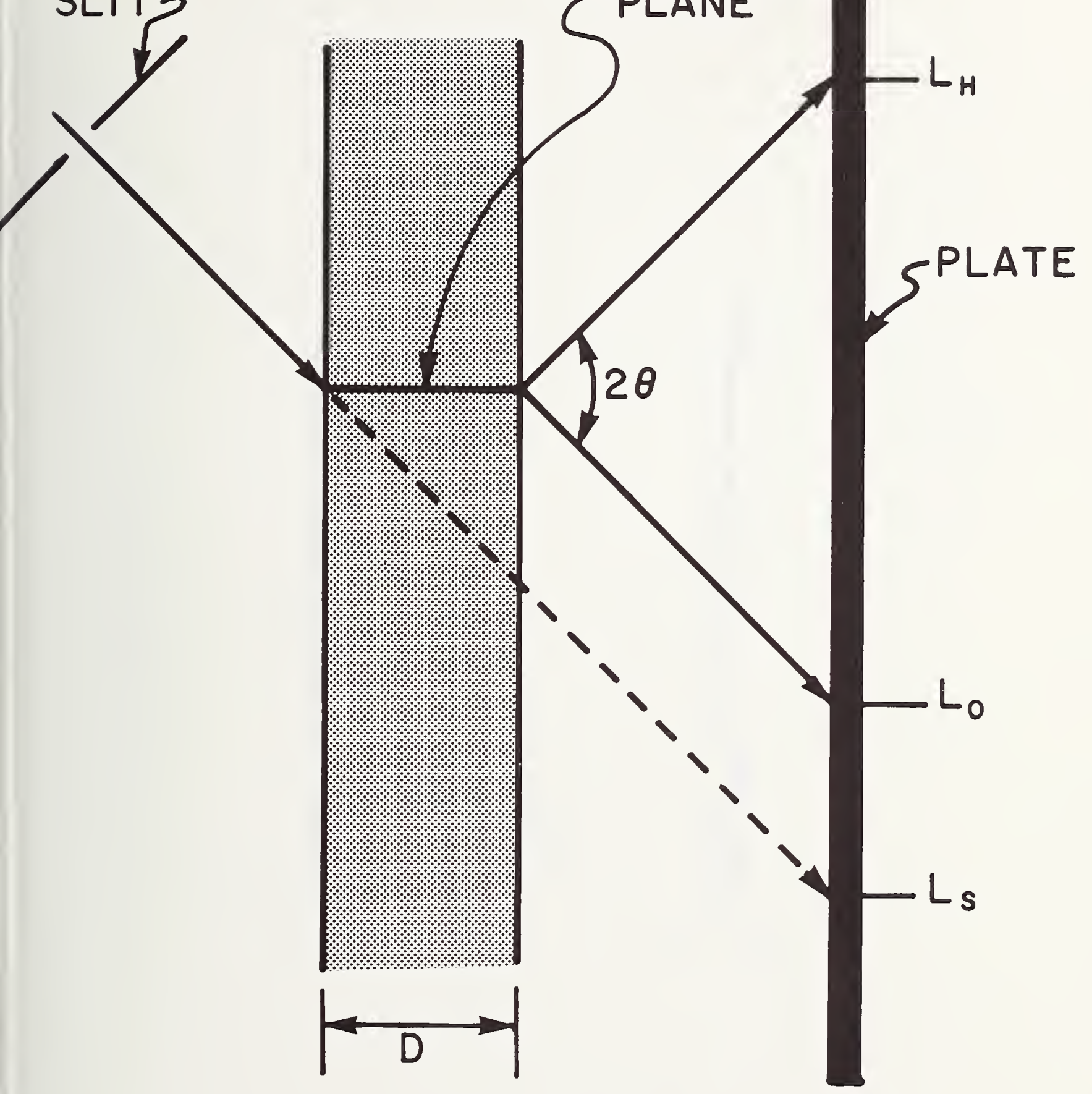





$$
1.1
$$


ASYMMETRICAL TOPOGRAPHIC CAMERA

(ATC)
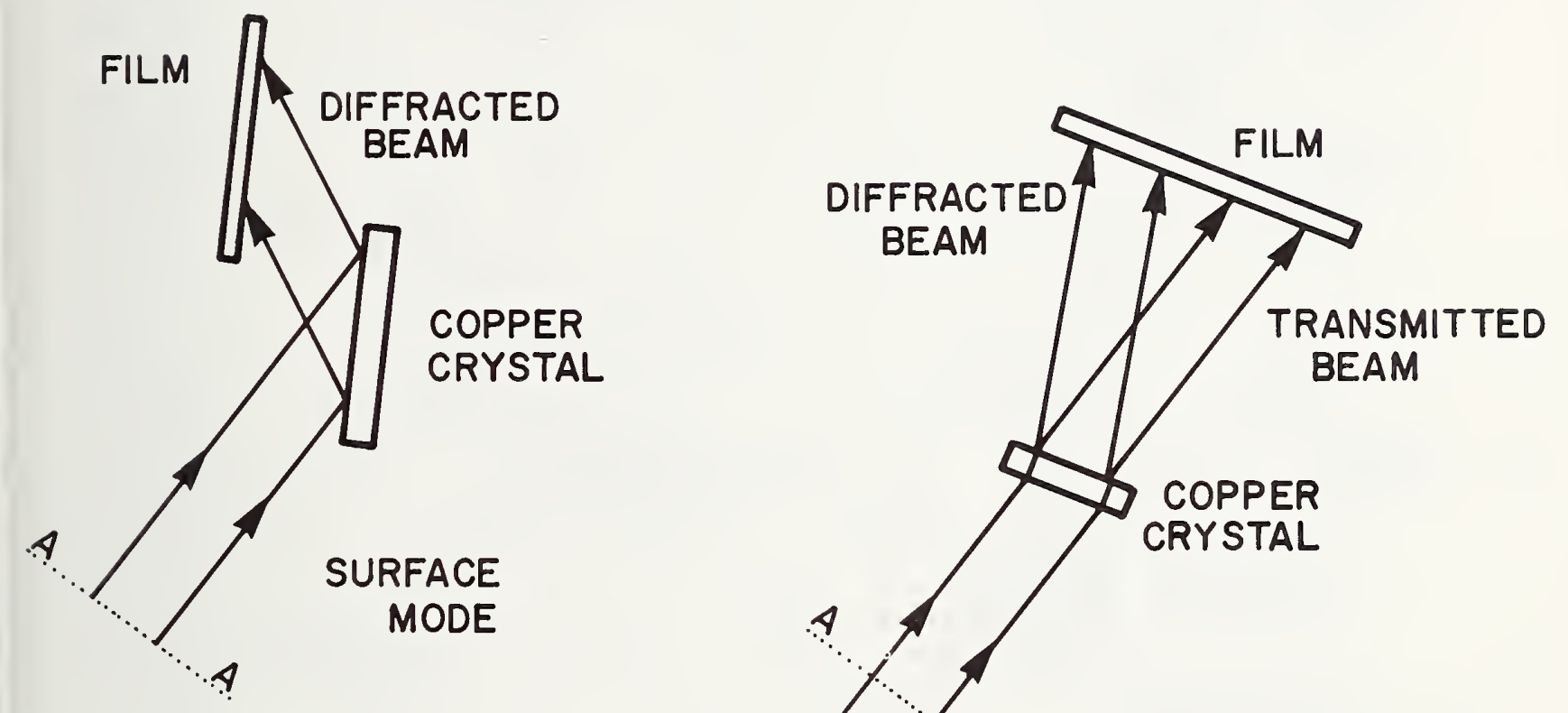

ASYMMETRICAL

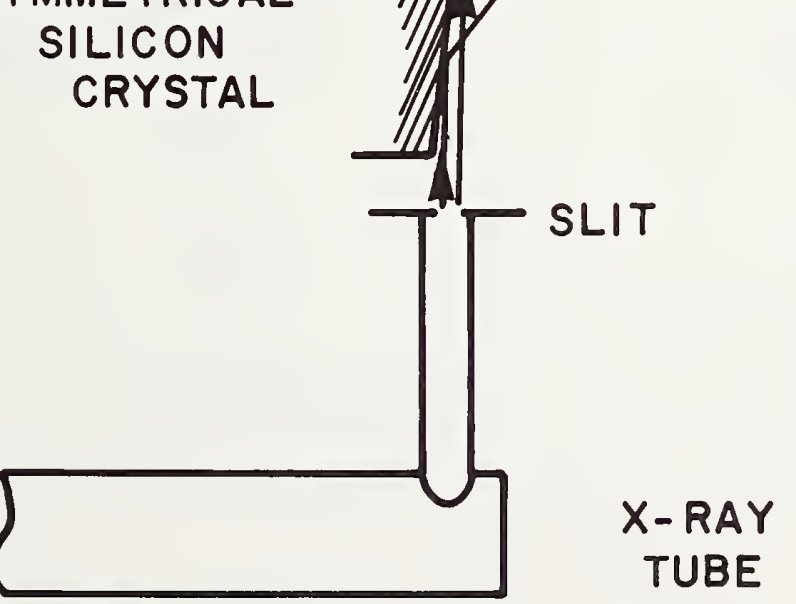

\section{TRANSMISSION MODE}

PRACTING

PLANE 2 



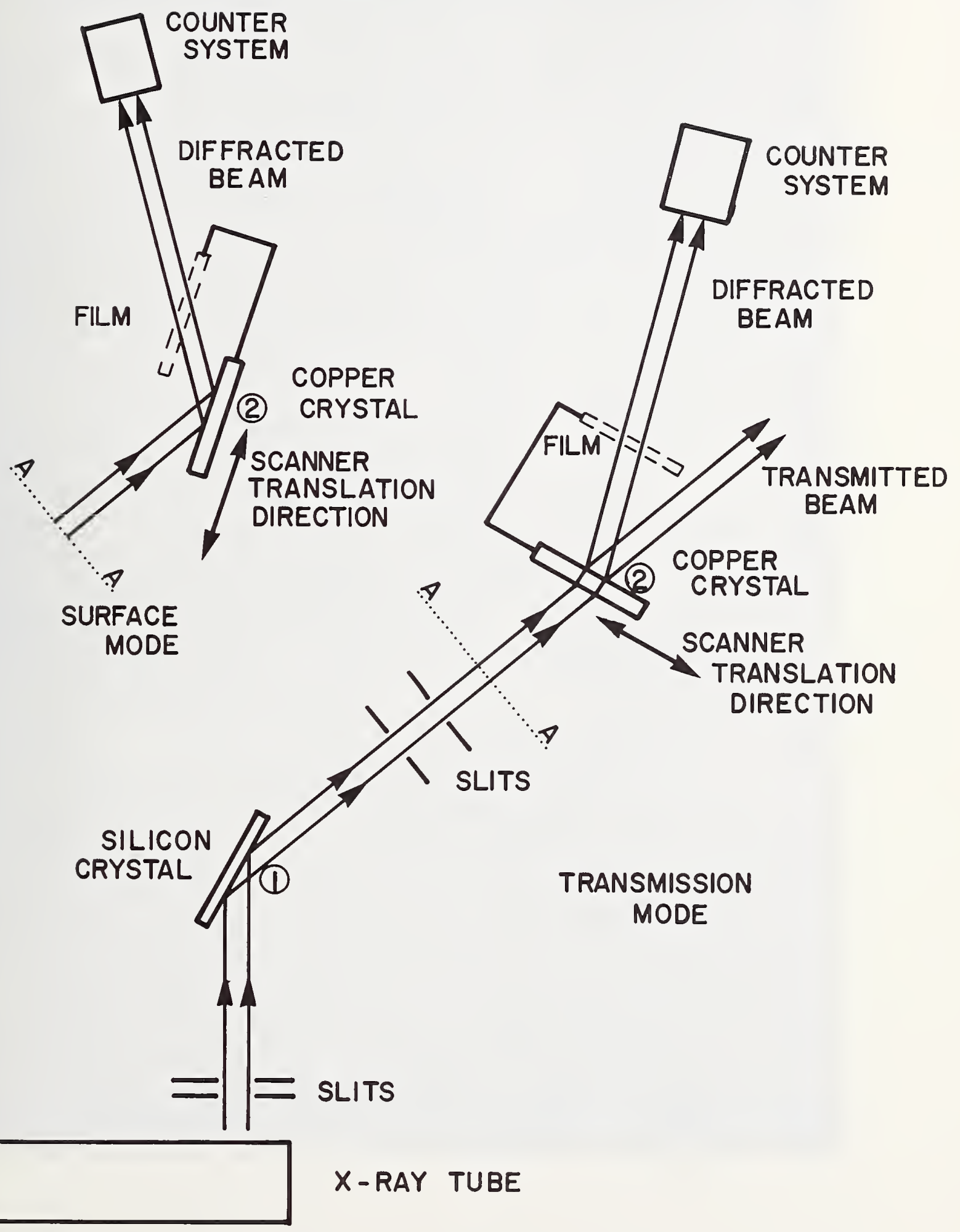





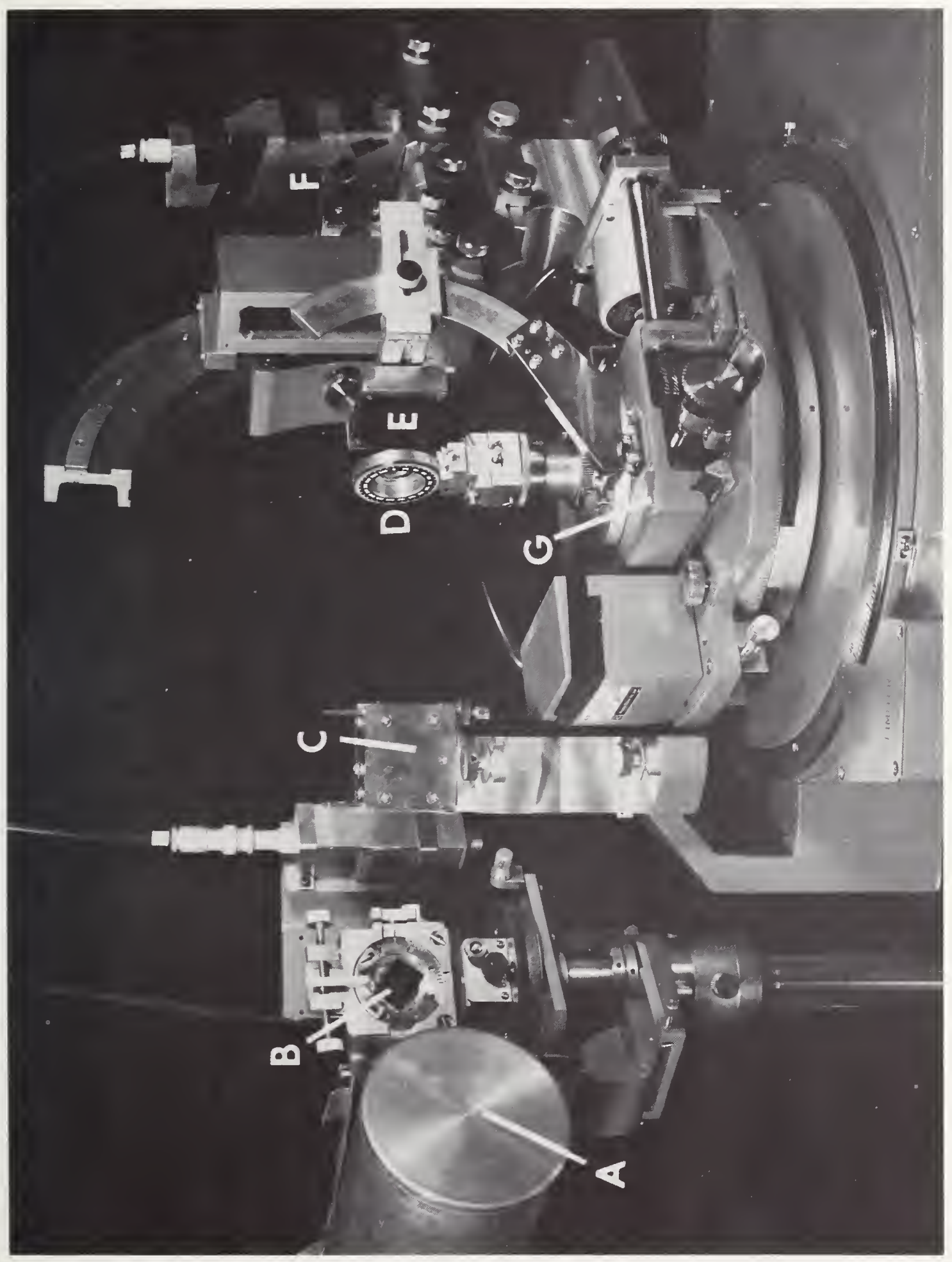






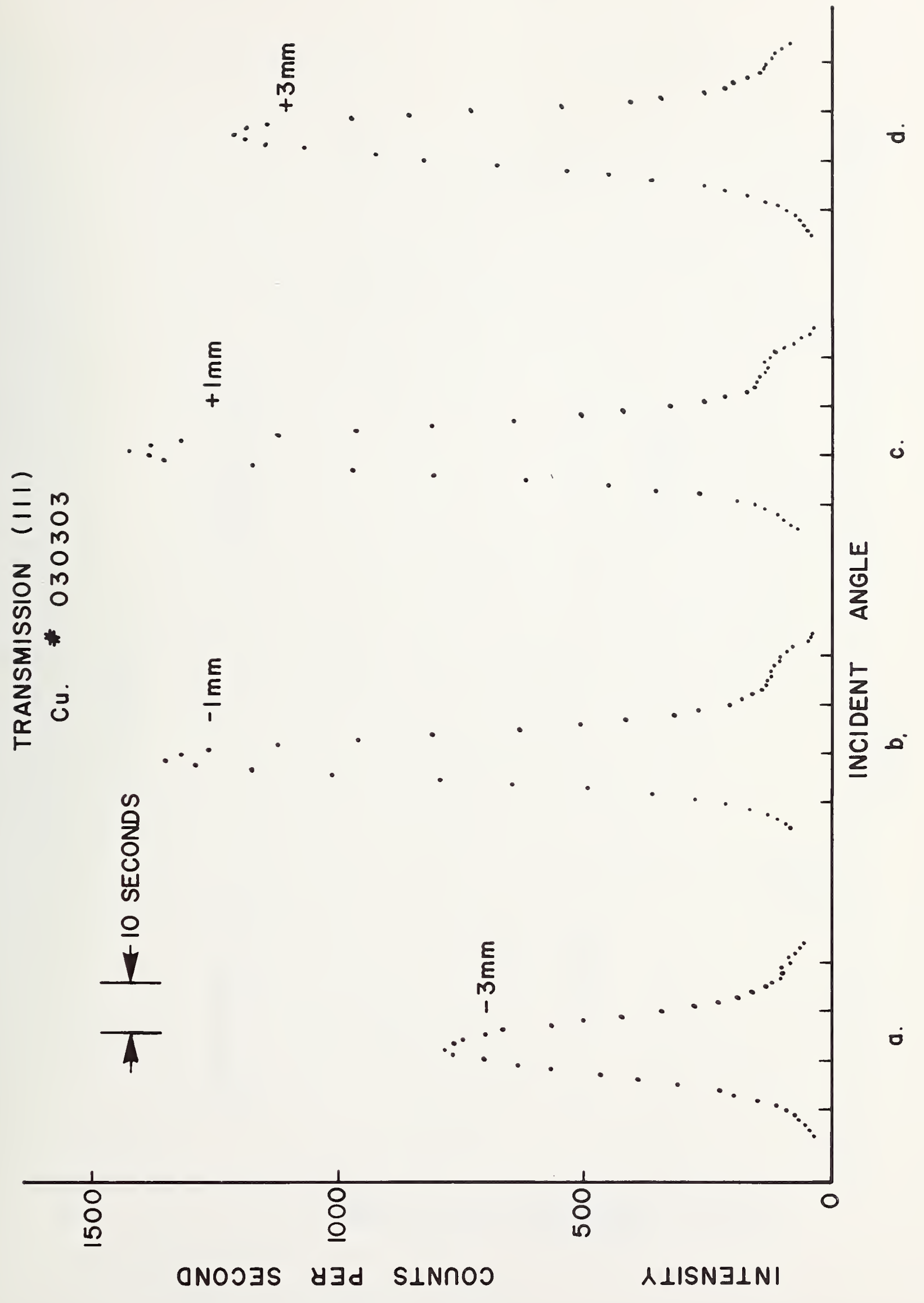





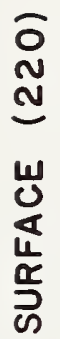

$N$
0
$m$
0
$N$
0
0
$*$
$\ddot{J}$
$J$

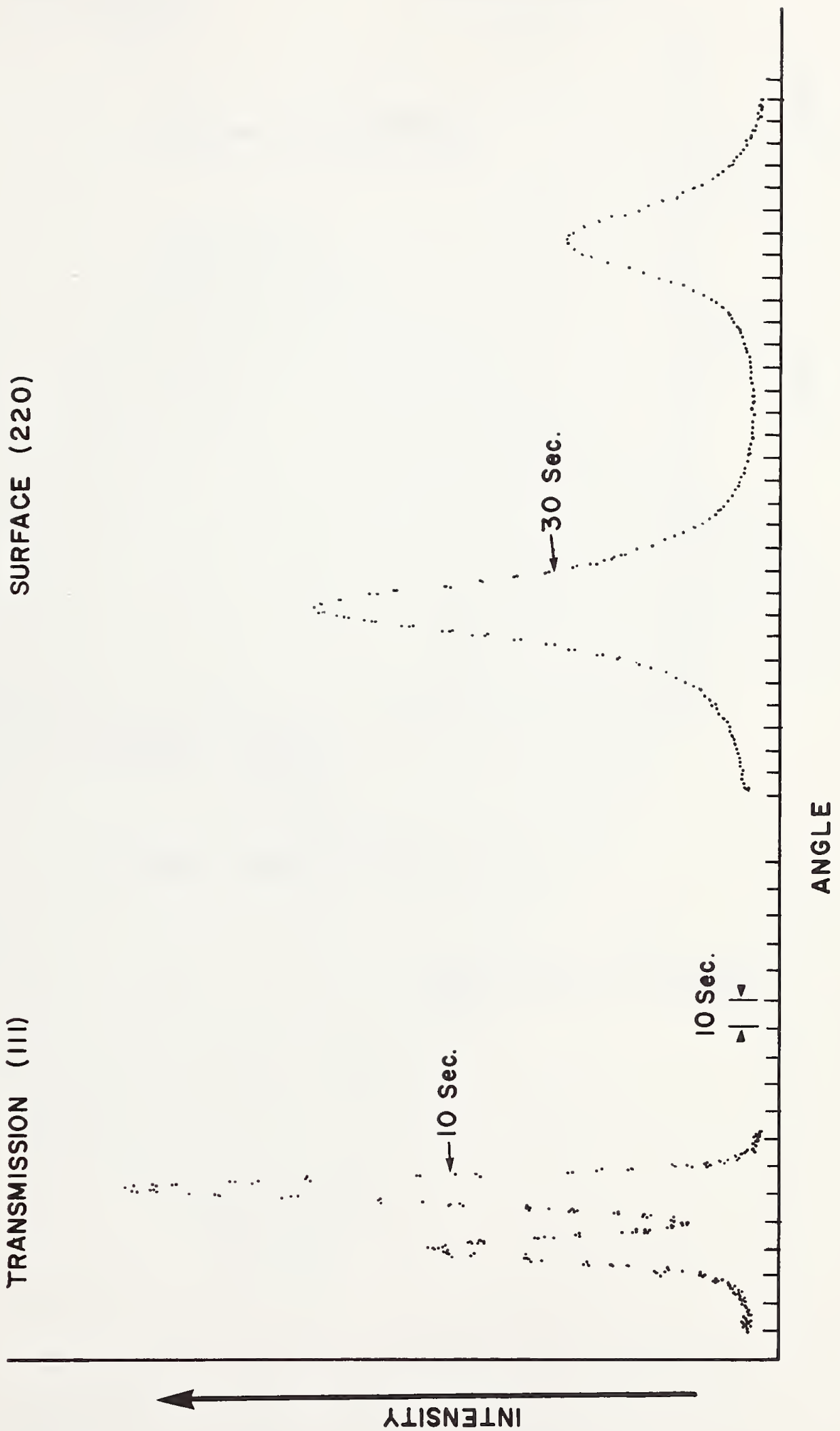

Fig. 10 

Cu. \#037303

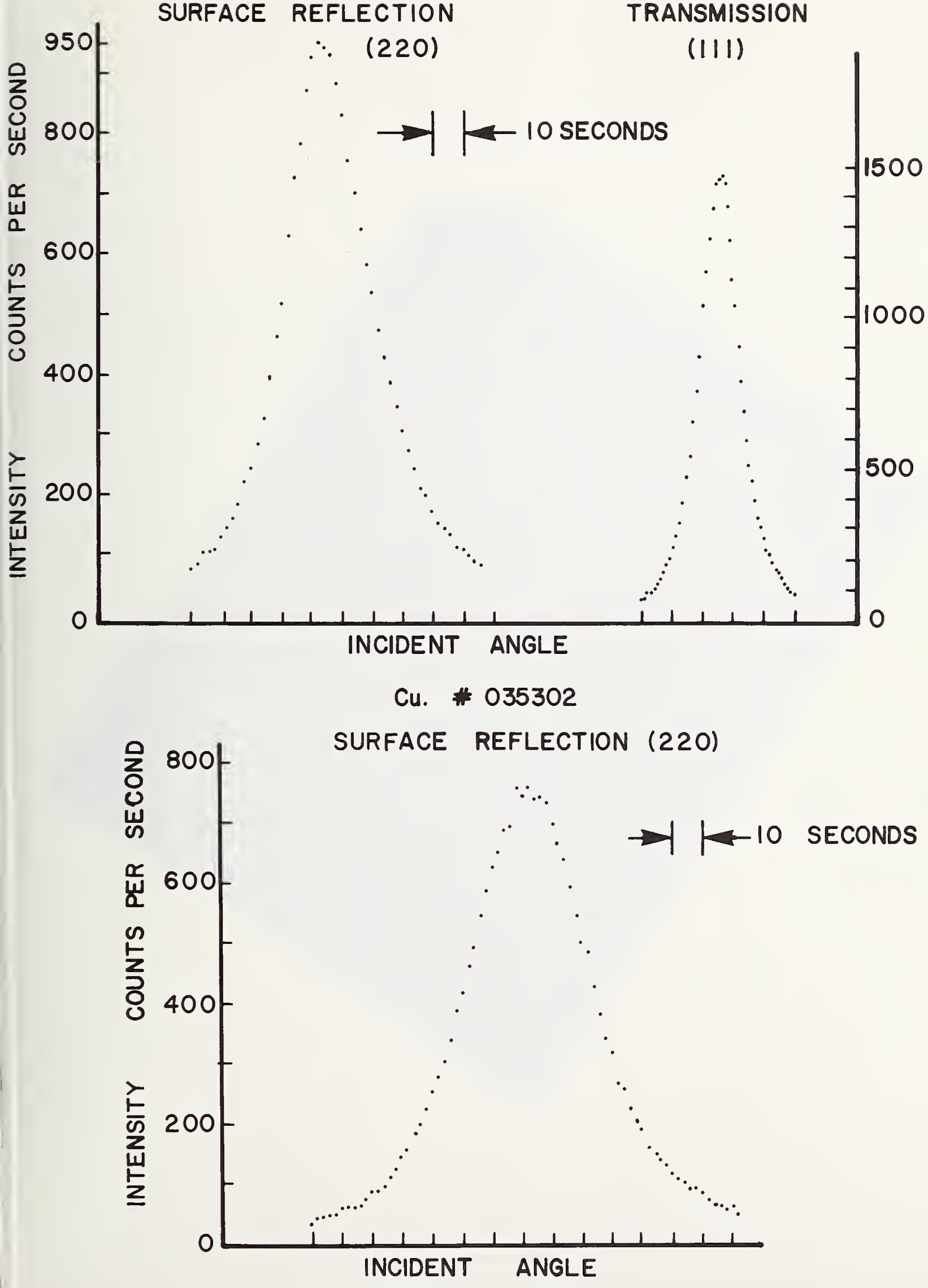





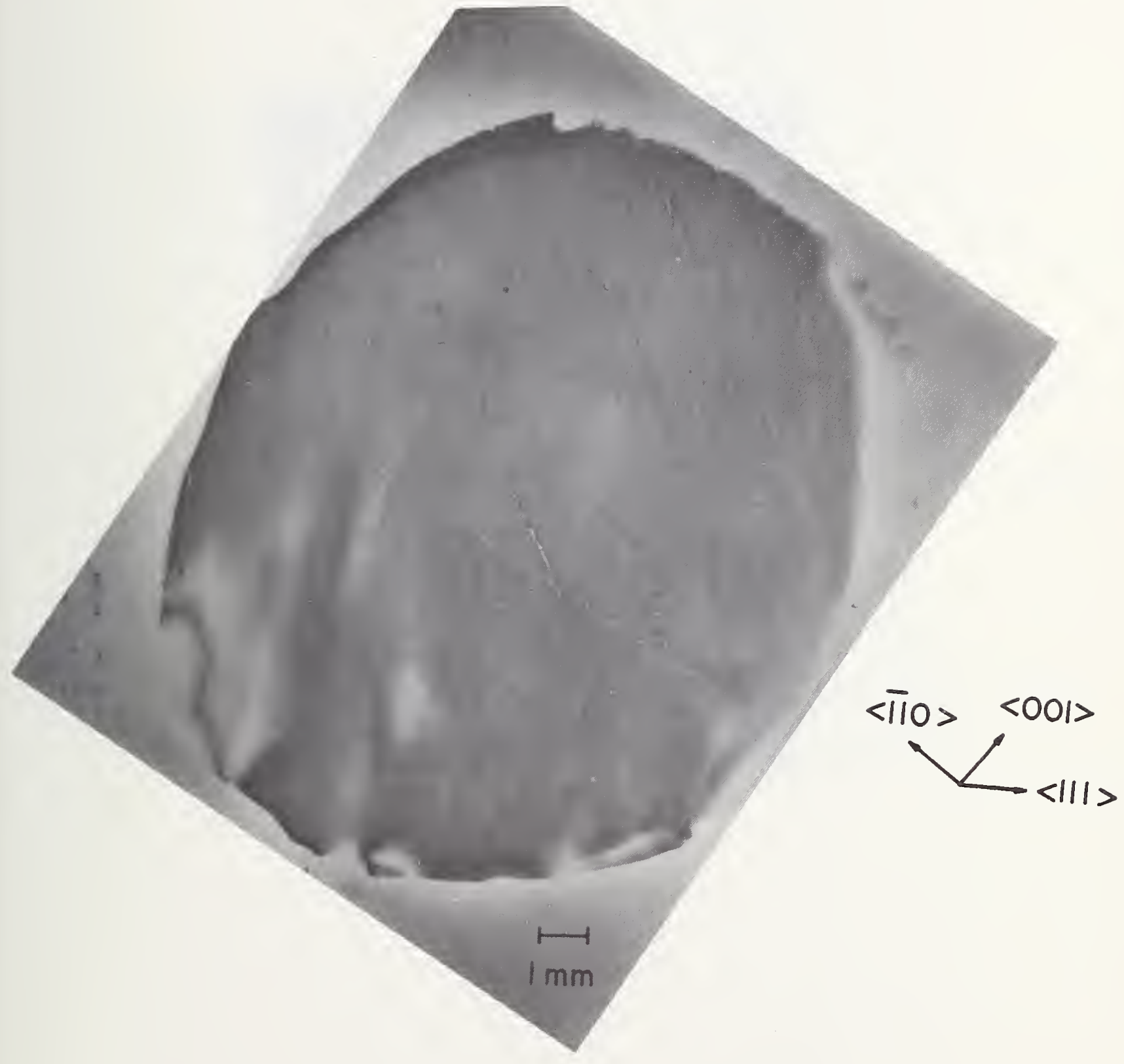

Fig. 12a 



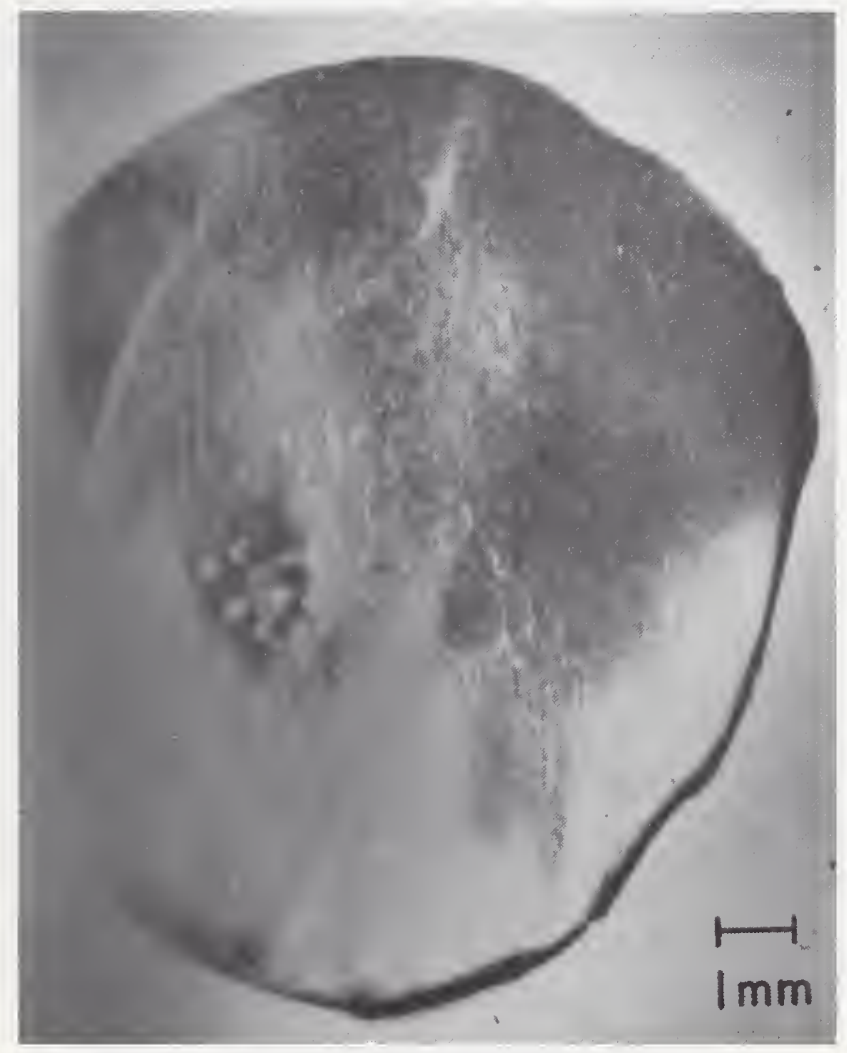

$\langle\pi \mid 0\rangle<001\rangle$

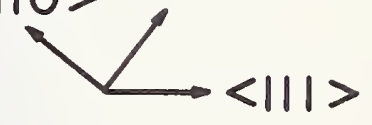

Fig. 12b 



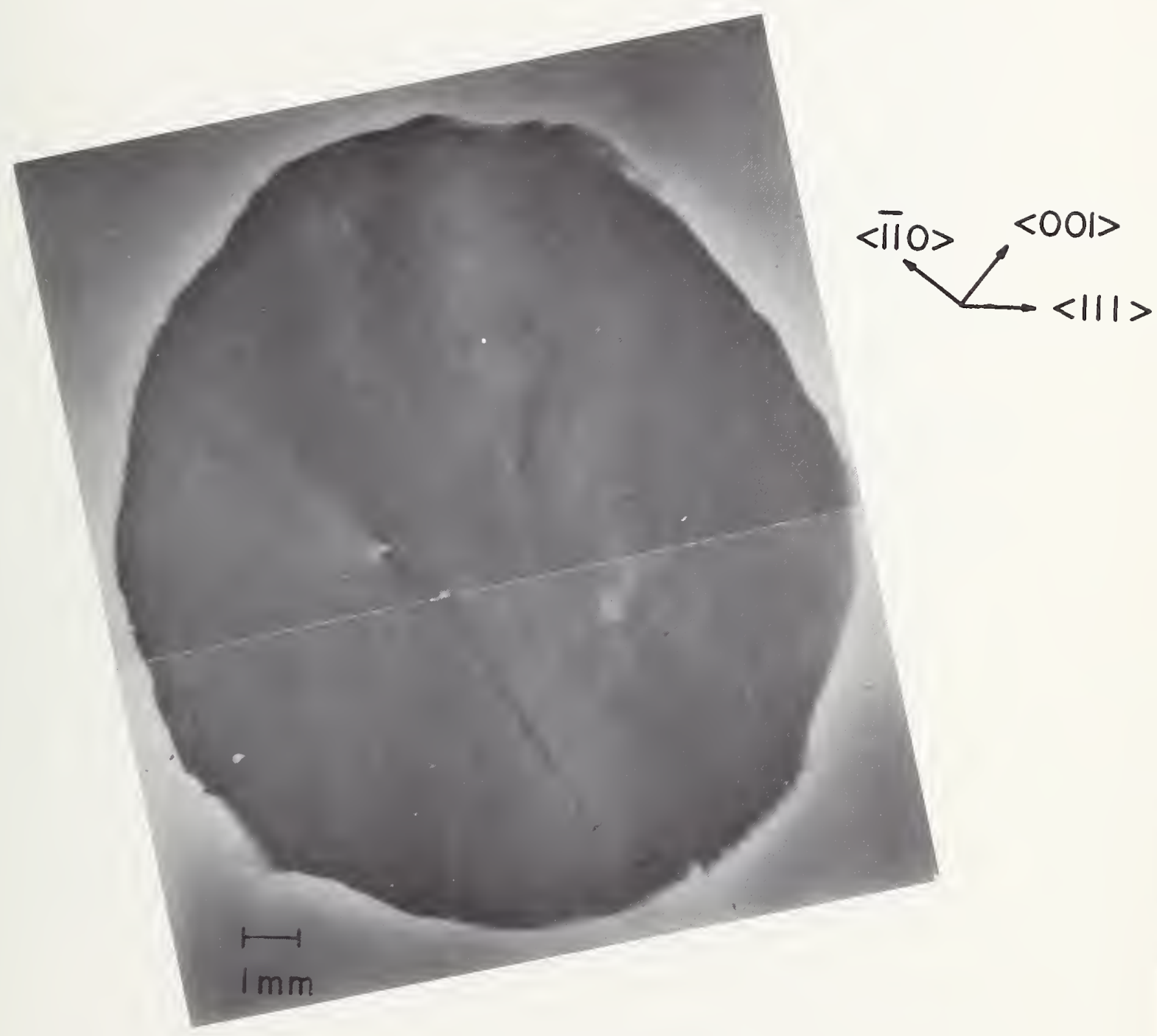

Fig. 13a 



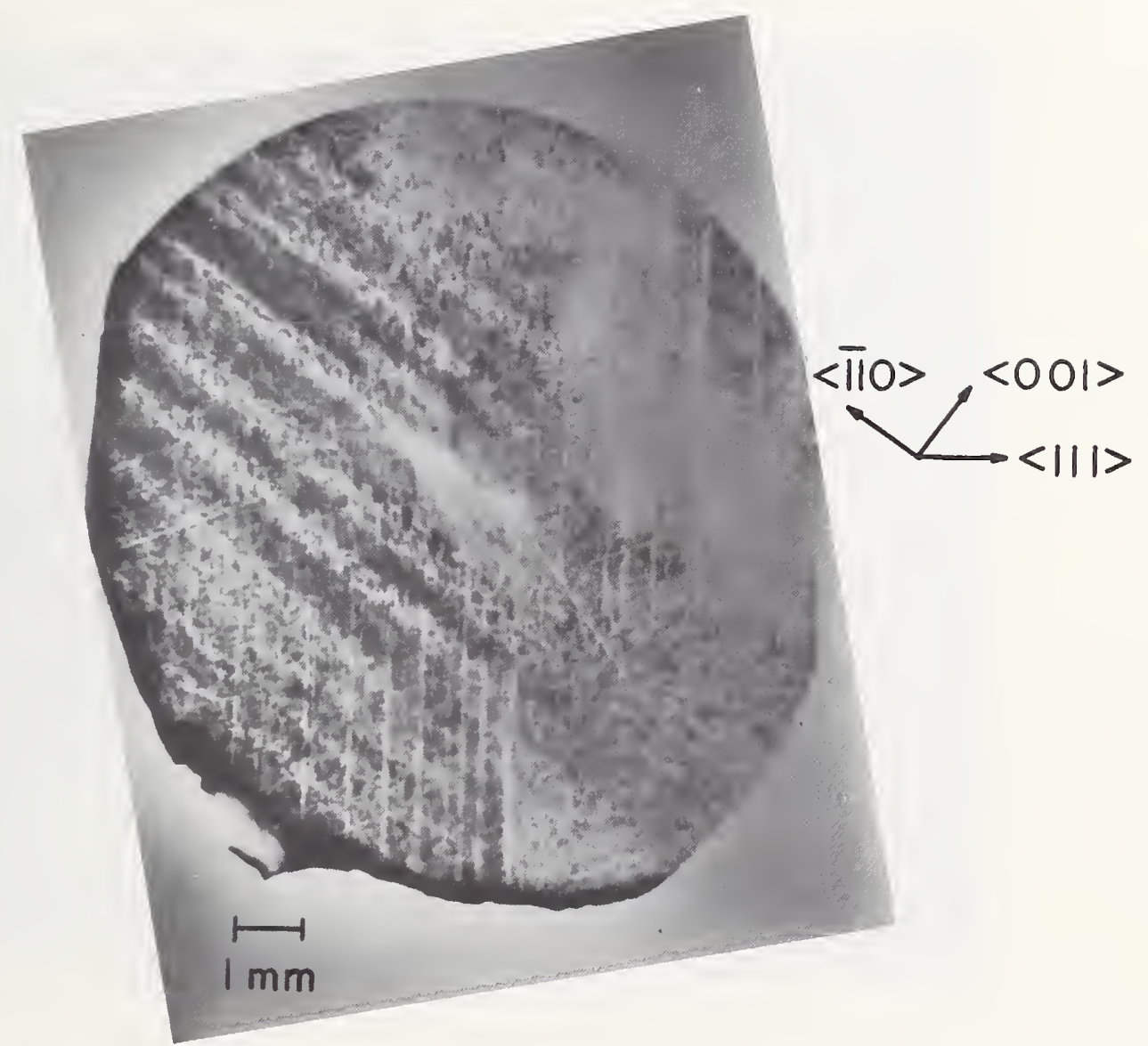

Fig. 13b 


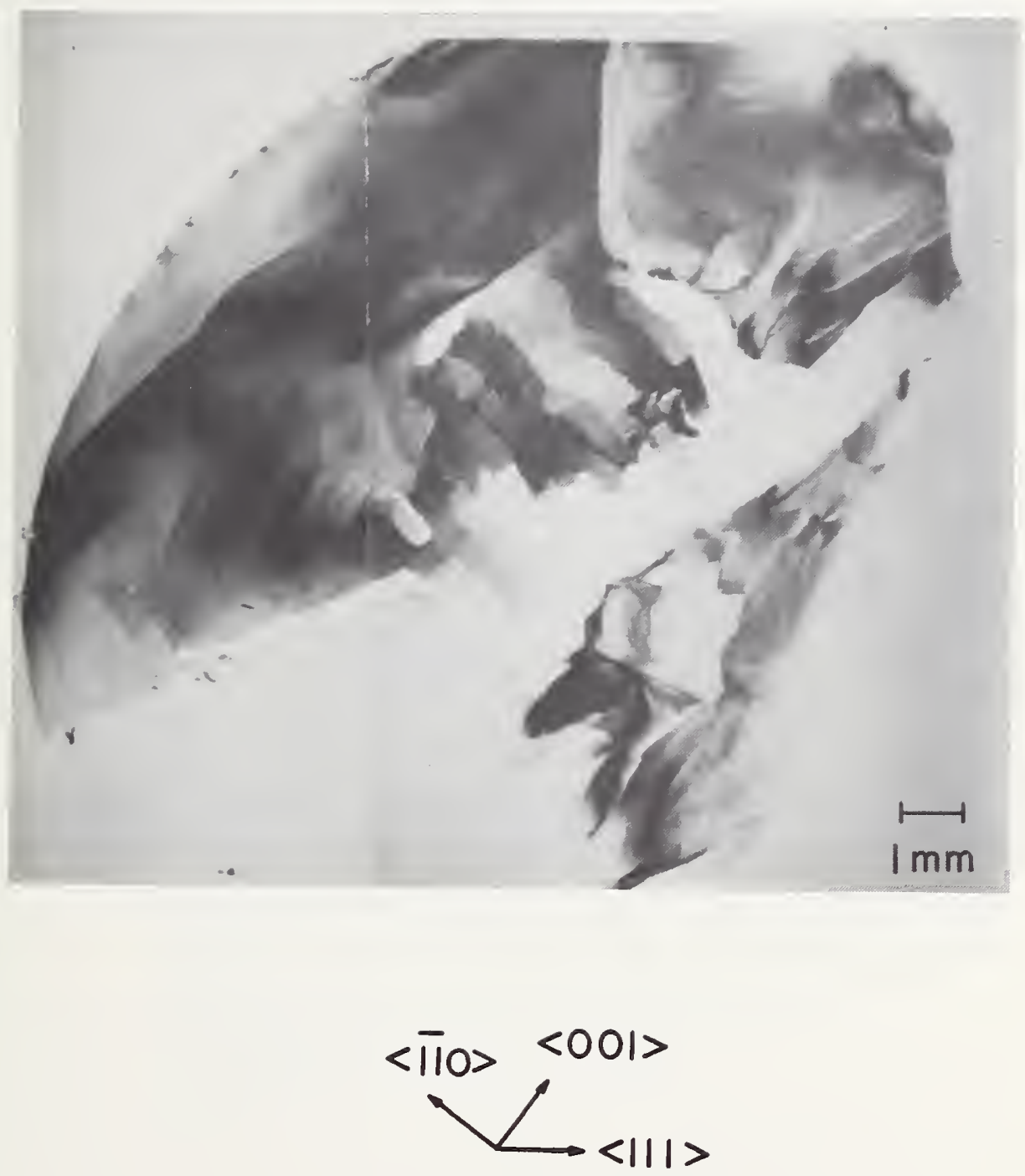

Fig. 14a 


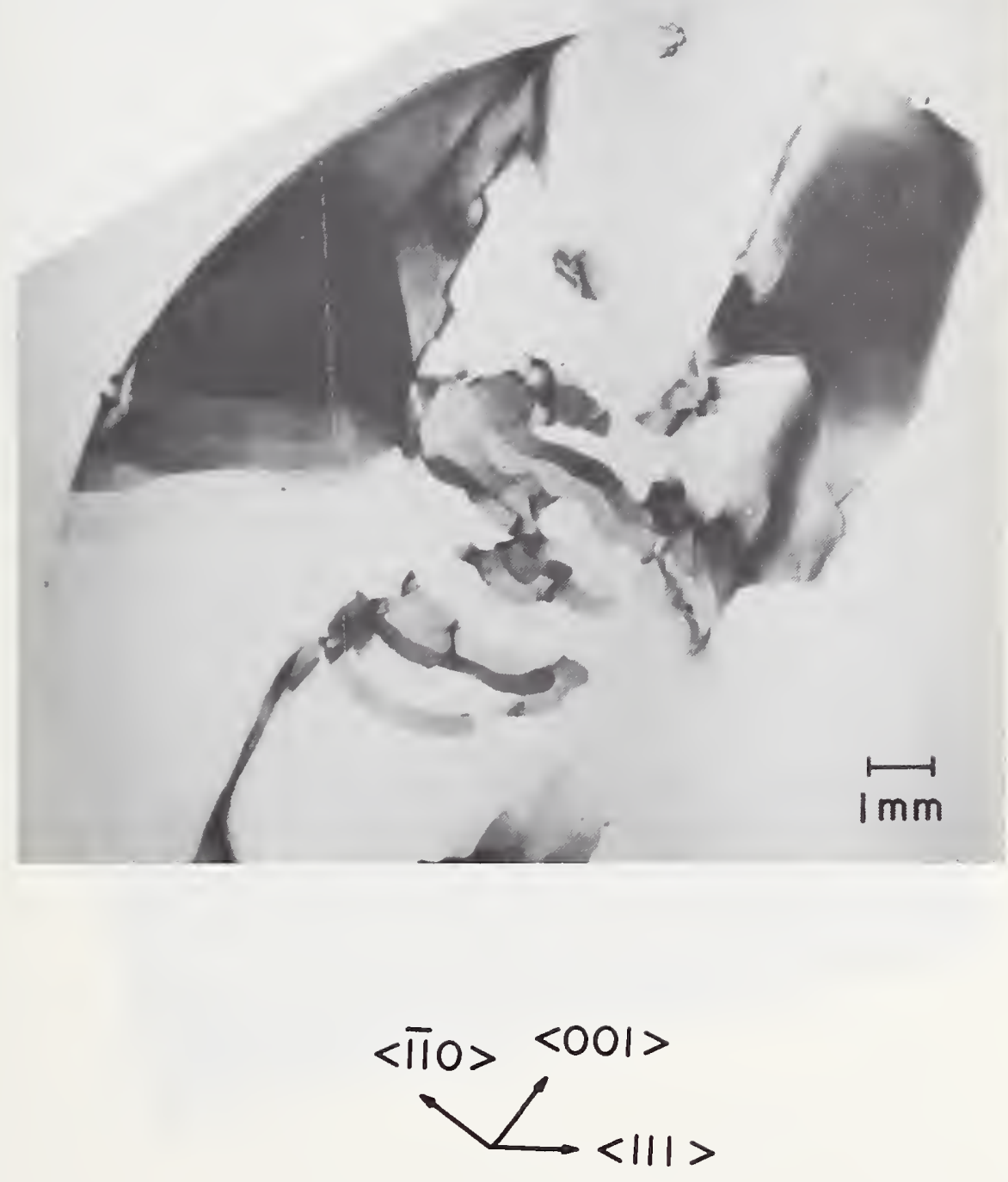



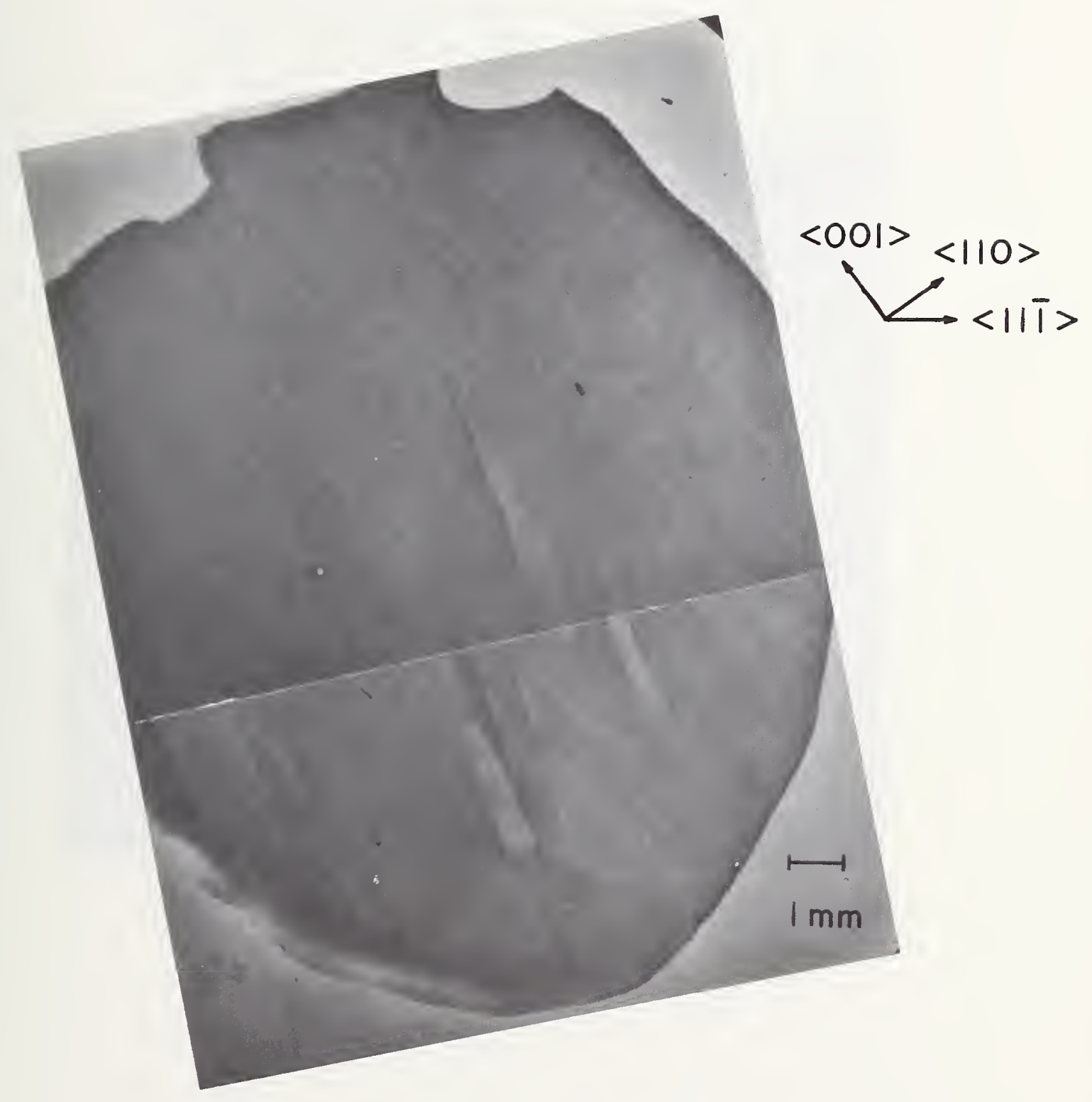

Fig. $15 a$ 



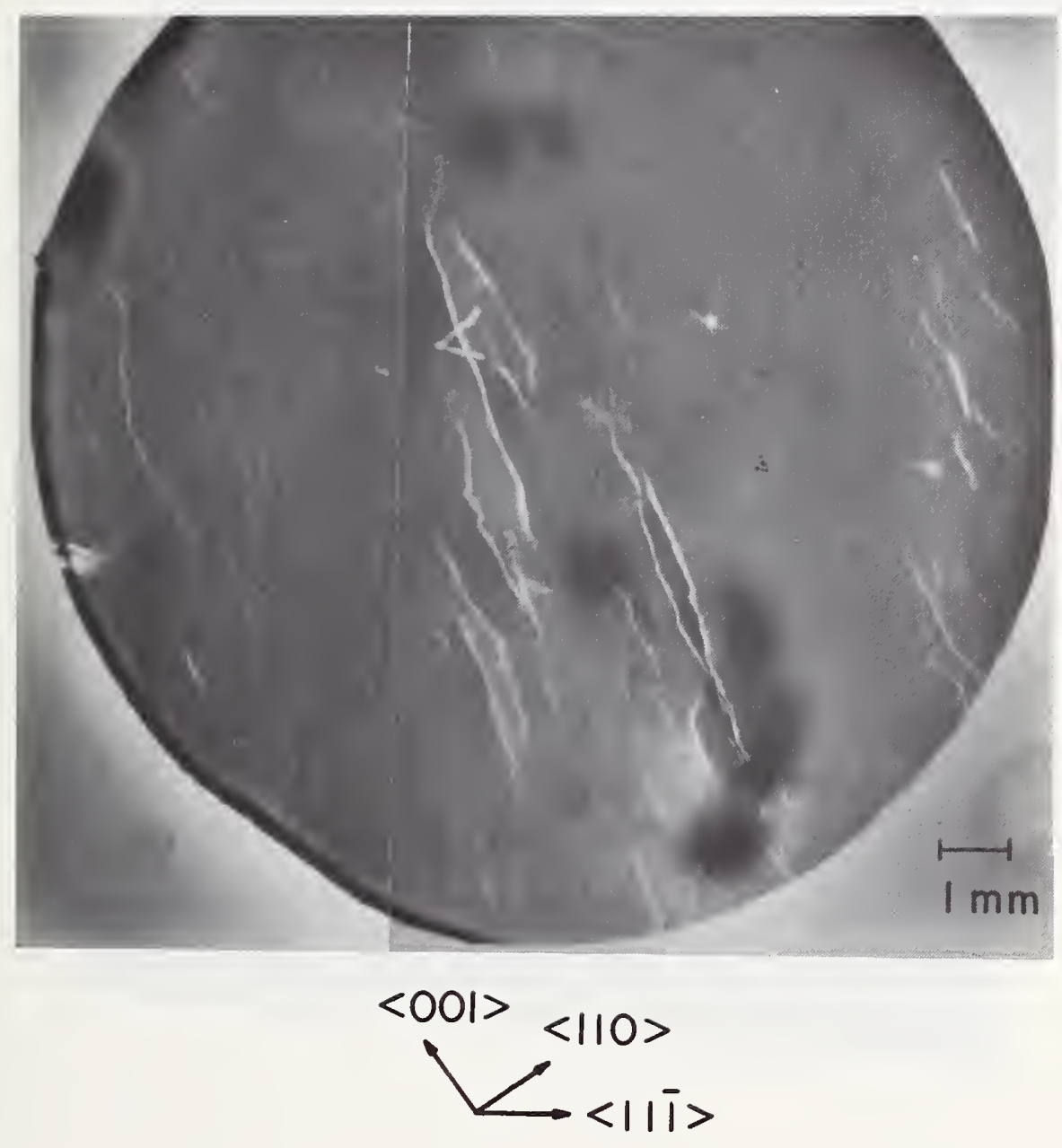

Fig. 15b 



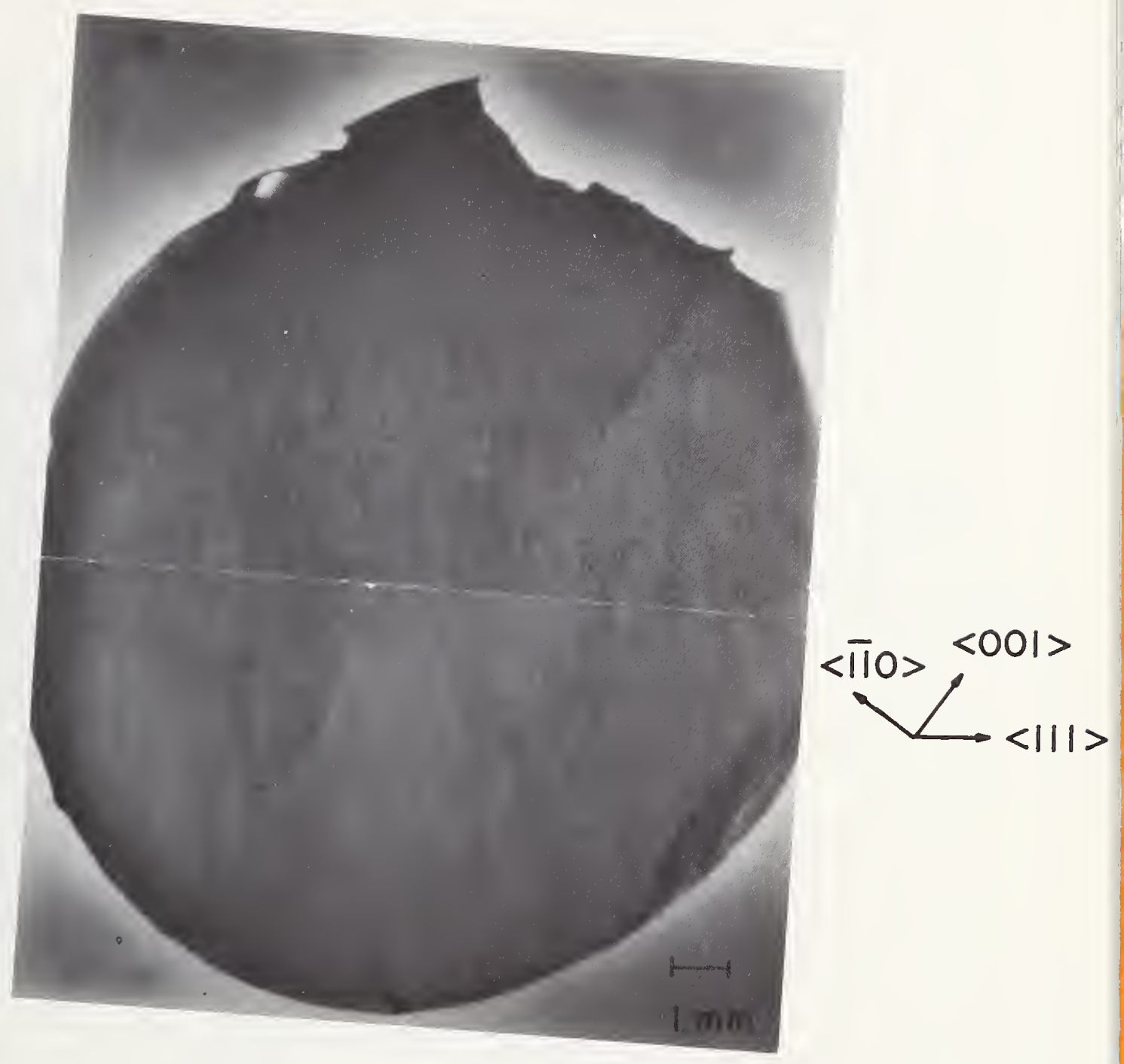

Fig. 16a 



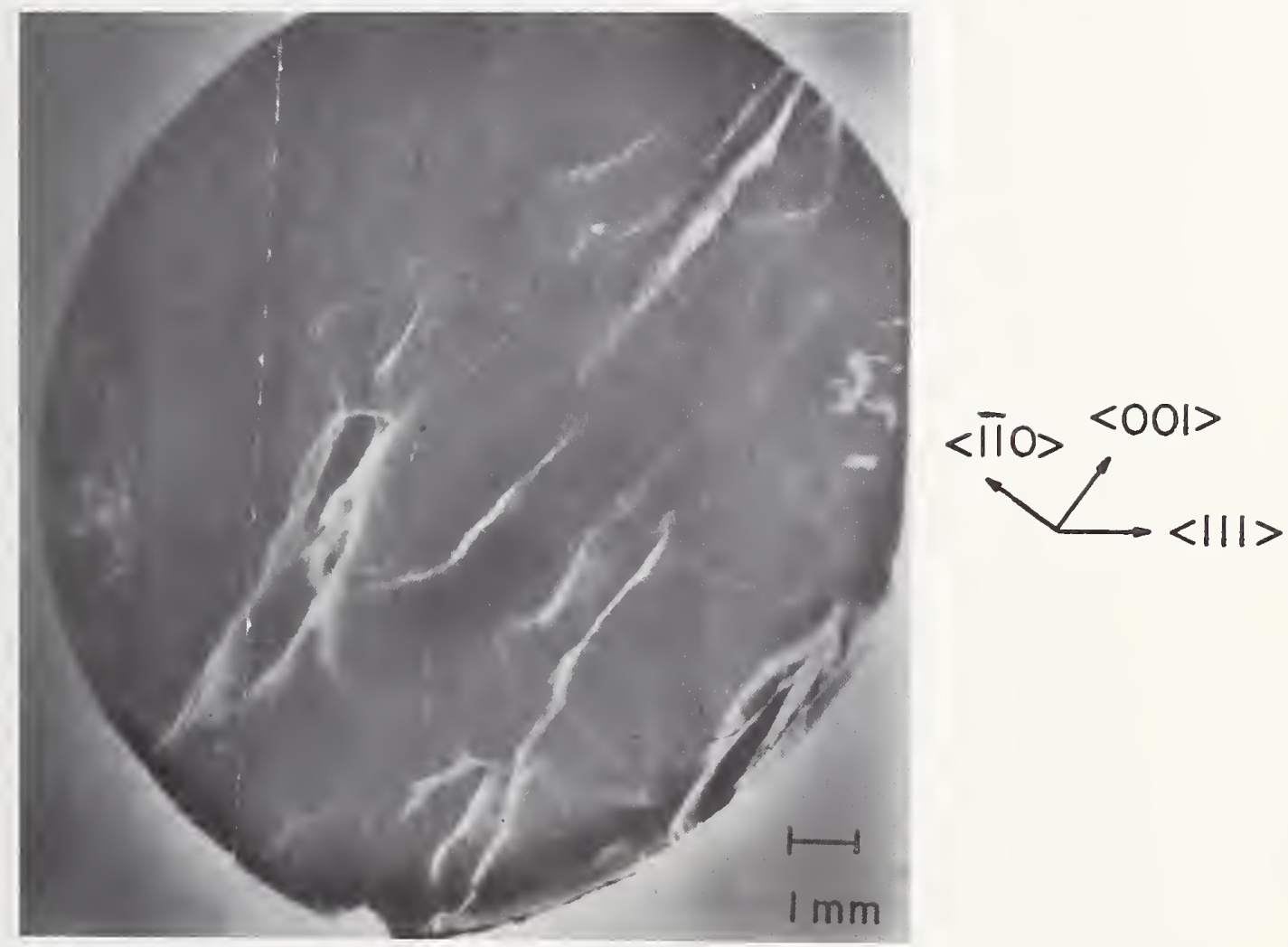

Fig. 16b 



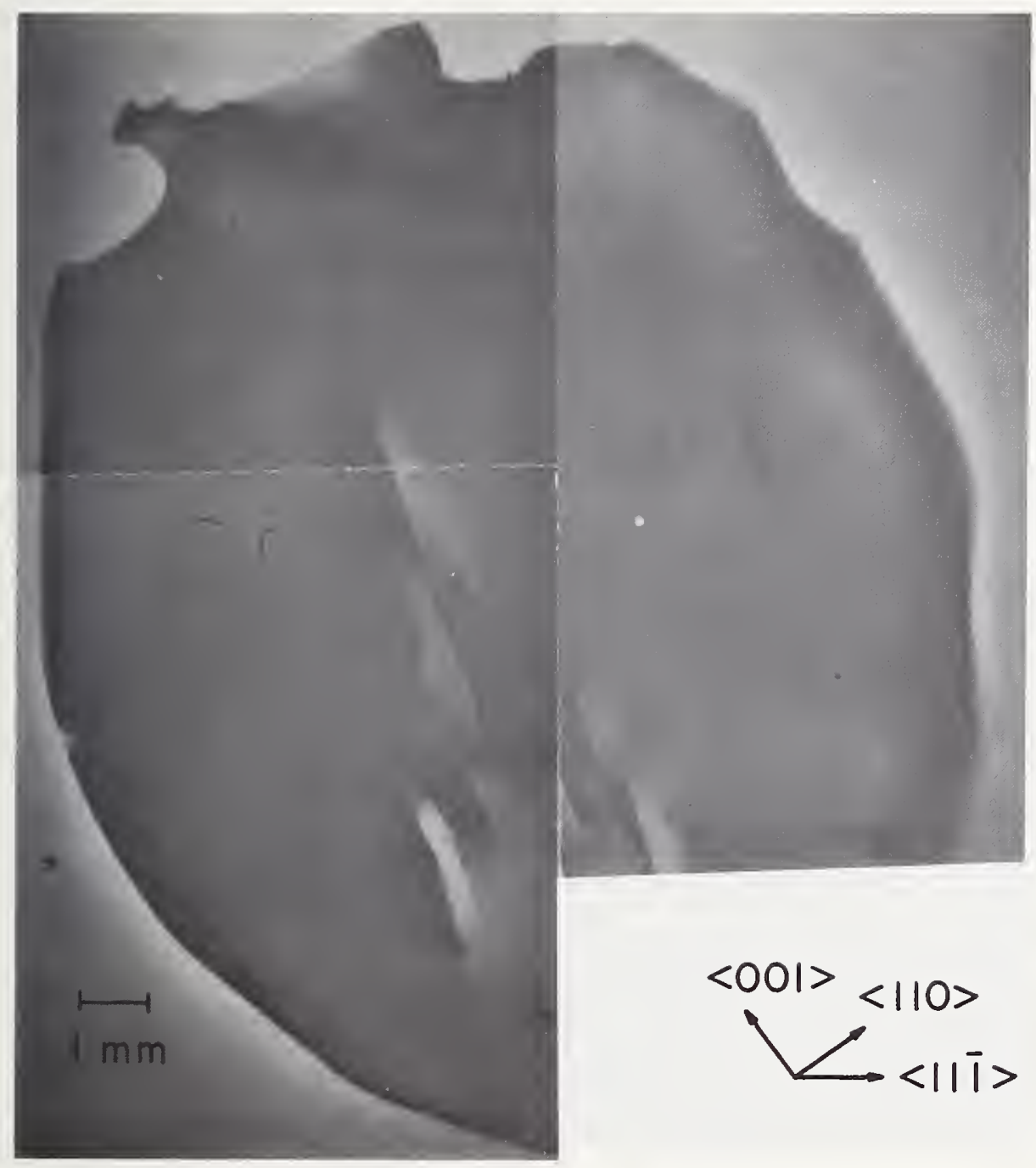

Fig. 17a 



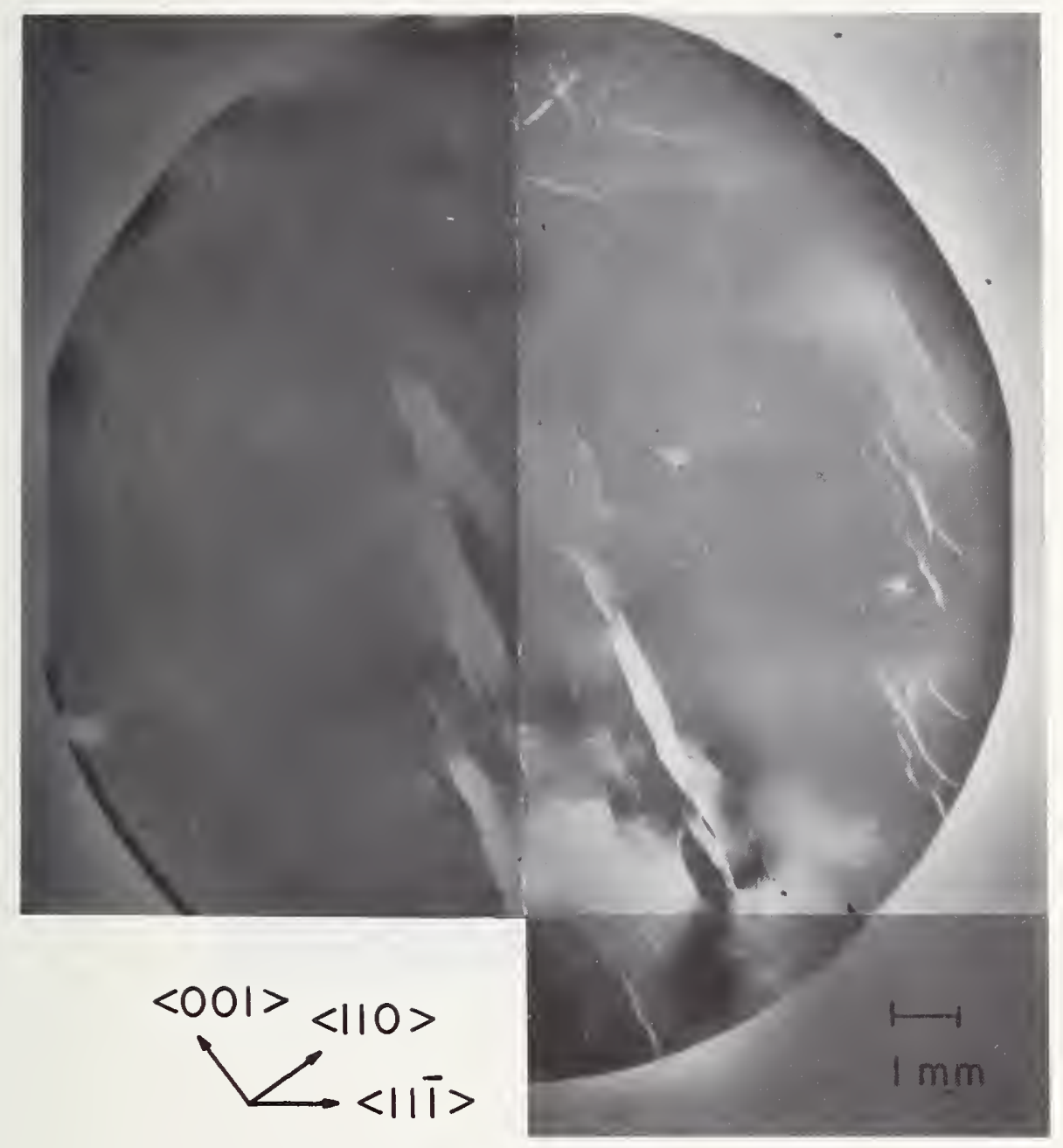

Fig. 17b 



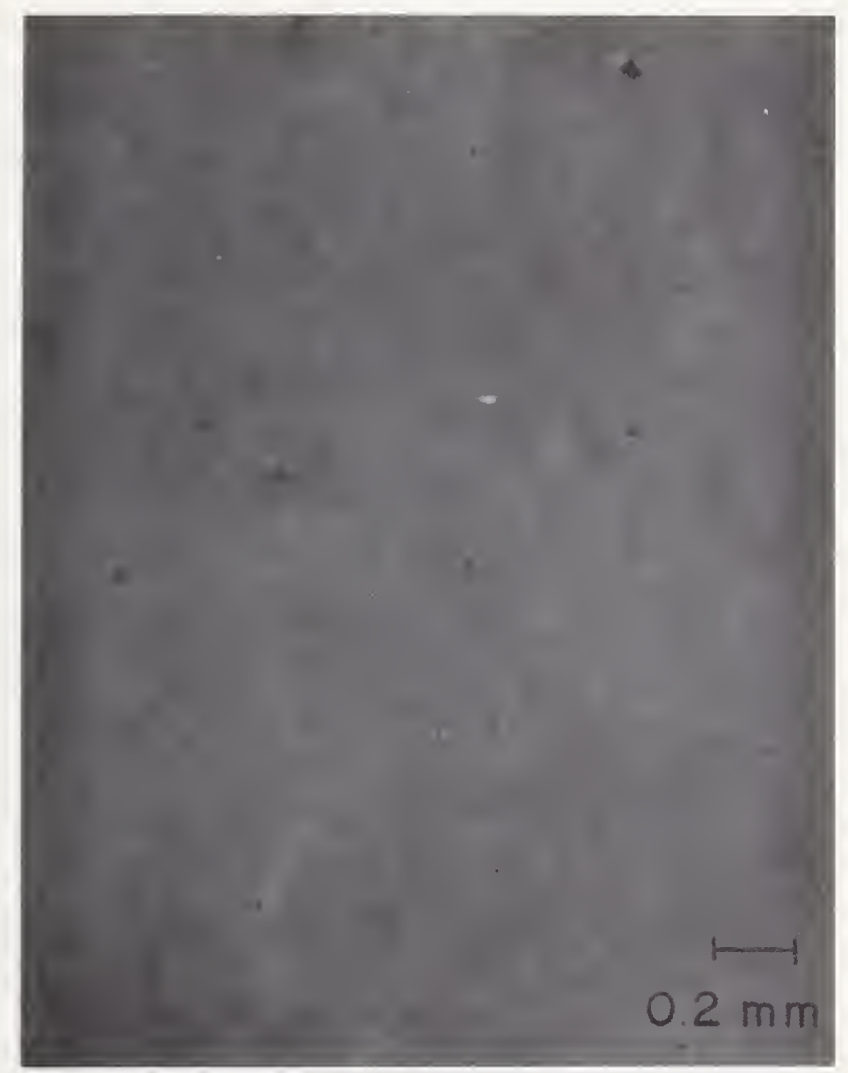

Fig. 18a 



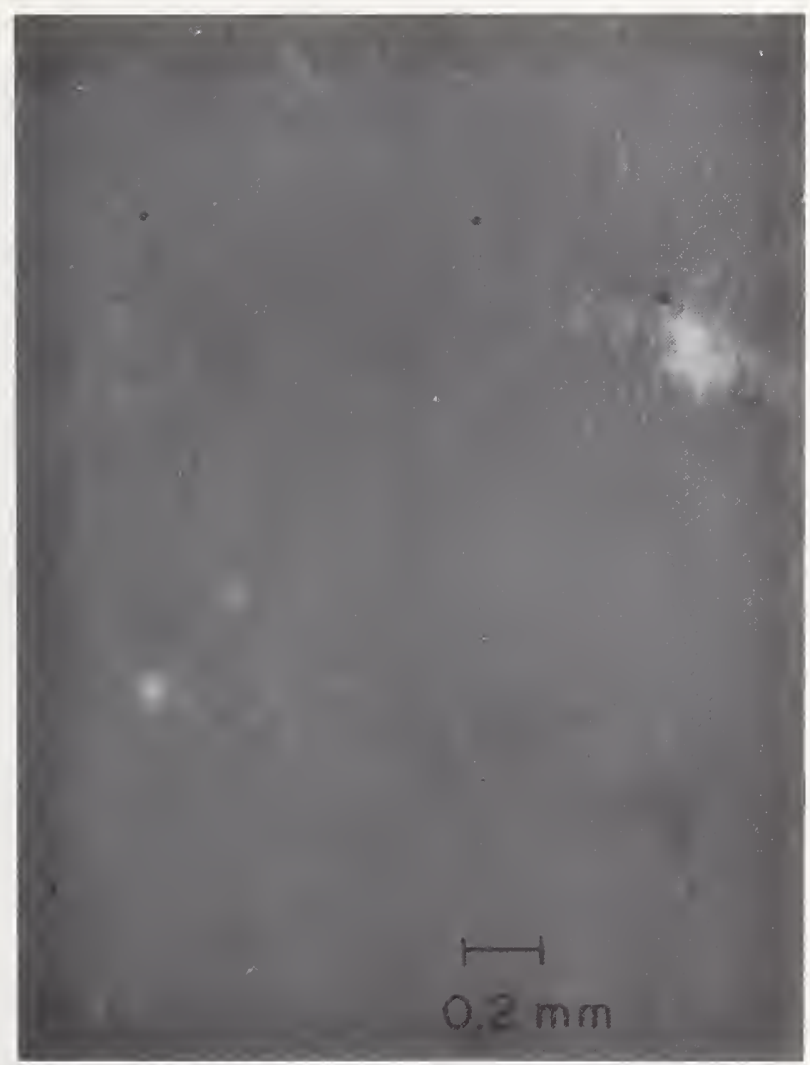

Fig. 18b 



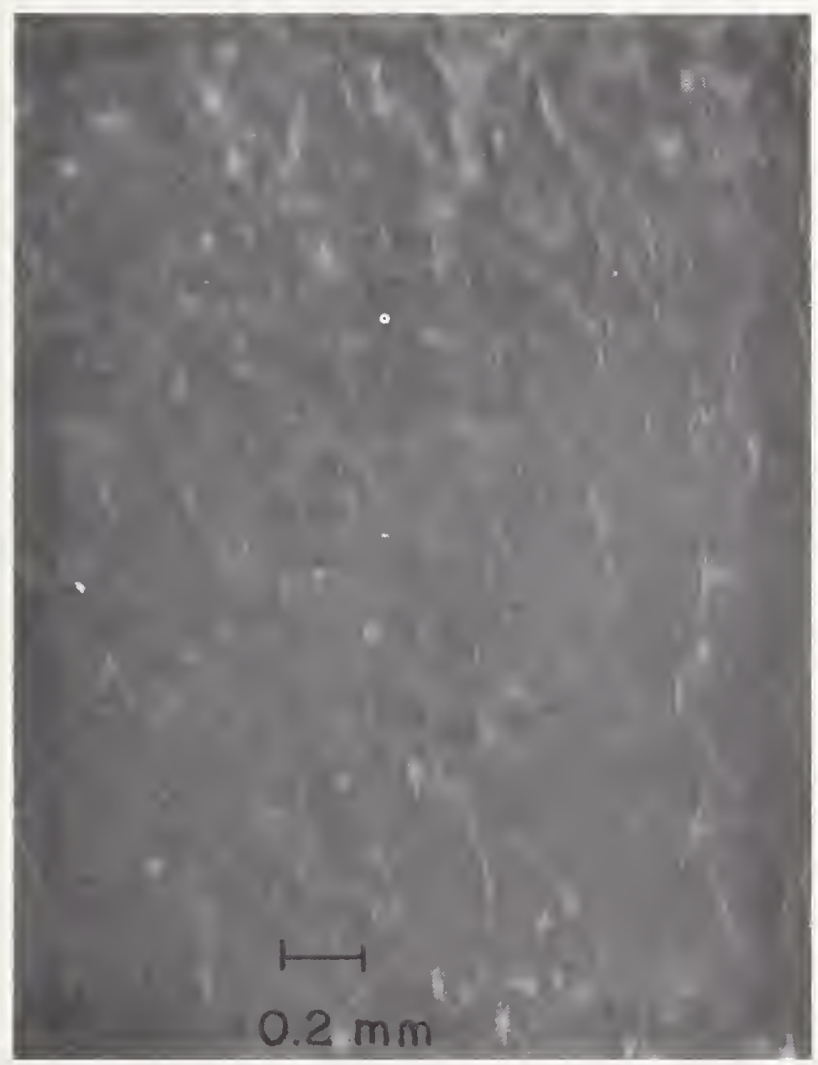

Fig. 18c 



\section{Task 2}

Vapor Transport Synthesis and Crystal Growth of Oxides

H. S. Parker

Inorganic Materials Division

Institute for Materials Research

\section{Summary}

The primary objective of this task is the development of advanced techniques for vapor transport synthesis and crystal growth in mixed oxide systems. The $\mathrm{ZrO}_{2}-\mathrm{Ta}_{2} \mathrm{O}_{5}$ system was chosen for investigation not only because it is a typical mixed oxide system but because successful development could provide a new type of stabilized $\mathrm{ZrO}_{2}$.

The results of transport experiments using $\mathrm{I}_{2}+\mathrm{S}_{2}$ and $\mathrm{ZrCl}_{4}$ for transport of $\mathrm{ZrO}_{2}$ in the 3-7 atmosphere range at average temperatures of about $950-1100^{\circ} \mathrm{C}$ were largely negative. Simultaneous transport experiments of $\mathrm{ZrO}_{2}+\mathrm{Ta}_{2} \mathrm{O}_{5}$ using $\mathrm{ZrCl}_{4}$ and $\mathrm{TaCl}_{5}$ resulted in severe attack of the quartz reaction tubes. Minor success was obtained in simultaneous transport using $\mathrm{ZrCl}_{4}+\mathrm{S}_{2}$ as transport agents. 
Introduction

The objectives of this study are the investigation of advanced techniques for vapor transport synthesis and crystal growth in binary and ternary oxide systems and definition of the limitations imposed by convective effects on the process at high pressures and large temperature gradients.

Crystal growth of binary and ternary chalcogenides by vapor transport reactions has received considerable attention in the past 1,2. Applications of the technique to the synthesis and growth of oxide crystals have been confined to single oxides in most cases, with the major exceptions being certain spinels and germanates ${ }^{2}$. Emmenegger ${ }^{3,4}$ and Emmenegger and Petermann ${ }^{5}$ have investigated the transport and crystal growth of ternary metal oxides and transition metal niobates and tantalates. More recently, Bowen and co-workers ${ }^{6}$ have described the growth of transition metal oxide solid solutions. The selection of ordered fluorite structure type phases in oxide systems for initial investigation was motivated by scientific interest in extension of the vapor transport growth technique and potential technological application of materials possessing this structure. The specific material for initial consideration is $\mathrm{ZrO}_{2}$ in combination with either $\mathrm{Ta}_{2} \mathrm{O}_{5}$ or $\mathrm{Nb}_{2} \mathrm{O}_{5}$. Zirconium dioxide is an important refractory material because of its high melting point, chemical inertness and low vapor pressure. In the pure form, $\mathrm{ZrO}_{2}$ undergoes a reversible phase transition from the monoclinic to tetragonal form at about $1000^{\circ} \mathrm{C}$ which is accompanied by a disruptive volume change of nine percent. In order 
to avoid this problem, $\mathrm{ZrO}_{2}$ is commonly stabilized in a cubic form by the use of up to 15 percent of $\mathrm{CaO}, \mathrm{Y}_{2} \mathrm{O}_{3}$ or $\mathrm{MgO}$ as an additive.

Work at NBS has indicated that an alternative method of stabilizing $\mathrm{ZrO}_{2}$ is the formation of ordered fluorite structure type phases (orthorhombic) $7,8,9$. This structure is an anion excess type rather than the oxygen (anion) deficient type obtained with $\mathrm{CaO}, \mathrm{Y}_{2} \mathrm{O}_{3}$ or $\mathrm{MgO}$ additives and should have greater stability. Melting points of suitable compounds in the $\mathrm{ZrO}_{2}-\mathrm{Ta}_{2} \mathrm{O}_{5}$ systems are in excess of $2000^{\circ} \mathrm{C}$, thus, a more stable form of $\mathrm{ZrO}_{2}$ would be of considerable importance. In addition, little is known about the structure, physical and electrical properties of these phases.

The high melting points present a problem in synthesis and growth of single crystals suitable for characterization and investigation. The largest crystals we have been able to obtain from flux or solid state techniques are of the order of $0.5 \mathrm{~mm}$ in $\mathrm{size}^{9}$. Vapor phase transport techniques offer the potential for obtaining larger sized crystals at temperatures well below the melting points.

The use of closed tube transport techniques for synthesis and crystal growth, together with the criteria for selection of a suitable transport reaction has been described by Schafer ${ }^{1,10}$ and Laudise ${ }^{11}$. Basically, an attempt is made to select a suitable transport agent such that the desired phase is the only solid product at the working temperatures, the equilibrium position is not extreme $\left(\Delta G^{\circ} \sim 0\right)$ and, for reasonable transport rates, the $\Delta \mathrm{H}^{\circ}$ value for the reaction should be near zero. 
The transport of $\mathrm{Ta}_{2} \mathrm{O}_{5}$ with halogens is well established ${ }^{1}$ according to the reaction:

$$
\mathrm{Ta}_{2} \mathrm{O}_{5}+3 \mathrm{TaCl}_{5} \stackrel{\leftarrow}{\rightarrow} \mathrm{TaOCl}_{3}
$$

at total pressures of 1 atmosphere at temperatures of $750^{\circ}$ and $650^{\circ}$ with transport rates in excess of $10 \mathrm{mg} / \mathrm{hr}$. However, only one report of the closed tube transport of $\mathrm{ZrO}_{2}$ was found in the literature. Nitsche ${ }^{2}$ reports the use of $\mathrm{I}_{2}+\mathrm{S}_{2}$ as transporting agents and temperatures of $1050^{\circ}-1000^{\circ} \mathrm{C}$ although no further experimental details were given.

\section{Experimental}

Transport studies were carried out in quartz tubes of $8 \mathrm{~mm}$ inside diameter and about $15 \mathrm{~cm}$ total length. Prior to use, the tubes were cleaned, evacuated and baked out at about $300^{\circ} \mathrm{C}$ at pressures of about $1 \times 10^{-6}$ Torr overnight prior to loading. A sorption rough pump and ion diffusion pumping system was used to avoid contamination from oil vapors.

Following bakeout, the tube was charged with an excess of high purity oxide together with the calculated amount of transport agent. The tube was then re-evacuated and sealed off at pressure of $5 \times 10^{-6}$ Torr or less. The oxides used were nominally of $99.99 \%$ or higher purity. In the case of simultaneous transport experiments, two different types of charge were used. In one case, the $\mathrm{ZrO}_{2}$ and $\mathrm{Ta}_{2} \mathrm{O}_{5}$ were added as the unreacted oxides. The alternative method chosen was to first react the two materials at $1500^{\circ} \mathrm{C}$ to yield a single phase product of the desired composition and subsequently use this material as the charge. 
The furnaces used were of the multizone type, with independent control of each zone. By the use of suitable thermal baffles, two isothermal regions $\left(+10^{\circ} \mathrm{C}\right)$ of about $15 \mathrm{~cm}$ length could be established, separated by a central region of about $1.5 \mathrm{~cm}$ over which the $\Delta \mathrm{T}$ for transport was established. Both vertical and horizontal configurations were used. The transport tubes were placed in the furnace such that the center of the tube coincided with the temperature gradient.

Total pressures for the various transport agents were calculated on the basis of average tube temperature and assumed ideal behavior of the gaseous species. Typical tube loadings were of the order of 4 to $7 \mathrm{mg}$ per $\mathrm{cm}^{3}$ of tube volume for the pressure ranges chosen, about 3-7 atmospheres.

\section{Results and Discussion}

The results of the transport experiments are summarized in Table 1. Because of the lack of information regarding the transport of $\mathrm{ZrO}_{2}$, the major effort was devoted to attempting to establish suitable conditions for the transport of reasonable amounts of $\mathrm{ZrO}_{2}$ alone. All attempts to duplicate the reported transport ${ }^{2}$ using $\mathrm{I}_{2}+\mathrm{S}_{2}$ were largely unsuccessful, up to the temperature and pressure limits of the quartz tubes. At the highest temperatures and pressures, only milligrams amounts of transport were achieved in reasonable times.

Attempts to use $\mathrm{ZrCl}_{4}$ as a transport agent yielded poor results except at the limits of the quartz tube, although crystallinity of the deposit was improved greatly. A more serious problem when transport of 
$\mathrm{ZrO}_{2}+\mathrm{Ta}_{2} \mathrm{O}_{5}$ was attempted was the severe attack on the quartz tube in the presence of $\mathrm{ZrCl}_{4}$ and/or $\mathrm{TaCl}_{5}$. The amount of attack was directly related to temperature. This resulted in a large percentage of tube failures during a run. Optical and $x$-ray diffraction examination of a typical run with $\mathrm{ZrCl}_{4}$ indicated the major reaction product to be low cristobalite with no detectable $\mathrm{ZrSiO}_{4}$ present. Thus, it appears that the devitrification of the fused quartz is enhanced by the presence of $\mathrm{ZrCl}_{4}$ and/or $\mathrm{ZrOCl}_{2}$. This limitation on maximum working temperature, together with the low transport rates observed, suggested that $\mathrm{ZrCl}_{4}$ with or without $\mathrm{TaCl}_{5}$ is not suitable for larger scale crystal growth in a closed quartz tube system.

Attempts to modify the transport reaction by the addition of another component to the system and thus reduce the temperature required as well as increase transport rates are being investigated. Preliminary results using $\mathrm{ZrCl}_{4}$ and sulfur at lower temperatures, $1070^{\circ}-970^{\circ} \mathrm{C}$, have yielded milligrams of transported material with small, well-formed crystals. However, the transport rate must be increased if sizeable amounts of material are to be grown.

Conclusions and Future Work

The major problem is the matter of transport rate of $\mathrm{ZrO}_{2}$. Future work will concentrate on the use of more complex transport reactions to produce a more favorable mass transport. The temperature and pressure limitations imposed by the use of quartz as a closed reaction chamber may necessitate the consideration of an open system of more refractory material such as $\mathrm{Al}_{2} \mathrm{O}_{3}$ in order that temperatures be increased to increase transport rates. 


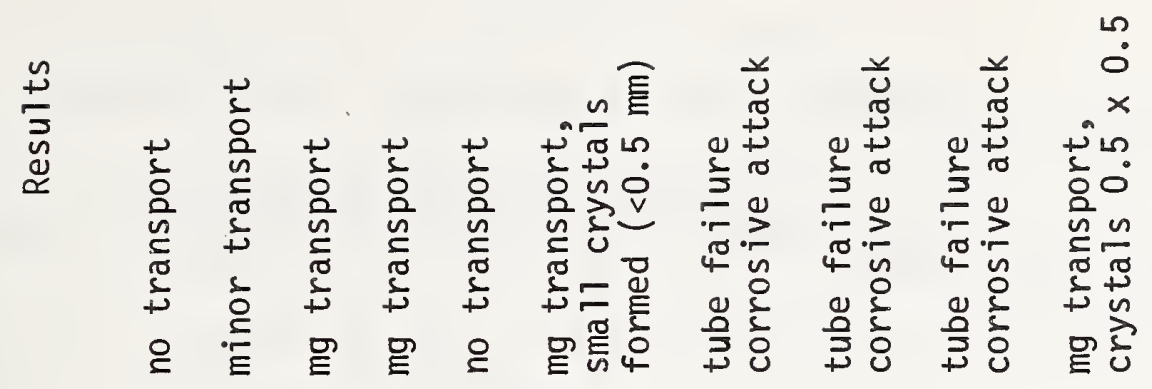

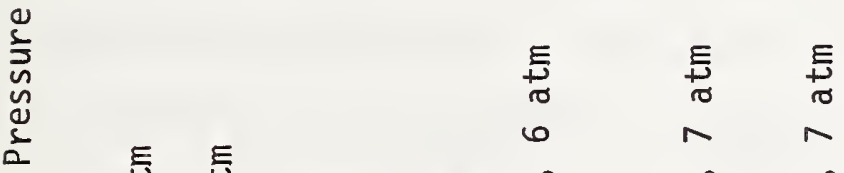

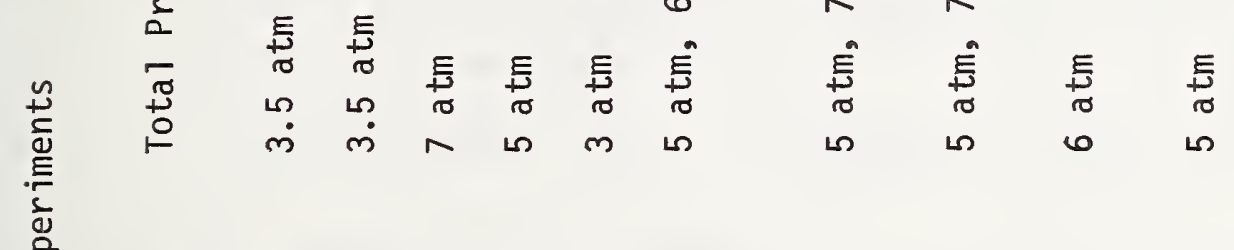

$$
\begin{aligned}
& \text { - 崖 }
\end{aligned}
$$

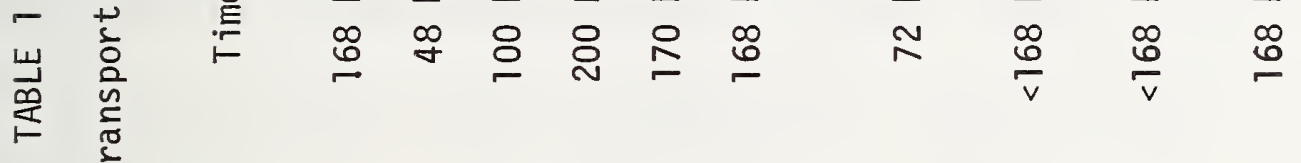

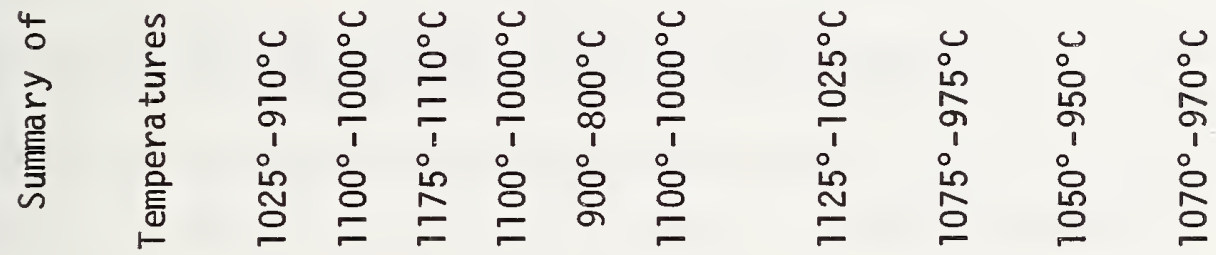

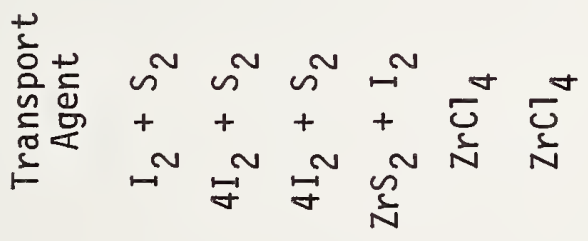

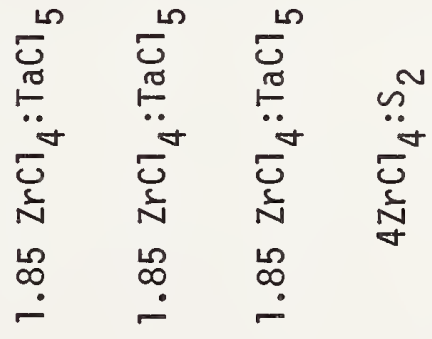

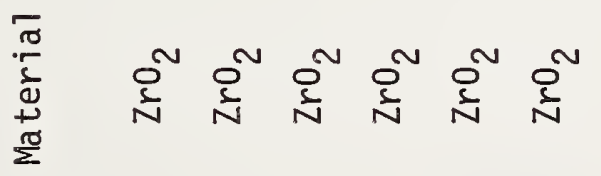

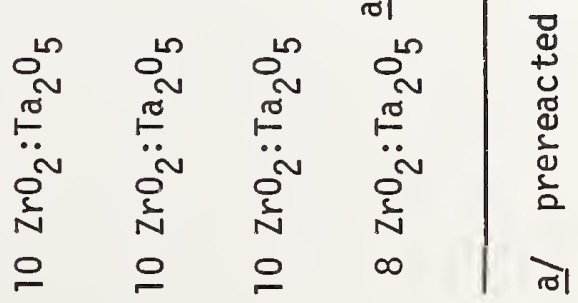


1. H. Schafer, Chemical Transport Reactions, Academic Press, New York 1964.

2. R. Nitsche, Crystal Growth, H.S. Peiser, Ed., 215-220, Pergamon Press, London 1967.

3. F. Emmenegger, J. Crysta1 Growth 2, 109-110 (1968).

4. F. Emmenegger, J. Crystal Growth 3, 4, 135-140 (1968).

5. F. Emmenegger and A. Petermann, J. Crystal Growth 2, 33-39 (1968).

6. H.K. Bowen, W.D. Kingery, M. Kinoshita and C.A. Goodwin, J. Crystal Growth 13, 14, 402-405 (1972).

7. R.S. Roth and L.W. Coughanour, J. Res. Natl. Bur. Stds. 55, 209-213 (1955) R.P. 2621.

8. R.S. Roth, J.L. Waring, W.S. Brower and H.S. Parker, "Proceedings of 5th Materials Research Symposium", R.S. Roth and S.J. Schneider, Jr., Eds., Natl. Bur. Stds., Special Publication 364, GPO Washington 1972.

9. Jean Galy and R.S. Roth, "The Crystal Structure of $\mathrm{Nb} 2 \mathrm{Zr}_{6} \mathrm{O}_{17}$ ", J. Solid State Chem., 7, 277-285 (1973).

10. H. Schafer, "Preparative Methods in Solid State Chemistry", P. Hagenmuller, Ed., 251-277, Academic Press, New York 1972.

11. R.A. Laudise, "The Growth of Single Crystals", 225-256, Prentice-Hall, Inc., New Jersey 1970. 


\section{Task 3}

Preparation of Ultrahigh Purity Material

R. C. Paule

Inorganic Materials Division

Institute for Materials Research

\section{Summary}

A calculational procedure involving the use of complex chemical equilibria has been developed to describe the purification of refractory materials in space. High temperature evaporative purification of refractories is considered under vacuum conditions and under conditions of very low oxidizing or reducing ambient pressures. The calculations show that extensive purification can be obtained and that very low oxidizing or reducing ambient pressures can be used to control the rates of purification. This method could also be used to allow the production of doped materials to pre-selected levels.

Consideration is given to the assumptions affecting the purfication calculations, and an experimental program is being developed to check the calculated results. This program involves mass spectrometric measurements on a sessile drop of molten $\mathrm{Al}_{2} \mathrm{O}_{3}$. 
Introduction

Hot containers used in the production and purification of refractory materials are themselves a common source of contamination. Space with its zero gravity, high vacuum conditions offers an opportunity for containerless purification of refractories. The heating and distilling out of impurities is a natural means of purification. Evaporative purification of refractories normally involves many complex equilibria since numerous minor impurities are present and since the high temperatures involved allow many "side" reactions. The general formalism for the calculation of complex equilibria has been modified and adapted to describe evaporative purification. Four classes of problems have been investigated. The evaporating gases are described under conditions of
(1) constant pressure,
(2) constant volume,
(3) vacuum, and (4) vacuum but with a low oxidizing or reducing ambient pressure. The latter two conditions ( 3 and 4) are of particular interest to this project since they allow for greatest isolation of sample and least chance of container contamination.

\section{Calculations}

There is much work in the literature dealing with the calculation of complex equilibria $(1-7)$. Available calculations and computer programs, however, do not deal with the problem at hand and would have required extensive modifications. We, therefore, developed our own equations and computer programs. Modifications and adaptations were made to Kandiner and Brinkley's ${ }^{(1)}$ general formalism for the calculation of 
complex equilibria. Some basic changes were required to properly describe evaporation into vacuum.

The general formalism for the calculations is not particularly difficult, but the actual calculations do get involved and do require the aid of a computer. The calculations, in general terms, can be described as follows:

One needs to determine the number of moles of all chemical species in a system during purification and to determine the distribution of moles between the condensed phase and the evaporating (gas) phase. For the sake of simplicity one wants to work with the minimum information needed to fully describe the system. This is equivalent to determining a set of independent chemical species. All chemical species are thereby separated into two groups: independent components and dependent constituents. The solution to our problem then deals primarily with the determination of the amount of each independent component. Independent mass balance equations are written for each component. These equations do not directly involve any dependent constituents, and the NewtonRaphson iteration method $(8,9)$ is used to simultaneously solve the mass balance equations.

The dependent constituents are determined from equilibrium constant relationships which only involve the activities and pressures of the independent components. Ideal solution properties are used to describe the condensed phase activities and, for the vacuum evaporation case, the Knudsen equation is used to describe 
the pressures in terms of the number of moles. A series of sequential solutions are obtained for fixed evaporation times with the condensed phase results from each mathematical solution being used as input feed data in the following problem. It is thus possible to sequentially follow the evaporative purification of a material.

The above general calculational approach is very general and allows for relatively easy and direct modifications to describe a variety of situations of practical interest. A manuscript describing the calculations and examples of their use has been written and NBS approved, and will be submitted for publication. It is enclosed as an Appendix.

$\underline{\text { Results }}$

Our calculations show that good evaporative purification of refractories in vacuum can be obtained, and that the introduction of a low oxidizing or reducing ambient pressure can be used to control rates of vaporization.

Table 1 shows the results for calculations of $\mathrm{Al}_{2} \mathrm{O}_{3}$ evaporative purification in vacuum at $2400 \mathrm{~K}$, where $10 \mathrm{ppm}$ (mole basis) $\mathrm{FeO}$ and $\mathrm{SiO}_{2}$ impurities are initially present. Row 3 of the table shows that the rate of $\mathrm{Al}_{2} \mathrm{O}_{3}$ loss is very low, while rows 4 and 5 show that $\mathrm{Fe} 0$ and $\mathrm{SiO}_{2}$ are rapidly lost from the melt. The $\mathrm{FeO}$ and $\mathrm{SiO}_{2}$ concentrations are approximately halved over a period of only 1.15 seconds. The remaining 12 species in the table, under the heading "Moles of Species Present", represent the moles of gases vaporized during each time 
interval (0-0.005 seconds, 0.005-0.28 seconds, 0.28-0.46 seconds, etc.). Finally the instantaneous pressures of all species are reported at the bottom of the table. It is evident that the calculations yield considerable information. The computer results, as indicated by this table, are automatically obtained from the solution of each problem. Calculations showing very high rates of purification (as above) may not be completely accurate in describing the evaporative process. High rates of purification can result in a depletion of impurities at the surface and a concentration gradient can occur. The calculations assume a completely mixed, homogeneous melt. Numerous processes, however, can occur to minimize the concentration gradient. Task 4 (Role of Surface Traction and Related Phenonema in Processing in Space), being carried out by A. L. Dragoo, is looking into some these processes. A general view of the problem would seem to minimize concern regarding surface depletion and concentration gradients since practical purification times can be of the order of 10 minutes rather that the above $0-1.15$ seconds. Mixing processes can occur during these longer time periods. Further investigations into this possible problem area are still needed. Purification rates can be slowed to allow better mixing, or to better control the evaporation process. One should not overlook the possibility of controlled low level doping of materials to pre-selected levels. Slower purification of $\mathrm{Al}_{2} \mathrm{O}_{3}$ can be obtained by exposing the melt to a low ambient oxygen pressure. Such a pressure can be kept low enough to maintain vacuum (Knudsen) flow conditions and yet be high enough to shift chemical equilibria and slow the varporization rates. 
Table 1

Vacuum Evaporation of $\mathrm{Al}_{2} \mathrm{O}_{3}+10$ ppm FeO and $\mathrm{SiO}_{2}$

Moles of Species Present

- Temperature (K)

Cuml. Time (Sec) 0.005

$1.0000 \mathrm{E}+00$

$9.9821 \mathrm{E}-06$

9.9667E-06

1. $0000 \mathrm{E}+00$

9.0607E-06

$8.3538 \mathrm{E}-06$

1.0000E+00

8.5012E-06

$7.4416 \mathrm{E}-06$

6. 2370E-06

$2.0593 \mathrm{E}-07$

6.1007E-09

3.1734E-06

8.9146E-08

A1

A10

$\mathrm{AlO}_{2}$

$\mathrm{A}_{2}{ }^{\mathrm{O}}$

$\mathrm{Al}_{2} \mathrm{O}_{2}$

$\mathrm{Fe}$

$\mathrm{Fe} 0$

$\mathrm{Si}$

Si0

$\mathrm{SiO}_{2}$
1. $2000 \mathrm{E}-08$

$6.6628 \mathrm{E}-10$

$1.8579 \mathrm{E}-09$

$1.0292 \mathrm{E}-11$

$1.7815 \mathrm{E}-08$

$8.2998 \mathrm{E}-11$

2. $2587 \mathrm{E}-13$

3. $3262 \mathrm{E}-08$

2.0138E-11
6. 3661E-0 6

$2.0833 \mathrm{E}-07$

3. 3121E-06

4. 3523E-07

2.3590E-08

6.9864E-08

$3.7780 \mathrm{E}-10$

2. 5330E-09

6. 3420E-12

9. $1167 \mathrm{E}-07$

5. 3881E-10
5. 5694E-07
2400

.46

.81

1.15
9.9999E-01

$7.4910 \mathrm{E}-06$

5.9152E-06
$9.9999 \mathrm{E}-01$

6.6129E-06

$4.7170 \mathrm{E}-06$

Pressure of Species Present (Atm)

Gases

\begin{tabular}{|c|c|c|c|c|c|}
\hline 0 & $3.5140 \mathrm{E}-06$ & $3.4610 \mathrm{E}-06$ & $3.4303 \mathrm{E}-06$ & $3.3774 \mathrm{E}-06$ & $3.3343 \mathrm{E}-06$ \\
\hline $\mathrm{O}_{2}$ & $1.6659 \mathrm{E}-07$ & $1.6161 \mathrm{E}-07$ & $1.5875 \mathrm{E}-07$ & $1.5389 \mathrm{E}-07$ & $1.5000 \mathrm{E}-07$ \\
\hline $\begin{array}{l}\mathrm{A} 1 \\
\mathrm{~A} 10\end{array}$ & $2.2352 \mathrm{E}-06$ & $2.2867 \mathrm{E}-06$ & $2.3175 \mathrm{E}-06$ & $2.3721 \mathrm{E}-06$ & $2.4182 \mathrm{E}-06$ \\
\hline $\begin{array}{l}\text { A10 } \\
\text { A10 }\end{array}$ & $3.7976 \mathrm{E}-07$ & $3.8265 \mathrm{E}-07$ & $3.8437 \mathrm{E}-07$ & $3.8736 \mathrm{E}-07$ & $3.8986 \mathrm{E}-07$ \\
\hline $\mathrm{AlO}_{2}$ & $2.4700 \mathrm{E}-08$ & $2.4514 \mathrm{E}-08$ & $2.4405 \mathrm{E}-08$ & $2.4216 \mathrm{E}-08$ & $2.4061 \mathrm{E}-08$ \\
\hline $\mathrm{A}_{2} \mathrm{O}$ & $7.5013 \mathrm{E}-08$ & $7.7327 \mathrm{E}-08$ & $7.8718 \mathrm{E}-08$ & $8.1202 \mathrm{E}-08$ & $8.3313 \mathrm{E}-08$ \\
\hline $\mathrm{Al}_{2} \mathrm{O}_{2}$ & $4.6061 \mathrm{E}-10$ & $4.6766 \mathrm{E}-10$ & $4.7185 \mathrm{E}-10$ & $4.7923 E-10$ & $4.8542 \mathrm{E}-10$ \\
\hline $\mathrm{Fe}$ & $6.4267 \mathrm{E}-07$ & $5.9228 \mathrm{E}-07$ & $5.6068 \mathrm{E}-07$ & $5.0180 \mathrm{E}-07$ & $4.4870 \mathrm{E}-07$ \\
\hline $\mathrm{Fe} 0$ & $3.3961 \mathrm{E}-09$ & $3.0826 \mathrm{E}-09$ & $2.8923 \mathrm{E}-09$ & $2.5486 \mathrm{E}-09$ & $2.2499 \mathrm{E}-09$ \\
\hline Si & $5.7788 \mathrm{E}-12$ & $4.9931 \mathrm{E}-12$ & $4.5279 \mathrm{E}-12$ & $3.7127 \mathrm{E}-12$ & $3.0377 \mathrm{E}-12$ \\
\hline SiO & $1.0661 \mathrm{E}-06$ & $9.0729 \mathrm{E}-07$ & $8.1546 \mathrm{E}-07$ & $6.5834 \mathrm{E}-07$ & $5.3178 \mathrm{E}-07$ \\
\hline $\mathrm{SiO}_{2}$ & $7.5356 \mathrm{E}-10$ & $6.3161 \mathrm{E}-10$ & $5.6264 \mathrm{E}-10$ & $4.4724 E-10$ & $3.5665 \mathrm{E}-10$ \\
\hline
\end{tabular}

6.0993E-06

$1.9652 \mathrm{E}-07$

$5.8593 \mathrm{E}-06$

3.2990E-06

4. $2682 \mathrm{E}-07$

$2.2778 \mathrm{E}-08$

$7.0130 \mathrm{E}-08$

$3.7339 \mathrm{E}-10$

4. 8504E-0 7

$2.1720 \mathrm{E}-09$

$5.0603 \mathrm{E}-12$

7.1622E-07

4.1677E-10

$3.2725 \mathrm{E}-06$

$4.1799 \mathrm{E}-07$

$2.2022 \mathrm{E}-08$

$7.0015 \mathrm{E}-08$

$3.6802 \mathrm{E}-10$

4.2203E-07

$1.8657 \mathrm{E}-09$

$4.0287 \mathrm{E}-12$

$5.6293 \mathrm{E}-07$

3. $2340 \mathrm{E}-10$

0

$$
{ }_{2}
$$

$$
\text { A1 }
$$

Al0

$\mathrm{AlO}_{2}$

$\mathrm{Al}_{2}$

22

$\mathrm{Fe}$

$\mathrm{FeO}$

Si

$\mathrm{SiO}_{2}$
3. 5140E-06

.

$.2352 \mathrm{E}-06$

$3.7976 \mathrm{E}-07$

$6.4267 \mathrm{E}-07$

.

1.0661E-06

6.3161E-10

$5.6264 \mathrm{E}-10$

$3.3774 \mathrm{E}-06$

2.3721E-06

$3.8736 \mathrm{E}-07$

$5.0180 \mathrm{E}-07$

$2.5486 \mathrm{E}-09$

3. $7127 \mathrm{E}-12$

(

3. $5665 \mathrm{E}-10$ 
Tables 2 and 3 list results for the evaporative purification of $\mathrm{Al}_{2} \mathrm{O}_{3}$ containing $10 \mathrm{ppm} \mathrm{CaO.} \mathrm{Table} 2$ is for the "pure" vacuum case and Table 3 is for a "vacuum" containing $10^{-5}$ atm oxygen. The higher oxygen pressures shown in Table 3 result in equilibrium shifts away from the reduced vapor species $\mathrm{Ca}(\mathrm{g})[\mathrm{Ca}(\mathrm{g})+\mathrm{O}(\mathrm{g}) \rightarrow \mathrm{CaO}(1)]$ and this causes slower rates of purification. Figure 1 shows the rate of $\mathrm{CaO}$ removal both for the case of "self-developed" oxygen (Table 2) and for the case of $P_{0}$ equal to $10^{-15}$ atm (Table 3 ).

It is clear that many modifications in oxidizing or reducing conditions can be used to achieve desired vaporization (purification) goals.

Some results from this Task and from Task 4 will be presented as a talk at the 12th Aerospace Sciences Meeting of the AIAA to be held January 30 - February 1, 1974 in Washington, D.C. This ta1k by A. L. Dragoo and R. C. Paule is entitled "Production of Ultrapure Materials: Containerless Evaporation and the Roles of Diffusion and Maragoni Convection."

\section{$\underline{\text { Discussion }}$}

In using the above calculated results one must ask: "How accurate are the calculations?" One can partially answer this question by noting that if the calculational assumptions are correct, then the calculations should be accurate. It appears that we should be able to pick purification conditions of practical interest that will satisfy the assumptions. In general, the method of evaporative purification should be feasible. 
Table 2

Vacuum Evaporation of $\mathrm{Al}_{2} \mathrm{O}_{3}+10 \mathrm{ppm} \mathrm{CaO}$

Moles of Species Present

Temperature $(\mathrm{K})$

2400

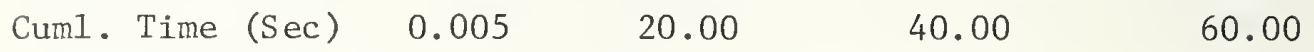

Liquids
$\mathrm{Al}_{2} \mathrm{O}_{3}$
$1.0000 E+00$
$9.9975 \mathrm{E}-01$
9.9950E-01
$9.9925 \mathrm{E}-01$
$\mathrm{CaO}$
9.9998E-06
9.2986E-06
8.6465E-06
8.0401E-06

Gases

$\begin{array}{lllll}0 & 1.6143 \mathrm{E}-07 & 6.4560 \mathrm{E}-04 & 6.4548 \mathrm{E}-04 & 6.4535 \mathrm{E}-04 \\ \mathrm{O}_{2} & 4.8005 \mathrm{E}-09 & 1.9197 \mathrm{E}-05 & 1.9193 \mathrm{E}-05 & 1.9189 \mathrm{E}-05 \\ \mathrm{Ca} & 1.8850 \mathrm{E}-10 & 7.0120 \mathrm{E}-07 & 6.5210 \mathrm{E}-07 & 6.0643 \mathrm{E}-07 \\ \mathrm{~A} 1 & 1.0670 \mathrm{E}-07 & 4.2676 \mathrm{E}-04 & 4.2671 \mathrm{E}-04 & 4.2665 \mathrm{E}-04 \\ \mathrm{Al} 0 & 1.2741 \mathrm{E}-08 & 5.0957 \mathrm{E}-05 & 5.0949 \mathrm{E}-05 & 5.0941 \mathrm{E}-05 \\ \mathrm{Al} 0{ }_{2} & 6.2753 \mathrm{E}-10 & 2.5097 \mathrm{E}-06 & 2.5092 \mathrm{E}-06 & 2.5088 \mathrm{E}-06 \\ \mathrm{Al}_{2}{ }^{\mathrm{O}} & 2.3611 \mathrm{E}-09 & 9.4435 \mathrm{E}-06 & 9.4424 \mathrm{E}-06 & 9.4413 \mathrm{E}-06 \\ \mathrm{Al}_{2}{ }_{2}{ }_{2} & 1.1602 \mathrm{E}-11 & 4.6402 \mathrm{E}-08 & 4.6396 \mathrm{E}-08 & 4.6389 \mathrm{E}-08\end{array}$

Pressure of Species Present (Atm)

$\underline{\text { Gases }}$

$\begin{array}{lllll}0 & 3.1171 \mathrm{E}-06 & 3.1170 \mathrm{E}-06 & 3.1169 \mathrm{E}-06 & 3.1168 \mathrm{E}-06 \\ 0 & 1.3109 \mathrm{E}-07 & 1.3108 \mathrm{E}-07 & 1.3107 \mathrm{E}-07 & 1.3106 \mathrm{E}-07 \\ \mathrm{Ca} & 5.7606 \mathrm{E}-09 & 5.3581 \mathrm{E}-09 & 4.9838 \mathrm{E}-09 & 4.6355 \mathrm{E}-09 \\ \mathrm{AI} & 2.6754 \mathrm{E}-06 & 2.6756 \mathrm{E}-06 & 2.6757 \mathrm{E}-06 & 2.6758 \mathrm{E}-06 \\ \mathrm{Al0} & 4.0321 \mathrm{E}-07 & 4.0322 \mathrm{E}-07 & 4.0323 \mathrm{E}-07 & 4.0323 \mathrm{E}-07 \\ \mathrm{Al}_{2} & 2.3264 \mathrm{E}-08 & 2.3264 \mathrm{E}-08 & 2.3263 \mathrm{E}-08 & 2.3263 \mathrm{E}-08 \\ \mathrm{Al}_{2}{ }^{0} & 9.5332 \mathrm{E}-08 & 9.5338 \mathrm{E}-08 & 9.5343 \mathrm{E}-08 & 9.5348 \mathrm{E}-08 \\ \mathrm{Al}_{2}{ }_{2}{ }_{2} & 5.1926 \mathrm{E}-10 & 5.1927 \mathrm{E}-10 & 5.1929 \mathrm{E}-10 & 5.1930 \mathrm{E}-10\end{array}$


Table 3

Evaporation of $\mathrm{Al}_{2} \mathrm{O}_{3}+10 \mathrm{ppm} \mathrm{CaO}$, Vacuum $+10^{-5}$ Atm Oxygen

Moles of Species Present

Temperature (K)

2400

$\begin{array}{lllll}\text { Cuml. Time (Sec) } & 0.005 & 60.00 & 120.00 & 180.00\end{array}$

Liquids
$\mathrm{Al}_{2} \mathrm{O}_{3}$
$1.0000 \mathrm{E}+00$
$9.9984 \mathrm{E}-01$
$9.9967 \mathrm{E}-01$
$9.9951 \mathrm{E}-01$
$\mathrm{CaO}$
9.9999E-06
9.3413E-06
$8.7259 E-06$
8.1511E-06

Gases

$\begin{array}{lllll}\mathrm{Ca} & 5.8757 \mathrm{E}-11 & 6.5868 \mathrm{E}-07 & 6.1532 \mathrm{E}-07 & 5.7482 \mathrm{E}-07 \\ \mathrm{~A} 1 & 1.8569 \mathrm{E}-08 & 2.2281 \mathrm{E}-04 & 2.2278 \mathrm{E}-04 & 2.2276 \mathrm{E}-04 \\ \mathrm{~A} 10 & 7.1134 \mathrm{E}-09 & 8.5352 \mathrm{E}-05 & 8.5343 \mathrm{E}-05 & 8.5333 \mathrm{E}-05 \\ \mathrm{~A} 10{ }_{2} & 1.1240 \mathrm{E}-09 & 1.3486 \mathrm{E}-05 & 1.3485 \mathrm{E}-05 & 1.3483 \mathrm{E}-05 \\ \mathrm{Al}_{2} \mathrm{O} & 2.2941 \mathrm{E}-10 & 2.7526 \mathrm{E}-06 & 2.7523 \mathrm{E}-06 & 2.7520 \mathrm{E}-06 \\ \mathrm{Al}_{2}{ }_{2}{ }_{2} & 3.6165 \mathrm{E}-12 & 4.3393 \mathrm{E}-08 & 4.3388 \mathrm{E}-08 & 4.3384 \mathrm{E}-08\end{array}$

Pressure of Species Present (Atm)

$\underline{\text { Gases }}$

$\begin{array}{lllll}0 & 1.0000 \mathrm{E}-05 & 1.0000 \mathrm{E}-05 & 1.0000 \mathrm{E}-05 & 1.0000 \mathrm{E}-05 \\ 0 & 1.3491 \mathrm{E}-06 & 1.3491 \mathrm{E}-06 & 1.3491 \mathrm{E}-06 & 1.3491 \mathrm{E}-06 \\ \mathrm{Ca} & 1.7956 \mathrm{E}-09 & 1.6776 \mathrm{E}-09 & 1.5674 \mathrm{E}-09 & 1.4644 \mathrm{E}-09 \\ \mathrm{~A} 1 & 4.6560 \mathrm{E}-07 & 4.6560 \mathrm{E}-07 & 4.6560 \mathrm{E}-07 & 4.6560 \mathrm{E}-07 \\ \mathrm{~A} 10 & 2.2512 \mathrm{E}-07 & 2.2512 \mathrm{E}-07 & 2.2512 \mathrm{E}-07 & 2.2512 \mathrm{E}-07 \\ \mathrm{~A} 10 & 4.1669 \mathrm{E}-08 & 4.1669 \mathrm{E}-08 & 4.1669 \mathrm{E}-08 & 4.1669 \mathrm{E}-08 \\ \mathrm{~A}_{2}{ }_{2}{ }_{2} & 9.2626 \mathrm{E}-09 & 9.2626 \mathrm{E}-09 & 9.2626 \mathrm{E}-09 & 9.2626 \mathrm{E}-09 \\ \mathrm{Al}_{2}{ }_{2} & 1.6186 \mathrm{E}-10 & 1.6186 \mathrm{E}-10 & 1.6186 \mathrm{E}-10 & 1.6186 \mathrm{E}-10\end{array}$


We must, however, still pick optimum conditions and be able to predict the extent of purification.

Some questions that need to be considered in the evaluation of the accuracy of the calculations are as follows:

Are there significant vapor species other than those used in the calculations?

Are the literature values of the thermodynamic equilibrium constants correct?

Is ideal solution behavior observed? (Because of the low impurity levels considered we would expect Henry's law to be obeyed, but this does not insure that the impurities will obey Raoult's law.) Is there adequate mixing of the melt to avoid surface depletion and concentration gradients?

Are the evaporation coefficients equal to unity or near unity? We are now engaged in an experimental program to get an overall check on these and other possible problem areas. We plan to directly observe evaporative purification from $\mathrm{Al}_{2} \mathrm{O}_{3}$ samples and to be able to check the calcuations. If necessary, correction factors could be developed to describe any non-ideal behavior.

\section{Current and Future Experiments}

Our current work is in preparation for the experimental measurement of impurity vaporization from $\mathrm{Al}_{2} \mathrm{O}_{3}$ using the TOF mass spectrometer. Work is centered on improving usable M.S. sensitivity, and on improving quantitative M.S. measurements. A molecular beam chopping system has 
been built and a lock-in amplifier added to the system to allow modulated beam detection of species coming from a sessile drop of molten $\mathrm{Al}_{2} \mathrm{O}_{3}$. Lock-in detection will be particularly important for measuring evaporating - species such as $O_{1}$ and $O_{2}$ since these species are normally present in the M.S. background. The modulated beam system is now operational.

A new calibrated He and Xe leak system has been installed in our M.S. to improve reproducibility. Scales have been added to several instrument potentiometers for better reproducibility. New, more linear electron multiplier strips have been installed on the M.S.

A considerable effort has been devoted to minimizing the M.S. background to increase the usable sensitivity. In addition to extensive leak-checking, we have found it necessary to water cool the walls of the furnace to avoid excessive outgassing. A new smaller water-cooled furnace with a lower heat load is now being built and will replace our current furnace for the heating of the $\mathrm{Al}_{2} \mathrm{O}_{3}$.

M.S. measurements will be made on evaporating molten $\mathrm{Al}_{2} \mathrm{O}_{3}$ to determine any non-ideal behavior. This type of experiment should allow for an overall check of the calculations and, if necessary, for the development of correction factors. Other refractory materials may also be tested. 
1. H.J. Kandiner and S.R. Brinkley, Ind, Eng. Chem., 42, 850 (1950).

2. W.B. White, S.M. Johnson and G.B. Dantzig, Chem. Phys., 28, 751 (1958).

3. S. Gordon and B.J. McBride, NASA, SP-273 (1971).

4. H.F. Feldmann, W.H. Simons and D. Bienstock, U. S. Bur. of Mines, RI-7257 (1969).

5. F.J. Zeleznik and S. Gordon, Ind. Eng. Chem., 60, 27 (1968).

6. F. Van Zeggeren and S.H. Storey, The Computation of Chemical Equilibria, Cambridge University Press, 1970.

7. M. Klein, Physical Chemistry, Vol. 1/Thermodynamics, Chapter 7, edited by Eyring, H.E., Jost, W., and Henderson, D., Academic Press, New York, 1971.

8. H. Margenau and G.M. Murphy, The Mathematics of Physics and Chemistry, 2nd. ed., page 492, D. Van Nostrand Company, Princeton, New Jersey, 1956.

9. F.E. Hildebrand, Advanced Calculus for Engineers, page 353, Prentice-Hall, New York, 1949. 
Figure 1

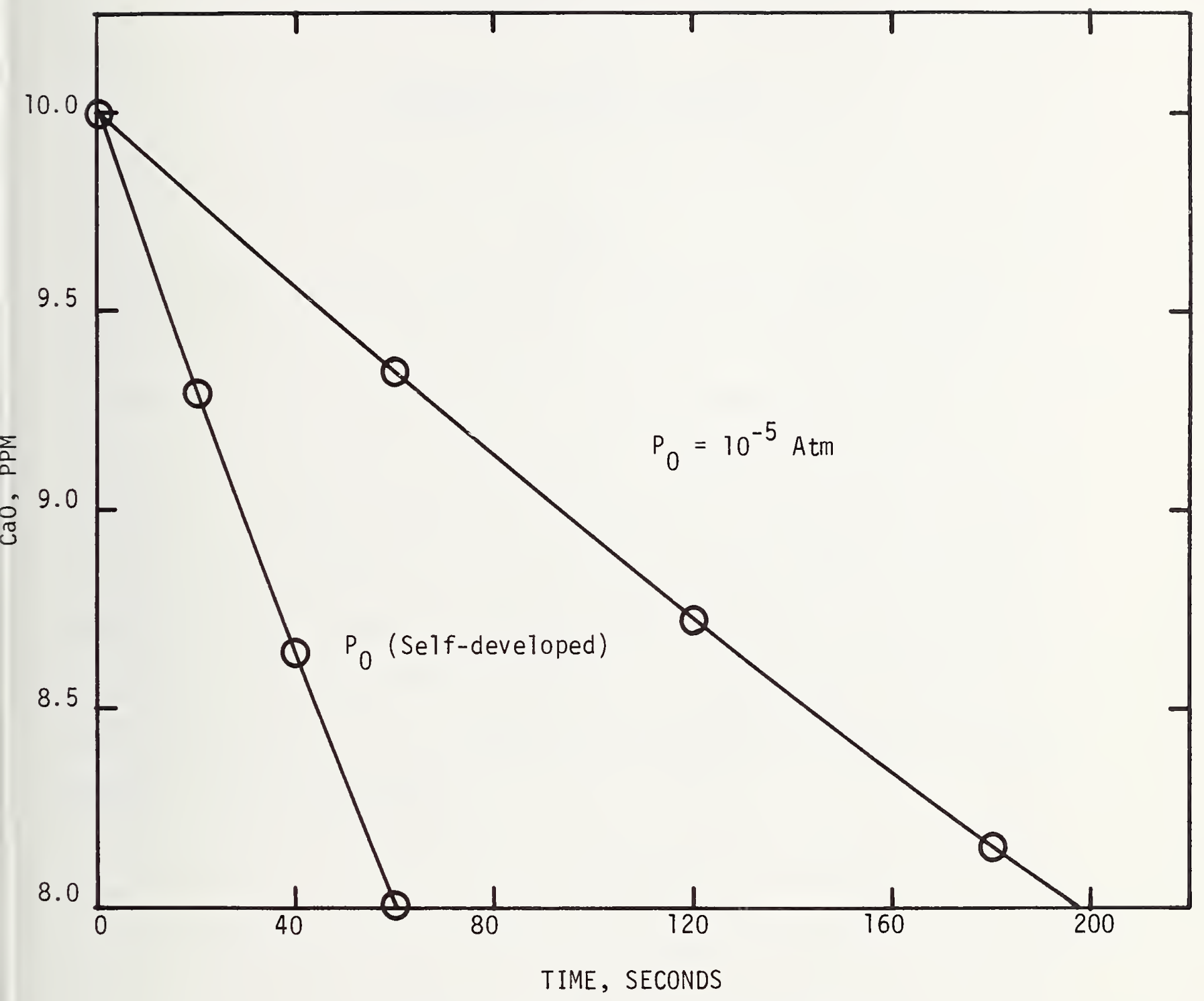

CaO Vaporization from $\mathrm{Al}_{2} \mathrm{O}_{3}$ at $2400 \mathrm{~K}$ 

Task 4

Role of Surface Traction and Related Phenomena

in Chemical Processing in Space

A. L. Dragoo

Inorganic Materials Division

Institute for Materials Research

\section{Summary}

Theoretical analyses of processes occurring in levitated melts during evaporative purification were carried out. The interactions of non-uniform evaporation and of thermal and solutal capillary convection were considered qualitatively. Studies were begun on pure diffusion coupled with non-uniform evaporation. The pattern of thermocapillary convection cells in a drop with an axially symmetric temperature field on the surface was deduced by determining the zero-points in the velocity field and the streamlines in the liquid drop. Initial work on the derivation of a formula for the circulation time associated with such cells is described. 
Until May of this year, work on this project overlapped with an earlier NASA project on the "Investigation of Convective Effects and Crystal Growth" (Contract No. W-13475). Since there was no clear demarcation between the work on these two projects, all the work through May was presented in a final report for the latter project. In this report, I will describe two problems which have remained under investigation since then. I will summarize the results that were reported in May and then I will focus on current work.

These two problems are:

1. thermal and solutal capillary convection and mass transfer with non-uniform evaporation (Section 2.4 in the May report);

2. thermocapillary convection for a general steady-state temperature field on the surface of a drop (Section 2.5).

Thermal capillary, or thermocapillary, convection is convection driven by a surface tension gradient which is generated by a gradient in the superficial temperature. Solutal capillary convection is convection caused by a superficial concentration gradient including a surface tension gradient. Where the meaning is clear, the word "capillary" will be dropped and only the terms "thermal convection" and "solutal convection" will be used.

Both of these problems are important to the fluid dynamics of levitated melts. Implicit in both is the assumption that any practical heating configuration will produce a non-uniform heating of the surface of the drop which can result in thermal convection and other effects. 
The first problem appears when one attempts to describe the evaporative purification of a melt in which convective-diffusion, non-uniform evaporation, thermal capillary convection and solutal capillary convection are present. Qualitative aspects of all four of these phenomena are considered here. Next, progress on a problem involving pure diffusion coupled with non-uniform evaporation is described.

Work on the second problem extends results, given in the May report, of an analysis of the components of the velocity field. The arrangement of. convection cells and the location of zero-points in the velocity field for the general axially symmetric case are considered in this report. Current work on a general expression for the circulation time is described.

1. Thermal and Solutal Convection; Diffusion with Non-uniform Evaporation In the previous report, a simple convective-diffusion-evaporation problem was solved in which the evaporation rate was assumed to be uniform over the surface although the surface temperature was not uniform. The non-uniform superficial temperature was assumed to operate only through the thermocapillary effect. The convective-diffusion equation was solved by splitting the concentration into a spherically symmetric and an angular dependent part. The former part was found to be expressible in terms of a standard solution to the diffusion equation plus a perturbation term. Furthermore, the rate of loss could be expressed in terms of a standard diffusion result evaluated at the surface plus a perturbation term similar to the above. A self-consistent method of solution was outlined. This simplified solution had two weaknesses: 
1. the non-isotropic thermal condition was assumed to influence the surface tension but not the evaporation rate constant, 2. an attendent variation of concentration over the surface and its influence on the surface tension was ignored.

a. Qualitative aspects of the more general problem

The more general problem is one in which convection is driven by surface tension gradients arising both from thermal and solutal gradients and in which diffusion is perturbed both by convection and by non-uniform evaporation. Moreover, these various processes interact. For example, diffusion will alter concentration gradients on the surface which were produced by non-uniform evaporation. The change in these gradients will modify the convection which will react back on both the diffusion and the evaporation processes. A more general problem is which heat transfer is coupled to the above processes was not considered; instead, steady-state heat transfer was assumed to persist throughout.

To simplify the further discussion, the drop will be assumed to be heated at one pole and to be cooled at the other. Evaporation will be faster at the hotter pole, so that the concentrations of volatile impurities will be lower there than at the colder pole. If normal thermal convection is present, liquid adjacent to the surface will be pulled toward the colder pole, liquid will descend in the colder hemisphere and will rise in the hotter one. The impurity-rich liquid from the interior will tend to replenish the depleted liquid near the hotter region of the surface while surface currents will tend to smooth out concentration differences between hotter and colder surface regions. The net effect of non-uniform evaporation and normal thermal convection is toward 
homogenization of the surface concentration. Anomalous thermal capillary convection, on the other hand, will tend to enhance the variation in surface concentration brought about by evaporation.

If, in addition to thermal capillary convection, solutal capillary convection is present, not only will interactions take place in terms of concentration but they will also appear in the velocity. If normal solutal convection is assumed to produce movement of surface liquid from regions of high impurity concentration to regions of low concentration, it will tend to oppose the flow due to thermal convection. As an additional contrast to normal thermal convection, it most likely will enhance the disparity in surface concentration because it will bring impurity-rich liquid from the interior to the colder surface region which already would be enriched with respect to the hotter surface by evaporation. However, the resulting surface flow will tend to level out the concentration disparity between the two regions, albeit not as effectively as the transfer of material from the interior.

The expected consequences of the various processes are summarized in Table I. Non-uniform evaporation is assumed to be present in processes "4." through "9." as the means to the concentration gradients needed for solutal convection although it is only cited explicitly in "1.". The second column shows the direction of fluid flow at the surface for each process both in terms of temperatures, e.g. hot $\rightarrow$ cold, and in terms of concentration, e.g., low $\rightarrow$ high. The third column gives the departure of surface concentration near the hotter pole from the average for the total surface. The changes in concentration are those for the process, per se, so that the net concentration is obtained by adding the effect of evaporation if it is required to be present. 
b. Pure diffusion coupled with non-uniform evaporation

Work was begun on the problem of diffusion with non-uniform evaporation, the evaporation rate constant having the form

$$
\alpha=\alpha_{0}+\alpha_{1} T_{1} \cos \theta
$$

Although the solution to the angular-dependent diffusion problem can be performed easily--the form of the solution being suggested by the analogous quantum mechanical problem of the wavefunctions for a threedimensional square well, the kinetic boundary condition

$$
-\left.D(\partial c / \partial r)\right|_{R}=\left.\alpha c\right|_{R}
$$

now introduces a major complication because its dependence on $\cos \theta$ couples successively higher order of the Legendre polynomials of the concentration expression

$$
c(r, \theta, t)=c_{0}-\sum_{\ell=0 s} \sum_{\ell s} e-k_{\ell}^{2} D t_{j \ell}\left(\kappa_{\ell s} r\right) P_{\ell}(\cos \theta) .
$$

The functions $j_{\ell}$ and $P_{\ell}$ are the $\ell$ th order spherical Besset function and the $\ell$ th order Legendre polynomial, respectively. The index s runs over values of the wavenumber $k_{\ell s}$ satisfying the boundary conditions.

2. Thermocapillary Convection for a General Steady-State Temperature Field on the Surface of a Drop

In the previous report, a mathematical analysis developed by Miller and Scriven ${ }^{1}$ for the oscillations of a fluid droplet immersed in a second fluid was applied to the steady-state problem of surface tension induced flow when an arbitrary superficial temperature field is present on the drop. The temperature field was described by a series expansion in spherical harmonics and the velocity components were found for an 
arbitrary term in the temperature field, say $\mathrm{Y}_{\ell}^{\mathrm{m}}(\theta, \phi)$. To obtain a solution it was necessary to introduce a function $B(\theta, \phi)$ which described small deformations of the surface of the drop. An expression was given for the generalized characteristic speed

$$
U_{\ell m}=\frac{\ell(\ell+1) \gamma_{0} \gamma_{T} T_{\ell m} R^{\ell}}{2 \mu\left[(2 \ell+1)(\ell+2) \gamma_{0}+\gamma_{T} R_{\ell}\right]}
$$

(the various coefficients are identified at the end of this report). The circulation time $\tau$ for the second-order mode $(\ell=2, m=0)$ was estimated and compared with the first-order mode $(l=1, m=0)$. It was found that

$$
\tilde{\tau}_{2} / \tilde{\tau}_{1} \simeq 20
$$

when $(\partial T / \partial R)_{r=R, \theta=0}$ was the same in both cases. This suggests that the first-order mode could be considerably more important than the secondorder mode in such processes as mass transfer.

Subsequent work has been carried out on

1. the identification of the zero-points of the flow rate $v$ for a "pure" axially symmetric mode, i.e., one corresponding to a $Y_{\ell}^{O}(\theta, \phi)$ term in the temperature expansion,

2. the development of a general solution for $\tilde{\tau}$ for the axially symmetric case.

The rate of flow

$$
v=\left[u_{r}^{2}+u_{\theta}^{2}+u_{\phi}^{2}\right]^{1 / 2}
$$

where 


$$
\begin{aligned}
& u_{r}=\sum_{l, m}^{1} u_{r}(l, m) \\
& u_{\theta}=\sum_{l, m}^{1} u_{\theta}(l, m) \\
& u_{\phi}=\sum_{l, m}^{1} u_{\phi}(l, m)
\end{aligned}
$$

are the components of the velocity field. For the axially symmetric case, $u_{\phi}=0$. The determination of the zero-points of $\mathrm{v}$ requires a detailed knowledge of the temperature field at the surface of the drop.

For a pure axially symmetric mode resulting from a superficial temperature field

$$
T_{S}(\theta)=T_{\ell 0} R^{\ell} Y_{\ell}^{O}(\theta, \phi)=T_{\ell} R^{\ell}[(2 \ell+1) / 4 \pi]^{1 / 2} P_{\ell}(\cos \theta),
$$

the rate of flow in reduced form is

$$
\tilde{v}_{\ell}=\frac{(\ell+2) J}{\ell(\ell+1)} \quad \tilde{r}^{\ell-1}\left\{\left(1-\tilde{r}^{2}\right)^{2}\left(P_{\ell}\right)^{2}+\left[(\ell+1)-(\ell+3) \tilde{r}^{2}\right]^{2}\left(P_{\ell}^{1}\right)^{2}\right\}^{1 / 2}
$$

where $\tilde{\mathrm{v}}_{\ell}=\mathrm{v}_{\ell} / \mathrm{U}_{\ell 0}[(2 \ell+1) / 4 \pi]^{1 / 2}$ and $\tilde{\mathrm{r}}=\mathrm{r} / \mathrm{R}$. It is obvious that $\tilde{\mathrm{v}}_{\ell}=0$ inside the drop where $\tilde{r}^{2}=(\ell+1) /(\ell+3)$ and $P_{\ell}=0$. Since $P_{\ell}$ has $\ell$ nodes, there must be $\ell$ of these points. On the surface of the drop (i.e., $\tilde{r}=1$ ), $\tilde{\mathrm{v}}_{\ell}=0$ if $\mathrm{P}_{\ell}^{1}=0 . \mathrm{P}_{\ell}^{1}$ has $\ell+1$ nodes, including one at each pole, so that $\tilde{v}_{\ell}=0$ at $(\ell+1)$ points on the surface. In addition, if $\ell>1, \tilde{v}_{\ell}=0$ when 
$\tilde{r}=0$ which implies that flow occurs through the center of the drop only if $\ell=1$. Finally, we must consider the possible occurrence of other internal zero-points. That is, are there other points such that

$$
\left(1-\tilde{r}^{2}\right)^{2}\left(P_{\ell}\right)^{2}+\left[(\ell+1)-(l+3) \tilde{r}^{2}\right]^{2}\left(P_{\ell}^{\prime}\right)^{2}=0 ?
$$

The answer is no. Since each term is either positive or zero, and since neither $\left(1-\tilde{r}^{2}\right)$ and $\left[(\ell+1)-(\ell+3) \tilde{r}^{2}\right]$ nor $\mathrm{P}_{\ell}$ and $\mathrm{P}_{\ell}^{\prime}$ vanish at identical values of $\tilde{r}$ and $\cos \theta$, respectively, there are no other internal zeroes for $\tilde{v}$.

Evaluation of the streamlines shows that each of the internal zeropoints serves as a focus for a set of streamlines. Thus, the lth-order axial-symmetric mode will consist of $\ell$ convection cells.

The circulation times $\tilde{\tau}$, which are given formally by

$$
\tilde{\tau}=\phi d L / V
$$

and which are associated with each of the $\ell$ convection cells, can be evaluated by requiring that the quantity of material circulating about a zero-point in a time $\tilde{\tau}$ equals the quantity of material in the volume containing the streamlines about that zero-point. It is not apparent from work performed to date that the circulation times associated with the various convection cells are necessarily equal. An expression for $\tilde{\tau}_{s}$, the circulation time associated with the "s" zero-point, has been obtained in terms of the angles $\theta_{s}, \theta_{s-1}^{\prime}$, and $\theta_{s}^{\prime}$, where $P_{\ell}\left(\cos \theta_{s}\right)=0$, $P_{l}^{\prime}\left(\cos \theta_{s-1}^{\prime}\right)=P_{l}^{\prime}\left(\cos \theta_{s}^{\prime}\right)=0$ and $\theta_{s-1}^{\prime}$ and $\theta_{s}^{\prime}$ are the nearest lower 
and upper bounds of $\theta_{\mathrm{S}}$, respectively. This expression is very complicated and $i t$ is hoped that the analyses of the roots of $\mathrm{P}_{\ell}$ and $\mathrm{P}_{\ell}$, which are now in progress, will help to simplify this expression, in addition to establishing the relationship between all the $\tilde{\pi}_{\mathrm{s}}^{\prime} \mathrm{s}$.

Symbols Used in This Report

$\begin{array}{ll}\mathrm{R} & \begin{array}{l}\text { radius of the drop } \\ \mathrm{T}\end{array} \\ \mathrm{C} & \text { temperature } \\ & \text { concentration } \\ \mathrm{u}_{\mathrm{r}}, \mathrm{u}_{\theta}, \mathrm{u}_{\phi} & \text { components of the velocity field } \\ \mathrm{V} & \text { rate of flow } \\ \mathrm{R} & \text { rate of evaporation } \\ \mathrm{D} & \text { diffusion coefficient } \\ \alpha & \text { evaporation coefficient } \\ \tilde{\tau}_{\mathrm{T}} & \text { circulation time } \\ \gamma_{0} & \text { surface tension coefficient } \\ \gamma_{\mathrm{T}} & \text { thermal coefficient of the surface } \\ & \text { tension, }(\partial \gamma / \partial \mathrm{T})\end{array}$

Quantities associated with the $(\ell, m)$-mode, i.e., $Y_{\ell}^{m}(\theta, \phi)$

$\begin{array}{ll}\mathrm{u}_{\mathrm{r}}(\ell, \mathrm{m}), \text { etc. } & \text { components of the velocity field } \\ \mathrm{U}_{\ell \mathrm{m}} & \text { characteristic speed } \\ \mathrm{v}_{\ell \mathrm{m}} & \text { rate of flow } \\ \mathrm{T}_{\ell \mathrm{m}} & \text { thermal coefficient of the temperature } \\ & \text { field expansion }\end{array}$




\section{References}

1. C.A. Miller and L.E. Scriven, J. Fluid Mech. 32, 417 (1968). 
Interaction of Evaporation, and Thermal and Solutal Convection

\section{Process}

1. Evaporation, $\partial \mathrm{a} / \partial \mathrm{T}>0$

2. Normal thermal conv.

3. Anomalous thermal

4. Normal solutal conv.

5. Anomalous solutal

6. $" 2 . " 1+4 . "$

7. "3. $"+1 " 5 . "$

8. "2. " + $" 5 . "$

9. "3. " +14 ."
Direction of Convective Flow at the Surface

hot $\rightarrow \operatorname{cold}$

(low $c \rightarrow$ high

c)

cold $\rightarrow$ hot

(high $\rightarrow$ low)

high $c \rightarrow$ low c

(cold $\rightarrow$ hot)

low $\rightarrow$ high

(hot $\rightarrow$ cold)

tend to cancel

tend to cancel

hot $\rightarrow \operatorname{cold}$

$\operatorname{cold} \rightarrow$ hot
Departure of Concn. at Hot Pole from Average

\section{Decrease}

Increase

slight increase

slight increase

Increase

Increase

Increase

strong increase

slight increase 
Task 5

Vacuum Effects in the Preparation of Composite Materials

\author{
H. Yakowitz and D. E. Newbury \\ Metallurgy Division \\ Institute for Materials Research
}

\title{
Summary
}

Useful composites usually have strong continuous bonds between matrix and core. Improved bonding might be obtained by improving the final vacuum under which the composite is prepared so as to remove most adsorbed gases from the matrix-core interface. Good bonding can be expected when strains between matrix and core are minimal and coherent. Hence, this exploratory phase of the study was largely devoted to obtaining a means to study the bond both microscopically and with regard to determining strains at or near the bond. For this purpose, the scanning electron microscope was chosen as the primary tool. A means to use electron channelling patterns prepared in the scanning electron microscope to obtain strain data was formulated. The effect of strain, surface coatings and specimen tilt with respect to the primary electron beam was studied. Divergent beam $x$-ray microdiffraction patterns were also prepared in the scanning electron microscope as a means to obtain strain data at the micrometer level of spatial resolution. 


\section{Introduction}

Composite materials are well known entities. Such materials have been used for a long time in an effort to obtain improved material characteristics through combining disimilar constituents such as soft matrices with very hard cores. One of the keys to preparing useful composites is to obtain strong, continuous bonding between the matrix and core. One of the ways improved bonding might be obtained would be to improve the vacuum under which the final composite is prepared. In this case, more adsorbed gases can be removed and better bonding is possible.

The purpose of the work carried out in the first phase was to explore whether or not bonding could be studied by means of electron channelling patterns in the scanning electron microscope. In this first phase, only conventional materials were used in order to establish techniques. One of the main objectives was to correlate channelling patterns with divergent beam (Kossel) x-ray patterns in order to obtain quantitative stress-strain data from the channelling pattern. Such a procedure would allow mapping of the strain field in the vicinity of the matrix-core interface. The lower the strains, the better the bond.

\section{Divergent Beam (Kossel) Microdiffraction}

This method can provide quantitative information about the stressstrain configuration in a material. In particular, the Kossel internal stress-strain analysis yields for the sampled volume:

(a) Average Cauchy strains

(b) Principal strains and their axes 
(c) Principal stresses and their axes

(d) Maximum shear strain in any (hk1) plane

(e) Total stored elastic energy

(f) Shear stored elastic energy

However, the time and effort needed to obtain a sufficient amount of data from a given material by the Kossel method is prohibitive ${ }^{1}$. Another problem is the large amount of data required to describe the results of a single point using the Kossel internal stress-strain analysis. More than one-hundred separate measurements are needed to completely describe the point. Hence, using the Kossel method alone represents a nearly impossible situation for carrying out a practical task. Therefore, another means of determining quantitative stressstrain relationships at the micrometer level of spatial resolution was sought for this task. The most appealing method is to use electron channelling patterns prepared with the aid of the scanning electron microscope. This is because the scanning electron microscope itself provides an ideal means to locate and examine regions of interest on the specimen, and electron channelling patterns can usually be obtained rapidly from the region of interest.

\section{Scanning Electron Microscopy}

In the scanning electron microscope, an electron beam of 1 to 50KV, having a small diameter, ranging from $100 \AA$ to $1 \mu \mathrm{m}$, is scanned in a square raster on a specimen. The beam interacts with the specimen to produce $(\leq 50 \mathrm{eV}), \mathrm{x}$-rays and visible light which can be monitored continuously by 
appropriate detectors. The detector signal is used to control the brightness of the flying spot of a cathode ray tube (CRT) which is scanned in synchronism with the same raster as the specimen. A one-toone correspondence is made to exist between points on the specimen and the image on the cathode ray tube. Thus, the micrograph is built up. The scanning electron microscope is useful for surface analysis because of (1) the high spatial resolution which can be achieved, (2) the large depth of focus - about 100 times greater than an optical microscope, and (3) the Iarge variety of contrast mechanisms which result from beamspecimen interactions. For further details see Ref. [2].

\section{Electron Channelling Patterns}

Electron channelling contrast arises because electrons can penetrate crystals more easily along certain directions than others (Fig. 1). When the electrons are able to enter open passages (channels) in the crystal lattices, they penetrate deeply, and few escape. By slightly altering the angle the beam makes with the crystal, these channels become difficult to enter, and the electrons interact with the specimen nearer the surface so that more escape. An electron channelling pattern can be obtained by rocking the beam through a range of angles in the form of a cone.

\section{Electron channelling patterns are capable of providing information} about the orientation of the crystal as well as its perfection. To date, almost the only quantitative use of electron channelling patterns has been in orientation determination. This is because the relationships by which the state of perfection can be determined contain factors such as the so-called extinction length ${ }^{3}$, which are not well known. For example, Schulson ${ }^{4}$ has suggested the following: 


$$
2 \omega_{g}=2 /\left(\xi_{g}|\vec{g}|\right)
$$

where $2 \omega_{\mathrm{g}}$ is the channeling pattern line width in radians

$\xi_{g}$ is the extinction distance for the reflection excited

$|\overrightarrow{\mathrm{g}}|$ is the reciprocal lattice vector translation.

Now $|\vec{g}|$ is equivalent to $1 / d$ where $d$ is the interplanar spacing for a plane of Miller indices ( $h k 1)$. It has been shown that if $\Delta d / d$ can be measured properly, then the entire stress-strain configuration for the sampled crystal volume can be determined ${ }^{5}$.

The use of a few Kossel patterns in order to provide a basis for inferring the needed d values from channelling patterns may, therefore, be attractive. In such a case, one would require a well annealed crystal and the capability of simultaneously preparing the electron channelling pattern and the Kossel pattern in the scanning electron microscope. Accurate d values could be obtained from the Kossel pattern; the corresponding channelling pattern line widths, $2 \omega_{g}$, can be measured. Changes due to strains result in changes in $2 \omega_{\mathrm{g}}$; from these $\Delta \mathrm{d}$ values can be obtained through simple manipulation of eqn. (1). Hence, $\Delta d / d$ can be determined from the channelling information. Hence, the factor $\left(2 / \xi_{g}\right)$ in Eqn. (1) could be determined empirically. Then, electron channelling patterns could be used to provide the necessary $\Delta d / d$ values for determining the stress-strain configuration from the sampled volume.

One of the major thrusts of this exploratory project was to see if such a correlation could be carried out. This necessitated devising a means to simultaneously prepare electron channelling patterns and Kossel 
patterns as well as a means to accurately observe and record electron channelling line profiles in the scanning electron microscope. In particular, we needed to know the effect of applied stresses on electron channelling patterns. The response of electron channelling patterns to experimental conditions such as specimen tilt had to be investigated as well as effects of surface deposits on the pattern. The former is an experimental response and the latter a material effect.

\section{Investigation of Electron Channelling Line Profiles}

A typical electron channelling pattern from a well-annealed single crystal of aluminum is shown in Fig. (2). There are crystallographic bands and lines whose width and intensity depend upon the state of perfection of the crystal and the basic crystal parameters such as the lattice spacing. The sample was electropolished to remove any surface damage after the crystal was held for fifteen hours at $610^{\circ} \mathrm{C}$ in a purified argon atmosphere. The crystal was normal to the electron beam which was accelerated through $30 \mathrm{kV}$. Aluminum was chosen for study since it is often used as the matrix in composite materials.

The line seen in Fig. (2) shows where the electron beam was made to scan in a single line along the crystal. The profile produced by this line is shown in Fig. (3). This profile was recorded on an oscilloscope screen; the y-intensity is shown as a function of position. The profile can be related to the lines and bands of Fig. (2) in a straightforward manner; features responsible for intensity variations can be identified. Next, the crystal was cold rolled $5 \%$ and electropolished again. Fig. (4) shows the electron channelling pattern after rolling. Clearly, the pattern is diffuse compared to Fig. (2). The corresponding profile 
(Fig. 5) shows that virtually all details except the major (200) type band have been eliminated. Material deformed up to $10 \%$ tensile strain has been successfully studied using electron channelling contrast ${ }^{8}$.

- The effect of surface layers was studied with a niobium single crystal. Niobium can be used in directionally solidified composite materials. The crystal was chemically polished in a mixture consisting of $70 \%$ concentrated $\mathrm{HNO}_{3}$ and $30 \%$ concentrated $\mathrm{HF}$. The electron channelling pattern of the as-polished crystal is shown in Fig. (6); the <012> pole is at the left of the pattern. The profile corresponding to the impressed line is shown in Fig. (7). Next, a $200 \AA$ layer of carbon was evaporated onto the surface of the crystal. The thickness was determined with a piezo-electric method said to be accurate to about $+10 \%$. The electron channelling pattern is shown in Fig. (8) and the line profile in Fig. (9). Noticeable changes in the profile have occurred. Increasing the carbon thickness to $450 \mathrm{~A}$ resulted in further degradation of the pattern as shown in Figs. (10 and (11). A layer of amorphous carbon $1000 \AA$ in thickness caused still more degradation but certainly an identifiable pattern remained as seen in Figs. (12) and (13). The crystal was a deep purple after this much carbon had been evaporated onto it.

These results were both surprising and extremely encouraging because previously it was believed that only a few hundred angstroms carbon deposit would wipe out the electron channelling pattern completely. The fact that this is not the case means that perhaps composites consisting of a metal matrix and non-metallic core can be studied by depositing a few hundred angstrom layers of carbon onto the surface to make it 
conducting. Perhaps totally non-metallic materials can be studied in this way as well.

As we shall see, a tightly bound oxide layer gives quite different and less encouraging results. Oxidizing the niobium crystal in a controlled fashion was somewhat difficult. We used a bath devised by Picklesimer ${ }^{6}$ to anodize the niobium, with layer thickness determined by color. A layer about $750 \AA$ A thick as indicated by the gold color produced was grown onto the surface. The clean crystal case is shown in Figs. and (15) while after anodizing, the corresponding results are shown in Figs. (16) and (17). This oxide thickness virtually destroys the channelling pattern. Anodizing until a purple color developed ( $>1000 \AA$ ) did destroy the pattern.

The effect of tilting the specimen on the properties of channelling bands and lines was investigated next. This effect is important since surfaces in a true composite will not necessarily be flat and perfectly aligned over long distances. Hence, it will be necessary to separate tilt effects from effects due to internal strains and/or surface layers. For the tilt study, a silicon crystal was chosen; silicon is frequently a component in composite materials.

The results are shown in Figs. (18) - (23). Tilting the crystal with respect to the electron beam causes the contrast to undergo a change in character. For example, the $\{440\}$ type reflections change from close black/white pairs at normal beam incidence to distinctly black or white lines for tilted specimens, as indicated by the corresponding line traces. 
Preparation of Kossel Patterns in the Scanning Electron Microscope

We were able to prepare both reflection and transmission Kosse1 patterns in the scanning electron microscope. The reflection patterns using a tilted specimen will almost certainly be the ones of most interest in the study of composites; preparing thin $(\sim 50 \mu \mathrm{m})$ sections of composites will be difficult so that transmission work may not be feasible. Hence, the tilted foil electron channelling study was essential in order to establish a basis for attempting to correlate Kossel patterns and electron channelling patterns prepared from composite materials.

Reflection patterns were prepared from an iron crystal; a typical pattern is shown in Fig. (24). Here, the crystal was tilted about $60^{\circ}$. The lines are sharp and have enough contrast to carry out meaningful measurements. Tilted foil electron channelling patterns can be prepared simultaneously using the NBS specimen current amplifier constructed for the scanning electron microscope ${ }^{7}$.

\section{Preliminary Study of Conventional Composite Materials}

Two types of composite materials were obtained from Sandia and the U.S. Army Research Center (Watertown, Mass.) respectively. The Sandia material consisted of plasma sprayed aluminum onto boron-silicon (borsic) fibers. The fibers were prepared using a thin tungsten wire as a base. This material, imaged in the scanning electron microscope, is shown in Fig. (25). First attempts to obtain electron channelling patterns from this material failed. The probable causes for this failure were the huge fabrication strains and the extremely fine "grain-size" of the aluminum matrix, as indicated by conventional x-ray 
diffraction techniques. The grains were probably smaller than the minimum region from which we could obtain an electron channelling pattern, i.e., about ten micrometers.

The Army material consists of carbon fibers in a magnesium matrix. Work will be underway on this material shortly. We also have some directionally solidified eutectic material on hand for study.

\section{Conclusions}

(1) Line profiles from electron channelling patterns can be measured with our apparatus so that the $2 \omega_{\mathrm{g}}$ term in Eqn. (1) can be determined for a variety of specimen conditions, i.e., strained, coated and tilted.

(2) Kossel patterns can be prepared from bulk specimens in the scanning electron microscope with sufficient information to provide

satisfactory $|\vec{g}|$ data for Eqn. (1). Then the term $\left(2 / \xi_{g}\right)$ in Eqn. (1) can be determined empirically for the specimen of interest. Hence, electron channelling patterns can be used to study strains at the micrometer level of spatial resolution.

(3) A reduction of $5 \%$ by rolling nearly destroys electron channelling contrast. Hence, highly strained material cannot be investigated by means of electron channelling contrast.

(4) Surface layers of oxides and carbon on the order of $1000 \AA$ destroy electron channelling contrast.

(5) Layers of $200 \AA$ affect the line profiles of electron channelling patterns. 
(6) Electron channelling patterns change characteristically as the specimen is tilted with respect to the electron beam; band contrast decreases and line character changes.

This work virtually completes the preliminary exploratory phase of the study. Next, strains in various materials will be investigated using electron channelling patterns. Then strains at matrix-fiber interfaces will be investigated. 
1. H. Yakowitz, NBS Monograph 130, 75p (1973).

2. C. Oatley, The Scanning Electron Microscope, Pt.I, The Instrument, Cambridge University Press, Cambridge (1972).

3. P.B. Hirsch, et al. Electron Microscopy of Thin Crystals, Butterworths, London, p. 100-103.

4. E.M. Schulson, phys. stat. sol. (b) 46, 95 (1971).

5. T. Imura, S. Weissman and J.J. Slade, Acta. Cryst. $\underline{8}, 786$ (1962).

6. M.L. Picklesimer, The Microscope 15, 472 (1967).

7. H. Yakowitz, C.E. Fiori and D.E. Newbury, SEM/1973 (). Johari, ed.) IITRI, Chicago, Ill. (1973) p. 173.

8. D.C. Joy and D.E. Newbury, SEM/1971 (0. Johari, ed.) IITRI, Chicago, Ill. (1971) p. 113. 


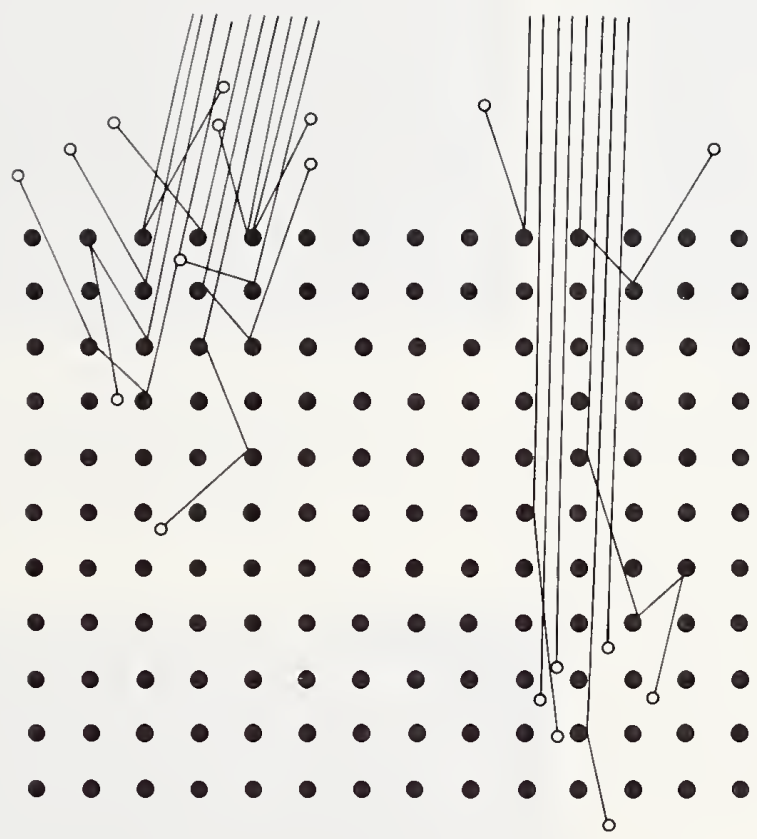

Fig. 1 Origin of electron channelling patterns; electrons penetrate the crystalline specimen more deeply in certain directions than in others. 



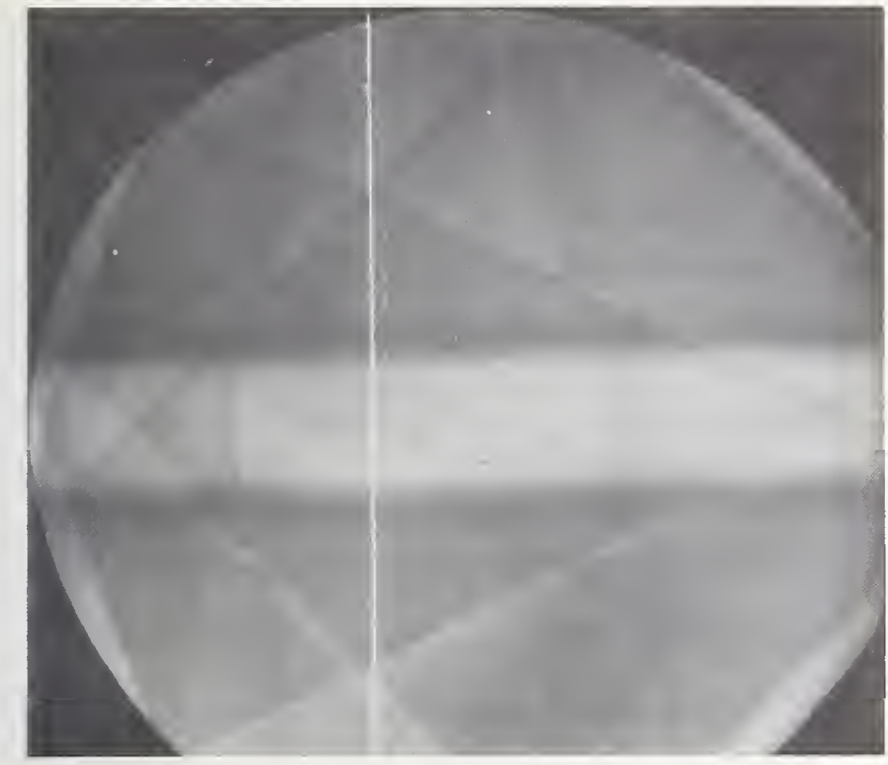

Fig. 2 Electron channelling pattern of annealed, electropolished aluminum. Line indicates region from which profile information was taken.

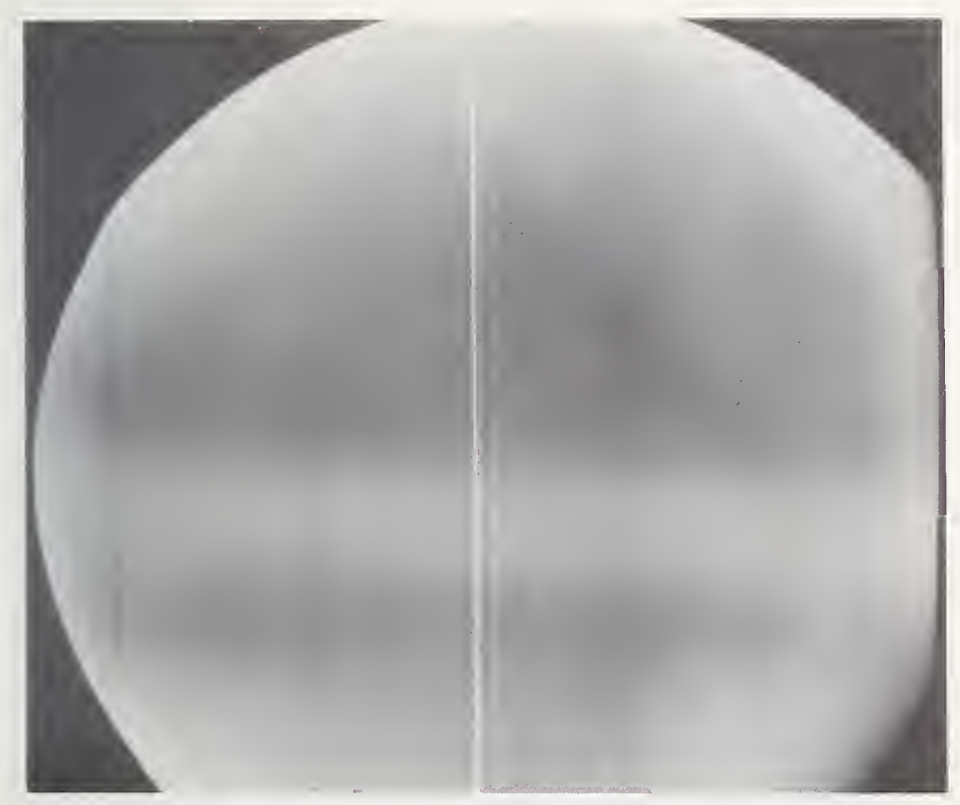

Fig. 4 Electron channelling pattern of aluminum crystal rolled to $5 \%$ reduction and then electropolished. Line indicates profile trace position.

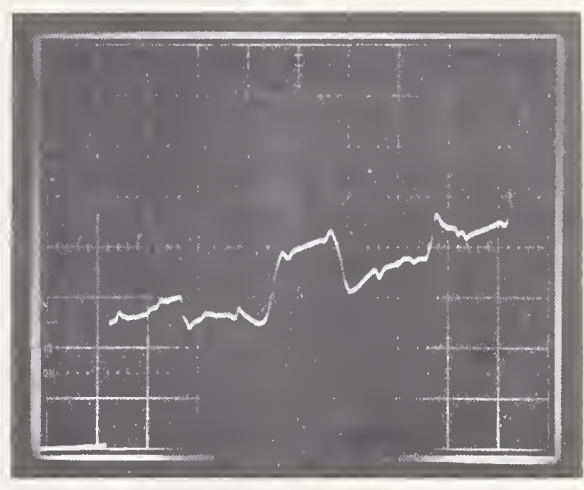

Fig. 3 Intensity profile along line in Fig. (2). Scale: 2 volts $/ \mathrm{cm}$

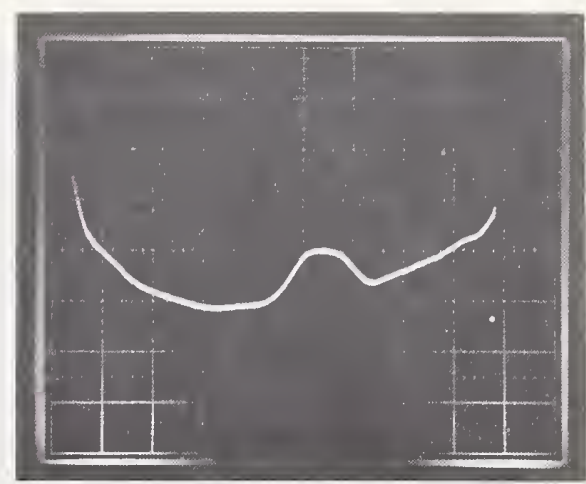

Fig. 5 Intensity profile along line in Fig. (4). Scale: 2 volts/cm. Compare with Fig. (3). 



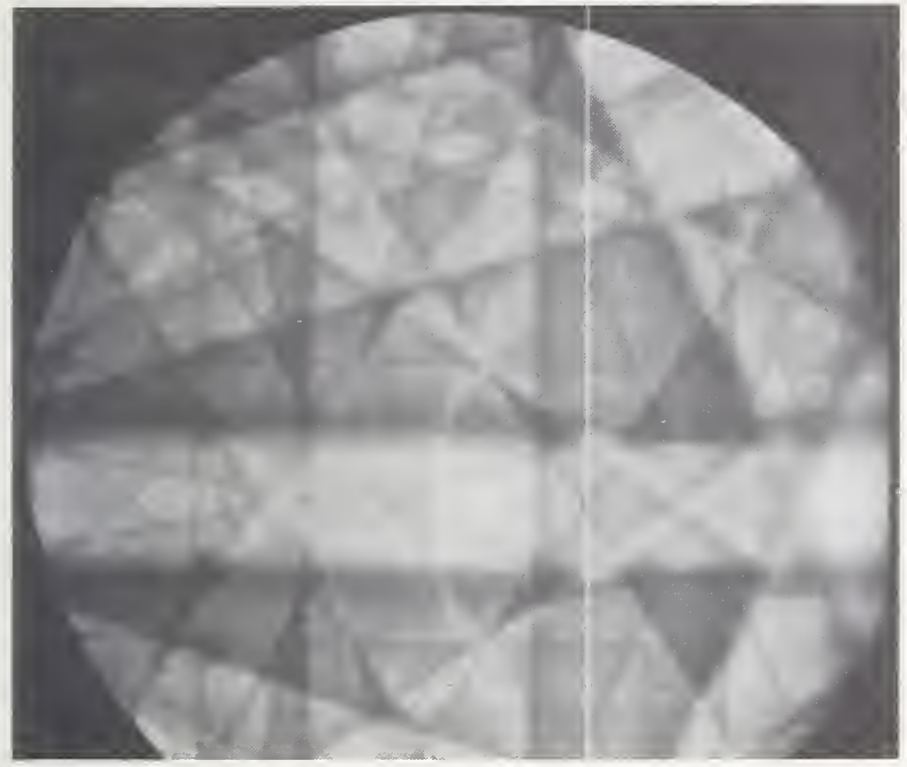

Fig. 6 Electron channelling pattern from chemically polished niobium crystal. Line indicates profile trace position.

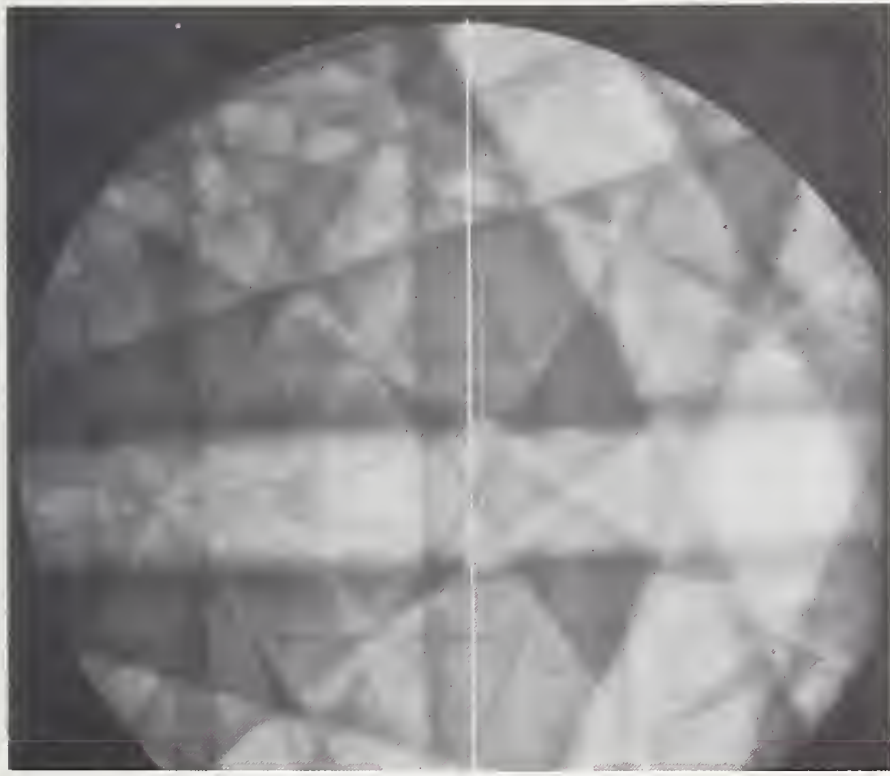

Fig. 8 Electron channelling pattern from niobium crystal after evaporation of $200 \AA$ thick carbon layer on to the surface. Line indicates profile trace position.

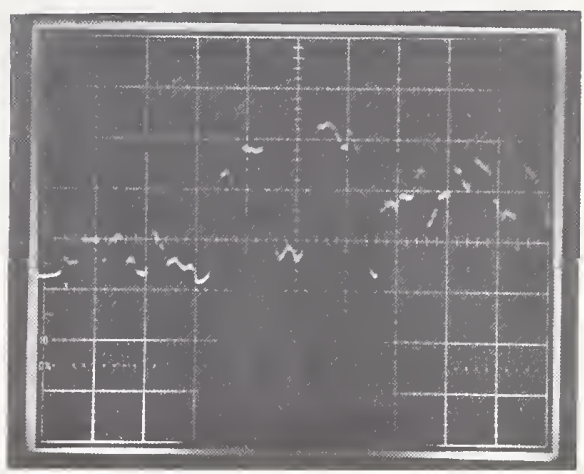

Fig. 7 Intensity profile along line in Fig. (6). Scale: 2 volts $/ \mathrm{cm}$.

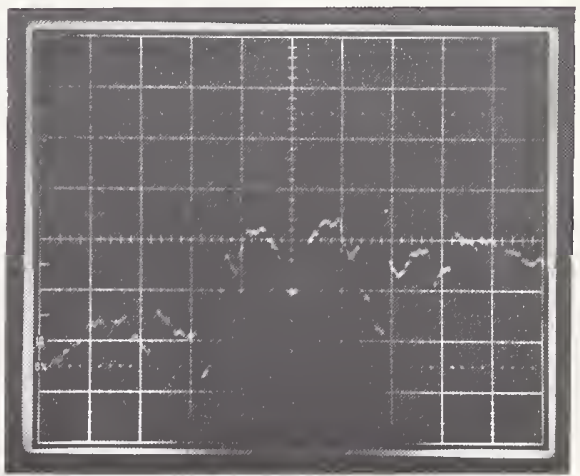

Fig. 9 Intensity profile along line in Fig. (8). Scale: 2 volts $/ \mathrm{cm}$. Compare with Figs. (7), (11) and (13). 



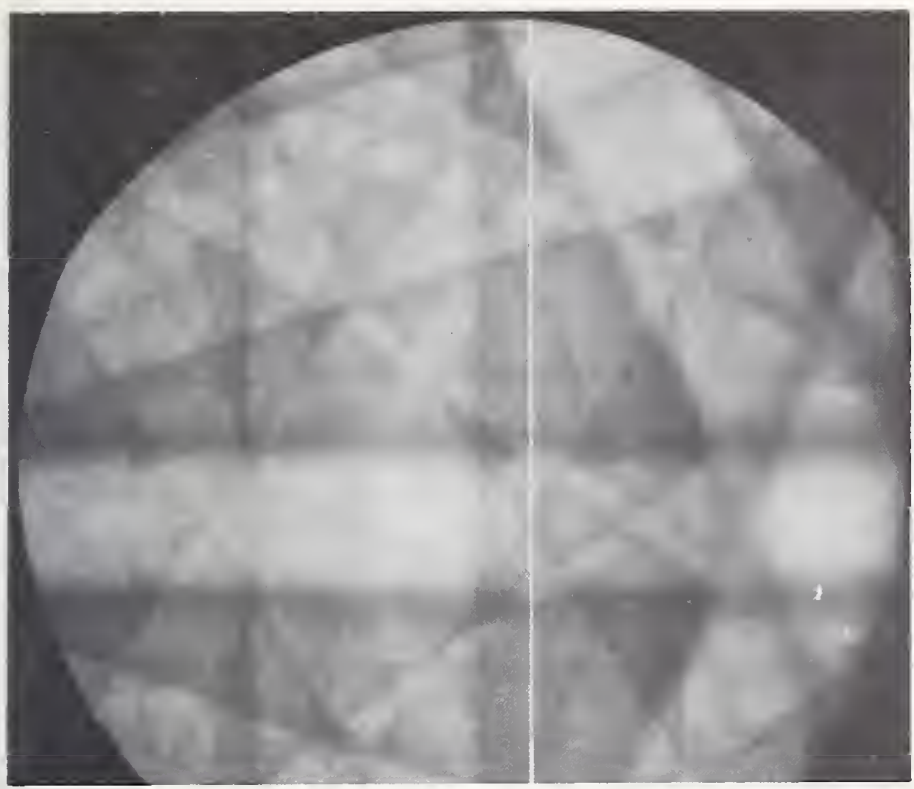

Fig. 10 Electron channelling pattern from niobium crystal after evaporation of $450 \AA$ thick carbon layer onto the surface. Line indicates profile trace position.

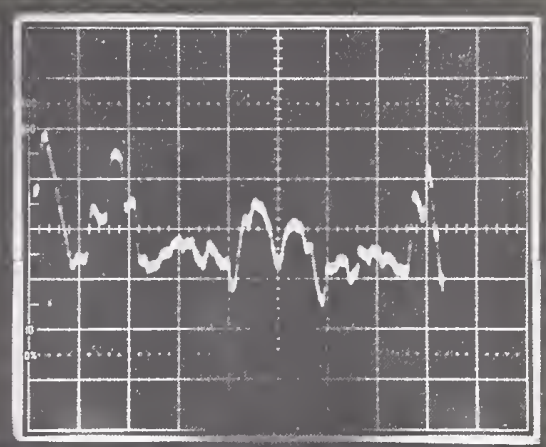

Fig. 11 Intensity profile along line in Fig. (10). Scale: 2 volts $/ \mathrm{cm}$ Compare with Figs. (7), (9) and (13).

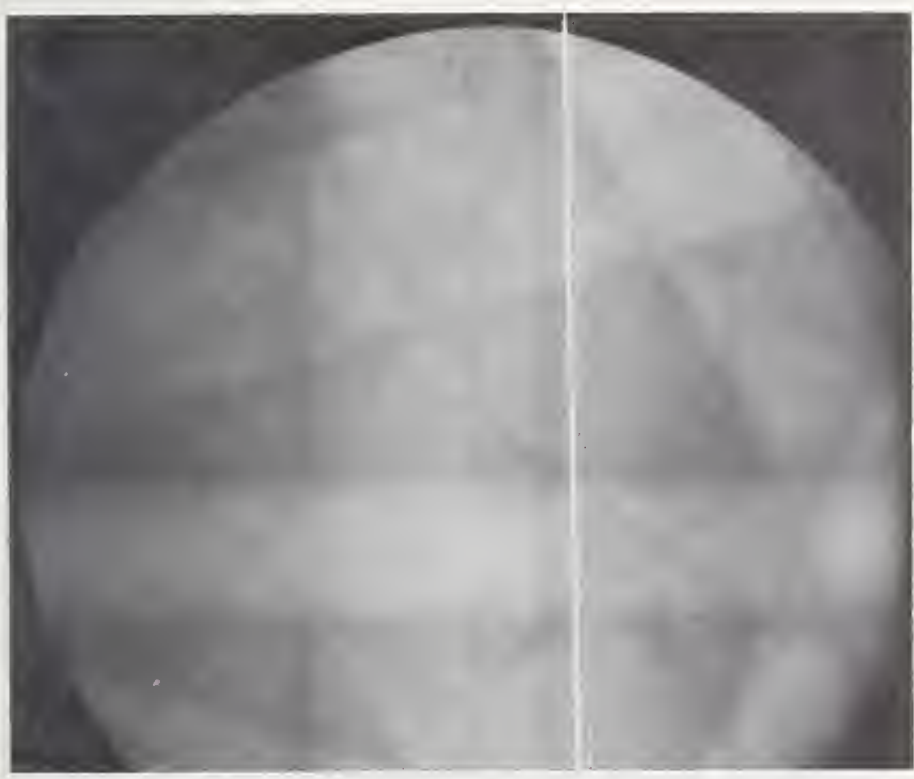

Fig. 12 Electron channelling pattern from niobium crystal after evaporation of $1000 \AA$ thick carbon layer onto the surface. Line indicates profile trace position.

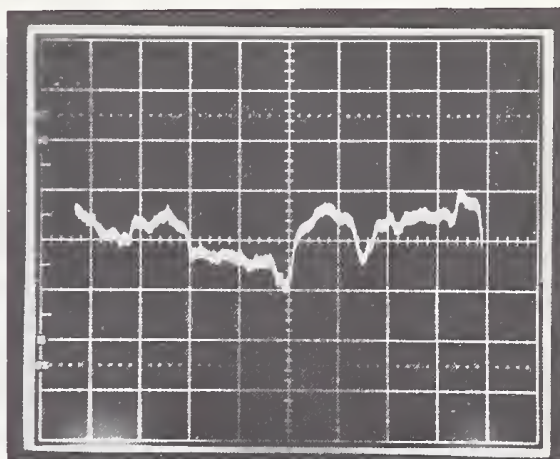

Fig. 13 Intensity profile along line in Fig. (12). Scale: 2 volts/cm Compare with Figs. (7), (9) and (11). 



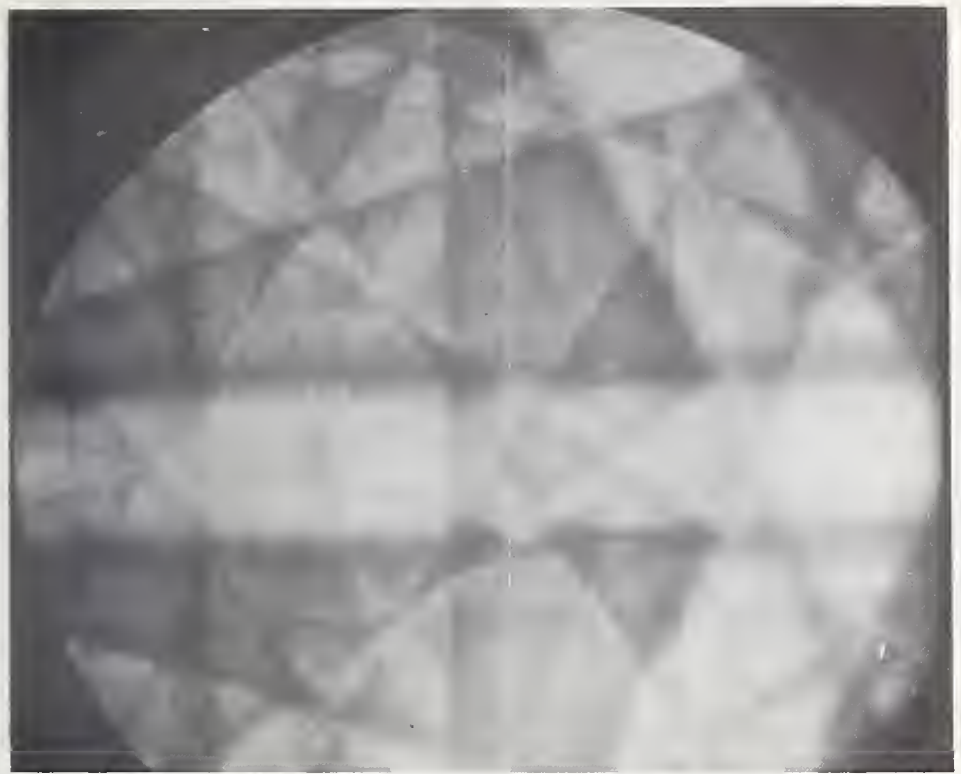

Fig. 14 Electron channelling pattern of chemically polished niobium crystal. Line indicates profile trace position.

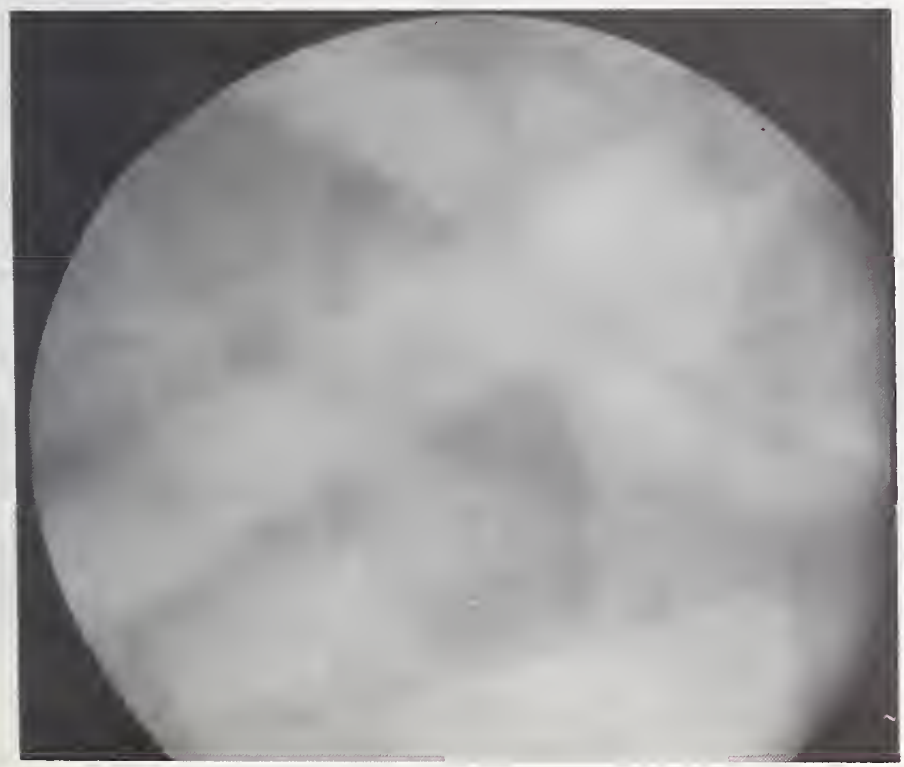

Fig. 16 Electron channelling pattern of niobium crystal after anodic oxidation yielding about $750 \AA$ thick layer as indicated by coloration. Line indicates profile trace position.

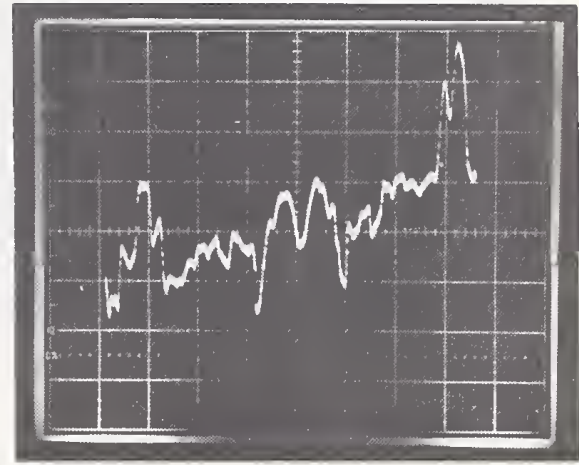

Fig. 15 Intensity profile along line in Fig. (14). Scale:2 volts/cm.

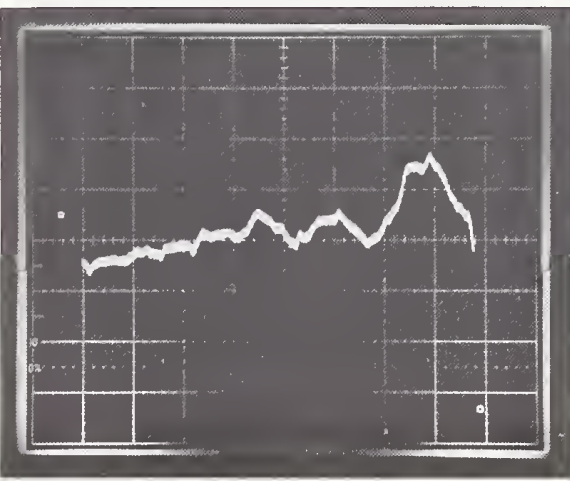

Fig. 17 Intensity profile along line in Fig. (16). Scale: 2 volts $/ \mathrm{cm}$. Compare with Fig. (15). 



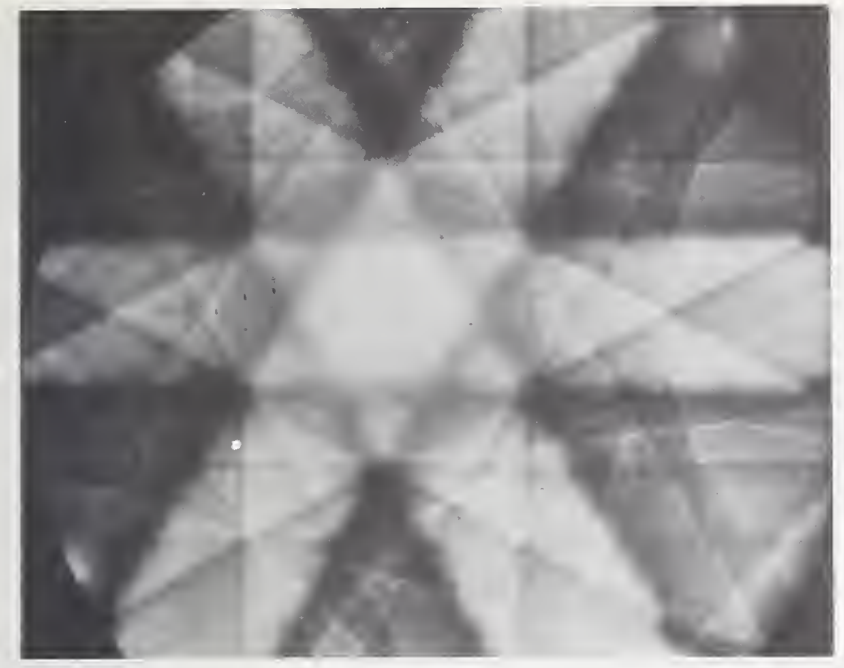

Fig. 18 Electron channelling pattern of silicon with crystal normal to electron beam axis. Line indicates profile trace position.

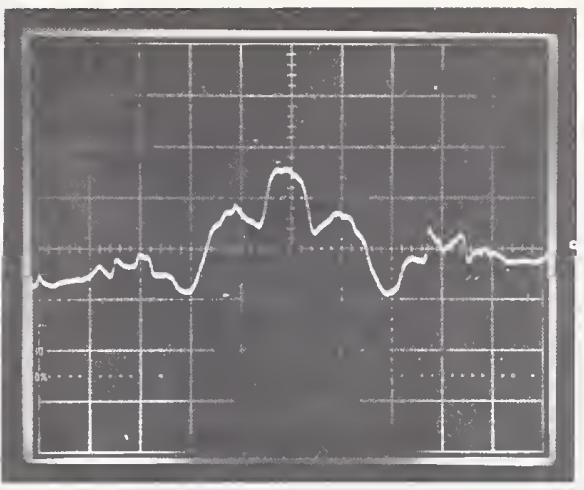

Fig. 19 Intensity profile along line in Fig. (18). Scale: 2 volts/cm.

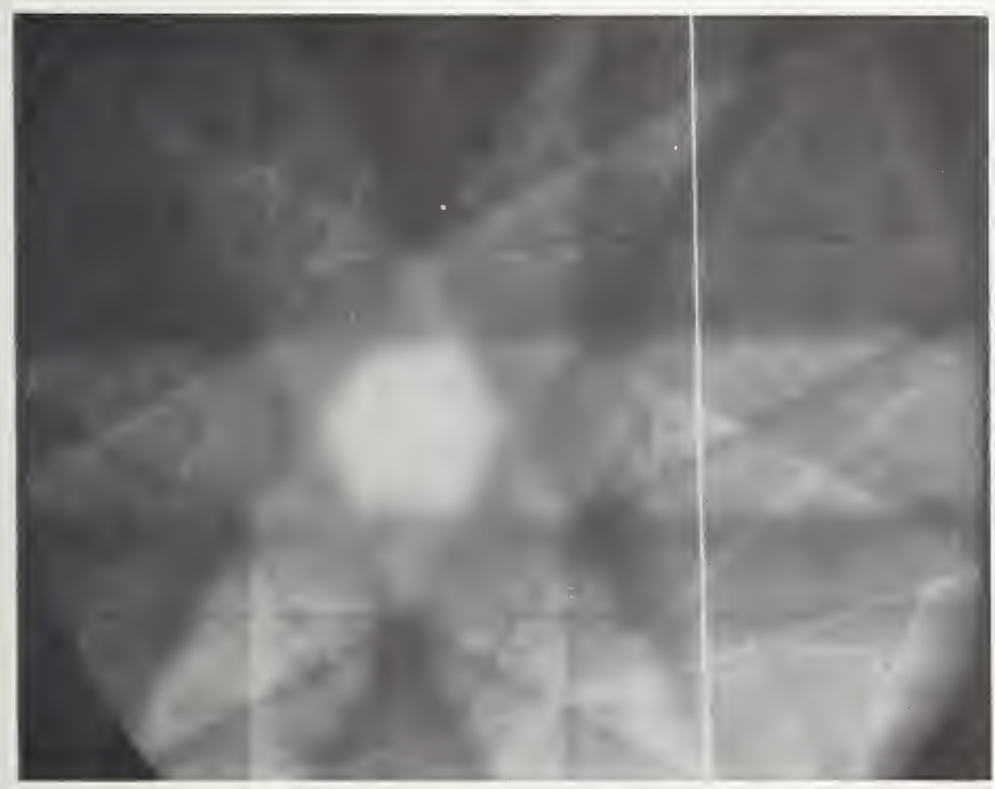

Fig. 20 Electron channelling pattern of silicon with crystal tilted $17^{\circ}$ with respect to electron beam axis. Line indicates profile trace position.

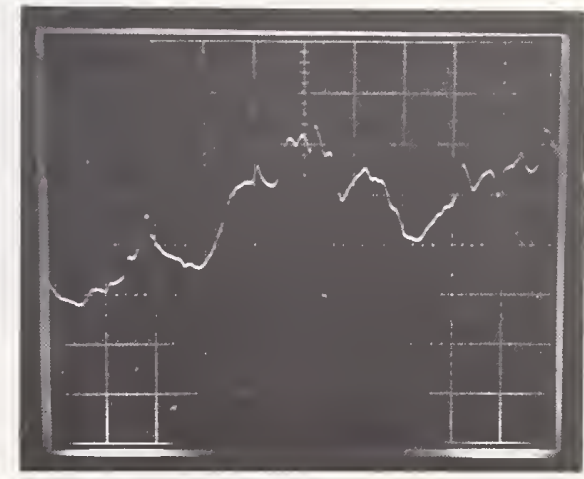

Fig. 21 Intensity profile along line in Fig. (20). Scale: 2 vol ts $/ \mathrm{cm}$. Compare with Figs. (19) and (23). 

Fig. 22 Electron channelling pattern of silicon with crystal tilted $24.6^{\circ}$ with respect to electron beam axis. Line indicates profile trace position.

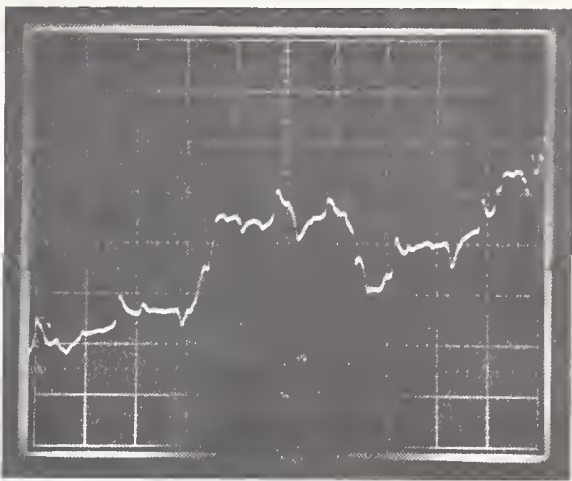

Fig. 23 Intensity profile along line in Fig. (22). Scale: 2 volts $/ \mathrm{cm}$. Compare with Figs. (19) and (21).

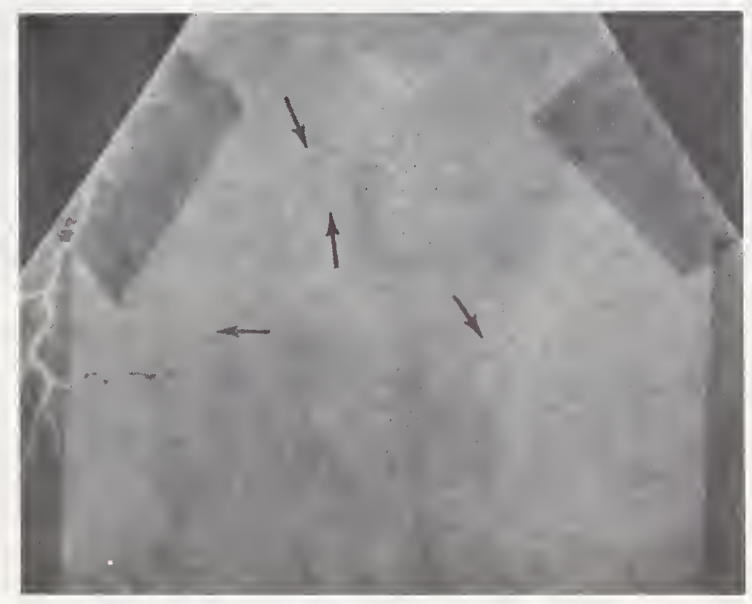

Fig. 24 Reflection Kossel pattern of iron crystal. Lines (indicated by arrows) include $\{220\},\{211\}$ and $\{200\}$ types. 



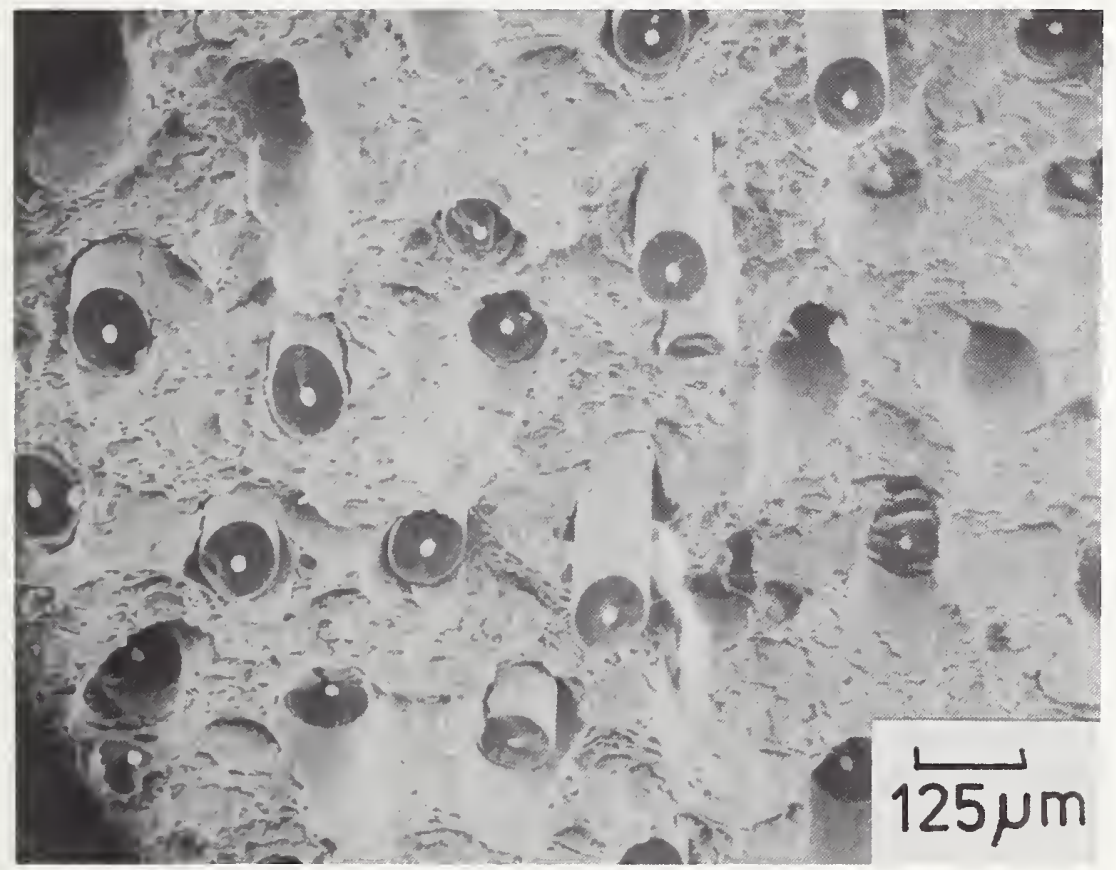

Fig. 25 Scanning electron micrograph of plasma sprayed aluminum matrix-borsic fiber composite. The bright central region of the borsic fiber is tungsten wire. 

CALCULATION OF COMPLEX EQUILIBRIA INVOLVING VAPORIZATION INTO VACUUM by

Robert C. Paule

\section{ABSTRACT}

A simplified, direct approach is presented to the description of complex equilibria involving vaporization into vacuum. Emphasis is on the basic problem solving process and on modification of existing techniques. Sequential solutions are presented to problems involving purification of a melt by vaporization into vacuum. The effects of concentration of melt and oxygen partial pressures on vaporization rates are demonstrated.

Key Words: $\mathrm{Al}_{2} \mathrm{O}_{3}$, chemical doping, complex equilibria, purification (evaporative), vacuum vaporization. 
Complex condensed phase equilibria with accompanying vaporization into vacuum is a problem that is frequently encountered by high temperature scientists. The problem is generally solved only for cases involving simple systems. We shall show that the general formalism for calculation of complex equilibria can be adapted to this problem.

We will develop the case for vaporization into vacuum and will show that the techniques are adequate for dealing with either equilibrium or non-equilibrium vaporization. Examples will be given of problems involving either vacuum evaporative purification or doping. Vaporization from solutions will be discussed.

There have been a number of articles describing calculations of complex equilibria( $1-7)$. The calculations of complex equilibria have been found to be widely useful and their development has closely followed the development of the high-speed digital computer. Elaborate, extensively documented computer programs have been developed for performing some of the calculations $(3,4)$. A number of modifications and approaches to the calculations have been reported $(5-7)$. 
The basic problem is to determine the number of moles of a 11 species present in a system, and to determine the distribution of these moles between the various physical phases. For our general analytical approach We want to work with the minimum information needed to fully determine the physical and chemical system. This is equivalent to specifying a set of independent physical properties and independent chemical species. In simplest terms, our task is to solve one mass balance equation for each independent chemical species. In this process we shall require that the equilibrium constant relationships between the independent and dependent chemical species be maintained. This problem could also be cast in terms of the free energy ${ }^{(2)}$.

\section{GENERAL CALCULATIONAL PROCEDURE}

As an introduction to the calculational procedures, consider the following simple equilibrium process in which we will allow any of the chemical species to be in stoichiometric excess.

$$
\mathrm{Al}_{2} \mathrm{O}_{3}(\mathrm{l}) \stackrel{2400 \mathrm{~K}}{\rightleftarrows} 2 \mathrm{Al}(\mathrm{g})+3 \mathrm{O}(\mathrm{g})
$$

(For simplification of this presentation we will ignore other chemical species that might be present. Our resultant "answers" are, of course, affected by this approximation. In actual practice, one must consider a11 species that are present.)

In our procedure we will first distribute all the gram-atoms of the elements present in the system among the independent chemical species and then follow, through the mass balance equations, the equilibration of the system. To be specific, assume that we have a system containing 
4 gram-atoms of $A 7$ and 3 gram-atoms of 0 . We may assign these two elements to an initial number of moles, $q_{j}$, of two independent chemical species (components) which are involved in the above chemical reaction. In this example, we have chosen $\mathrm{Al}_{2} \mathrm{O}_{3}$ and $\mathrm{Al}$ for our components.

$$
\begin{aligned}
& \text { gram-atoms } A 1=4=2 q_{A I_{2} O_{3}}+q_{A l} \\
& \text { gram-atoms } 0=3=3 q_{A l_{2} O_{3}} \\
& { }_{\mathrm{Al}_{2} \mathrm{O}_{3}}=1 \text { mole } \quad q_{A 1}=2 \text { moles. }
\end{aligned}
$$

and

(The rules for the proper choice of components will be discussed below.) The general equation for assigning the elements to the components is

$$
Q_{k}=\sum_{j=1}^{\# \text { of components }} \alpha_{j k} q_{j}
$$

where $Q_{k}$ is the number of gram-atoms of the kth element, and $\alpha_{j k}$ is the subscript occurring on the symbol of the kth element in the chemical formula of the jth component. The $q_{j}$ may be thought of as the initial feed components to the system, before any equilibration occurs. (In some problems the initial feed components $q_{j}$, are known, in which case one simply bypasses the above steps and starts at this point.)

For the vast majority of cases, the number of independent components that need to be considered will be equal to the number of elements present. 
In our example we have two elements, $A 1$ and 0 , and therefore two components. Exceptions to this general rule can occur when several chemical species have the same stoichiometric ratio of elements. This point will be further discussed in the Appendix.

The rules for choosing the components to describe the system are that the species must be stoichiometrically independent (e.g., KCl and $\mathrm{K}_{2} \mathrm{Cl}_{2}$ cannot both be used), and 217 elements in the system must be present within the group of components selected. Aiso, any chemical species whose concentration is not expressible by an equilibrium constant relationship, such as a pure solid phase, must be selected as a component.

With the components chosen and the $q_{j}$ assigned, we are now ready to make a mass balance for each independent component. For our example, let $n_{A_{2}{ }_{2} O_{3}}$ and $n_{A 7}$ be the number of moles of the independent components at equilibrium, and let $n_{0}$ be the corresponding number of moles of oxygen determined by the equilibrium constant for the reaction. Inspection of the chemical equation shows that each mole of oxygen gas produced came from the consumption of $1 / 3$ mole of $\mathrm{Al}_{2} \mathrm{O}_{3}(1)$ and resulted in the production of $2 / 3$ "extra" moles of $\mathrm{Al}(\mathrm{g})$.

Thus:

$$
\begin{aligned}
& { }_{A T_{2} O_{3}}-1 / 3 n_{0}=n_{A I_{2} O_{3}} \\
& a_{A 1}+2 / 3 n_{0}=n_{A T}
\end{aligned}
$$

The general mass balance equations have been conveniently described by Kandiner and Brinkley $(1)$ in the form:

$$
q_{j}-\sum_{i} v_{i j} n_{i}=n_{j}
$$


where the $j$ index refers to the independent components, the $i$ index refers to the dependent species, and $v_{i j}$ refers to the coefficient(s) of component $j$ in the $i$ chemical reaction(s) written in the form:

$$
1 / 3 \mathrm{Al}_{2} \mathrm{O}_{3}(1)-2 / 3 \mathrm{Al}(\mathrm{g})-\underline{\mathrm{O}(\mathrm{g})}=0 .
$$

Note that the products are transposed to the left side of the equation and that the equation is expressed in terms of one mole of the dependent (product) species. For the general case, one such chemical equation can be written for each dependent species, and each of these equations must be written so as to involve only one dependent species. The independent components will, of course, be used repeatedly in these equations.

At this point, for the problem at hand, we have two mass balance equations ( 1 \& 2) representing the two independent components, $n_{A 1} \mathrm{O}_{3}$ and $n_{A 7}$. We have an additional dependent unknown, $n_{0}$, which can be determined from the equilibrium constant relationship set up on the basis of one mole of oxygen.

$$
K=\frac{\left(P_{A I}\right)^{2 / 3}\left(P_{0}\right)^{7}}{\left[a_{A T_{2} O_{3}}=1\right]^{1 / 3}}
$$

For a usual system of contained gases, the pressures can be related to moles using Dalton's law

$$
P_{i}=\frac{n_{i}}{N} p
$$

where $N$ is the total number of moles of gas and $P$ the total pressure. 
and

$$
n_{0}=k\left(\frac{P}{N}\right)^{-5 / 3} n_{A T}^{-2 / 3}
$$

If we specify, in addition to the temperature, the total pressure or a]ternately the total volume, then we have three equations $(1,2,6)$

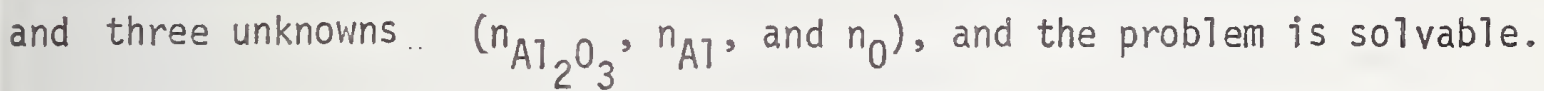
Mathematical solutions to the problems are frequently obtained by using the ilewton-Raphson method ${ }^{(8)}$, as described below.

\section{APPLICATION TO THE PROBLEM OF EVAPORATION INTO A VACUUM}

The above general procedure can also be used to describe a completely different situation, i.e., the case of evaporation into a vacuum. The equilibrium constant relationship [equation (3)] is still valid, but equation (4) now needs to be replaced by the Knudsen equation:

$$
P_{i}=\frac{n_{i}}{A t}\left(2 \pi R T M_{i}\right)^{1 / 2}
$$

where $n_{i}$ moles of vapor with molecular weight $M_{j}$ effuse from the condensed phase surface of area $A$ in time $t$. The analogs to equations (5 \& 6 ) are thus: 


$$
K=\left[\frac{n_{A L}}{A t}\left(2 \pi R T M_{A l}\right)^{1 / 2}\right]^{2 / 3}\left[\frac{n_{0}}{A t}\left(2 \pi R T M_{0}\right)^{1 / 2}\right]^{1}
$$

and $n_{0}=k\left[\frac{(2 \pi R T)^{1 / 2}}{A t}\right]^{-5 / 3} M_{A T}^{-1 / 3} M_{0}^{-1 / 2} n_{A T}-2 / 3$

Again we have three equations $(1,2,9)$ and the same three unknown, and the problem is solvable.

If non-equilibrium congruent evaporation occurs, the situation is described by introducing an evaporation coefficient, $\alpha$, to the Knudsen equation:

$$
P_{i}=\frac{n_{i}}{\alpha A t}\left(2 \pi R T M_{j}\right)^{7 / 2}
$$

Note that the above use of an evaporation coefficient assumes the nonequilibrium is related to the evaporation step, and that chemical equilibrium is maintained within the condensed phase.

For the case of evaporation from a solution containing several condensed species, it is necessary to modify the condensed phase activity term in the equilibrium constant equation. If we assume the solution to be homogeneous and ideal, we can write the activity of any component to be equal to the mole fraction of that component in the solution. As an 
example, consider a case where our original $\mathrm{Al}_{2} \mathrm{O}_{3}(1)$ contained $\mathrm{SiO}_{2}(1)$ impurity, and as a result the vapor phase also contained $\mathrm{Si}(\mathrm{g})$. We now have five chemical species, $\mathrm{Al}_{2} \mathrm{O}_{3}(1), \mathrm{Al}(\mathrm{g}), \mathrm{SiO}_{2}(1), \mathrm{O}(\mathrm{g})$, and $\mathrm{Si}(\mathrm{g})$, with the first three being assigned as components. Following the previously described rules and assuming the solution to be ideal, we can write chemical equations for the two dependent species, $O(g)$ and $S i(g)$, and can them write the mass balance equation for the components.

$$
\begin{aligned}
& 1 / 3 \mathrm{Al}_{2} \mathrm{O}_{3}(1) \rightarrow 2 / 3 \mathrm{Al}(\mathrm{g})+\underline{\mathrm{O}(\mathrm{g})} \\
& \mathrm{SiO}_{2}(1)+4 / 3 \mathrm{Al}(\mathrm{g}) \rightarrow 2 / 3 \mathrm{Al}_{2} \mathrm{O}_{3}(\mathrm{l})+\underline{\mathrm{Si}(g)} \\
& \mathrm{aAl}_{2} \mathrm{O}_{3}-1 / 3 \mathrm{n}_{\mathrm{O}}+2 / 3 \mathrm{n}_{\mathrm{Si}}=\mathrm{n}_{\mathrm{Al}} \mathrm{O}_{3} \\
& \mathrm{q}_{\mathrm{Al}}+2 / 3 \mathrm{n}_{\mathrm{O}}-4 / 3 \mathrm{n}_{\mathrm{Si}}=\mathrm{n}_{\mathrm{Al}} \\
& { }_{\mathrm{SiO}_{2}}-\mathrm{n}_{\mathrm{Si}}=\mathrm{n}_{\mathrm{SiO}_{2}}
\end{aligned}
$$

The equilibrium constant relationship between the dependent species and the components are as follows:

$$
K_{1}=\frac{\left(P_{A 1}\right)^{2 / 3}\left(P_{0}\right)^{1}}{\left(\frac{{ }_{A 1} O_{3}}{n_{A 1_{2} O_{3}+n_{S_{10}}}}\right)^{1 / 3}}
$$




$$
K_{2}=\frac{\left(\frac{n_{\mathrm{Al}_{2} \mathrm{O}_{3}}}{n_{\mathrm{Al}_{2} \mathrm{O}_{3}}+n_{\mathrm{SiO}_{2}}}\right)^{2 / 3}\left(P_{\mathrm{Si}}\right)^{1}}{\left(P_{\mathrm{AT}}\right)^{4 / 3}\left(\frac{n_{\mathrm{SiO}_{2}}}{n_{\mathrm{Al}_{2} \mathrm{O}_{3}+n_{\mathrm{SiO}_{2}}}}\right)^{1}}
$$

The above equations can be adapted to describe either evaporation into a vacuum, or evaporation in a contained gas system. The resultant five equations and five unknowns can then conveniently be solved by using the Newton-Raphson method. The use of a computer in handling the calculations is desirable at this stage of complexity.

For all situations to be described we have $j$ mass balance equations, where $j$ is the number of independent components, and $i$ equilibrium constant equations, where $i$ is the number of dependent chemical species. Various substitutions can be made for the pressures and condensed phase activities in the equitibrium constant equations depending on the physical system. The unknowns can then be determined since we have equal numbers of equations and unknowns. 
For very simple gas systems, most high temperature scientists have directly solved the equations for the unknowns. For more complex chemical systems involving larger numbers of unknowns, direct solution is impractical since the equilibrium constant equations are frequently non-linear. A number of methods have been devised for the solution of these equations ( 7$)$. One convenient approach makes use of iterative approximations to linearize the equations and solve for the unknowns.

The Newton-Raphson method ${ }^{(8)}$ is frequently used for the linearization. This iterative method involves an approximation consisting of truncating a Taylor series expansion(9). For example, for two equations involving two independent variables $U$ and $V$ we have:

$$
F(U, V)=0 \quad G(U, V)=0
$$

For the $1^{\text {th }}$ approximation:

$$
U \approx U_{1}+\Delta U_{1} \quad V \approx V_{1}+\Delta V_{1}
$$

and

$$
\begin{aligned}
& E(U, \forall)-F\left(U_{1}, V_{1}\right)=\left(\frac{\partial F}{\partial U}\right)_{U=U_{1}} \Delta U_{1}+\left(\frac{\partial F}{\partial V}\right)_{V=V_{1}} \Delta V_{1}+\cdots \\
& G(U, \forall)-G\left(U_{1}, V_{1}\right)=\left(\frac{\partial G}{\partial U}\right)_{U=U_{1}} \Delta U_{1}+\left(\frac{\partial G}{\partial V}\right)_{V=V_{1}} \Delta V_{1}+\cdots \cdot
\end{aligned}
$$

Equations (11) and (12) can, for the simple $\mathrm{Al}_{2} \mathrm{O}_{3}$ example, represent mass balance equations (1) and (2) with the dependent variable, $n_{0}$, being 
replaced by using equilibrium relationship $(6,9$, or 10$)$. To describe the simple $\mathrm{Al}_{2} \mathrm{O}_{3}$ vaporization into vacuum we use equations $(1,2,9)$ to obtain:

$$
\begin{aligned}
& q_{A]_{2} O_{3}}-\frac{1}{3}\left\{K\left[\frac{(2 \pi R T)^{1 / 2}}{A t}\right]^{-5 / 3} M_{A 1}^{-1 / 3} M_{0}^{-1 / 2} n_{A T}-2 / 3\right\}-n_{A 1_{2} O_{3}}=0 . \\
& \text { and } q_{A L}+\frac{2}{3}\left\{K\left[\frac{(2 \pi R T)^{1 / 2}}{A t}\right]^{-5 / 3} M_{A 1}^{-1 / 3} M_{0}^{-1 / 2} n_{A T}-2 / 3\right\}-n_{A T}=0 .
\end{aligned}
$$

To simplify notation we define

$$
k_{T}=-\frac{1}{3} K\left[\frac{(2 \pi R T)^{1 / 2}}{A t}\right]^{-5 / 3} M_{A 1}^{-1 / 3} M_{0}^{-1 / 2}
$$

and $k_{2}=\frac{2}{3} K\left[\frac{(2 \pi R T)^{1 / 2}}{A t}\right]^{-5 / 3} M_{A 1}^{-1 / 3} M_{0}^{-1 / 2}$

so that $a_{\mathrm{Al}_{2} \mathrm{O}_{3}}+k_{1} n_{A 1}-2 / 3-n_{\mathrm{Al}_{2} \mathrm{O}_{3}}=0$.

and

$$
a_{A 1}+k_{2^{n}} n^{-2 / 3}-n_{A 1}=0 \text {. }
$$

Using initial estimates, $n_{A 1} O_{3,1}$ and $n_{A 1,1}$, equations (13) and (14) are:

$$
\begin{aligned}
& -a_{A 1_{2} O_{3}}-k_{1} n_{A 1,1}-2 / 3+n_{A 1_{2} O_{3,1}} \approx(-1)\left(\Delta n_{A 1_{2} O_{3,1}}\right)+ \\
& \left(-\frac{2}{3} k_{1} n_{A 1,1}{ }^{-5 / 3}\right)\left(\Delta n_{A 1,1}\right)
\end{aligned}
$$

and

$$
-a_{A 1}-k_{2} n_{A 1,1}-2 / 3 \approx(0)\left(\Delta n_{A T_{2}{ }_{3,1}}\right)+\left(-\frac{2}{3} k_{2} n_{A 1,1}-5 / 3-1 .\right)\left(\Delta n_{A 1,1}\right)
$$




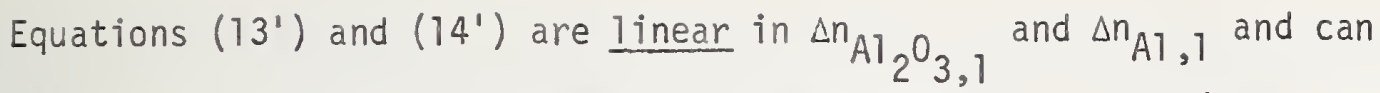
easily be solved to obtain better estimates for $n_{A 1} O_{3,2}$ and $n_{A 1,2}$ to be used in the next iteration of equations $\left(13^{\prime}\right)$ and $\left(14^{\prime}\right)$. The iteration process is repeated until acceptably constant $n_{A_{2} O_{3}}$ and $n_{A 7}$ are obtained. The $n_{0}$ is obtained from equation (9), $i_{\text {.e. }}$, from the relationship involving the equilibrium constant and values for the independent species. One advantage of this treatment is that it deals primarily with the independent components and thus minimizes the number of unknowns that need to be handled.

In using the iterative approach, it is sometimes found necessary to limit the relative size of the corrections to avoid large overcorrections which can even result in negative numbers of moles. Overcorrections can occur since we have truncated the Taylor series expansion after the first derivative.

\section{COMPLEX PURIFICATION PROBLEM}

Problems of practical interest frequently involve the description and handling of complex situations. The use of computers allows the convenient solution to these problems. As one example of a complex problem, consider the situation where we have one mole of $\mathrm{Al}_{2} \mathrm{O}_{3}$ containing $10 \mathrm{ppm} \mathrm{CaO}$ (mole basis) and wish to purify the $\mathrm{Al}_{2} \mathrm{O}_{3}$ by evaporation by heating it in vacuum at $2400 \mathrm{~K}$. Such a process might be used either for purification or for controlling the level of doping. Questions of interest are how much $\mathrm{Al}_{2} \mathrm{O}_{3}$ and $\mathrm{CaO}$ remain at given times and how fast does the purification proceed.

For this problem, there are three elements and three components. The independent components were taken to be $\mathrm{Al}_{2} \mathrm{O}_{3}(1), \mathrm{CaO}(1)$, and $\mathrm{O}(\mathrm{g})$, and the dependent gaseous species considered were $\mathrm{Al}, \mathrm{A10}, \mathrm{AlO}_{2}, \mathrm{Al}_{2} \mathrm{O}$, $\mathrm{Al}_{2} \mathrm{O}_{2}, \mathrm{O}_{2}$, and $\mathrm{Ca}$. For the sake of brevity we will only outline the calculational procedure. We first set up the three mass balance equations 
and the seven equilibrium constant relationships using JANAF data ${ }^{(10)}$ for the equilibrium constants, and then use the Knudsen equation to relate the pressures to moles. Unit evaporation coefficients were assumed. The evaporation area used in the Knudsen equation was calculated using a molten drop of spherical geometry and the number of moles and density of $\mathrm{Al}_{2} \mathrm{O}_{3}(1)$. The $\mathrm{AT}_{2} \mathrm{O}_{3}(1)$ and $\mathrm{CaO}(1)$ were assumed to have ideal activites and to be completely mixed in the melt. The initial time interval was taken as 0.005 seconds, and an iterative (Newton-Raphson) solution was obtained (see column one of the table). In this iteration procedure the corrections were limited to be either equal to or one half the estimated value. The pressures were calculated using equation (7), and represent initial vaporization pressures. Sequential calculations for vaporization were then made at subsequent twenty second intervals with the $\mathrm{Al}_{2} \mathrm{O}_{3}(1)$ and $\mathrm{CaO}(1)$ feed for each interval being obtained from the previous intervals results. The moles of gas represent vaporization during each time intervat. 
Moles of Species Present

Temp (K)

Cumulative Time ( $\mathrm{Sec}$ )

$\mathrm{Al}_{2} \mathrm{O}_{3}$

$\mathrm{CaO}$

0

$\mathrm{O}_{2}$

A]

A10

$\mathrm{AlO}_{2}$

$\mathrm{Al}_{2} \mathrm{O}$

$\mathrm{Al}_{2} \mathrm{O}, 2$

$\mathrm{Ca}$
0

$1.0000 \times 10^{0}$

$9.9998 \times 10^{-6}$

$1.6143 \times 10^{7}$

$4.8005 \times 10^{-9}$

$1.0670 \times 10^{-7}$

$1.2741 \times 10^{-8}$

$6.2753 \times 10^{-10}$

$2.3611 \times 10^{-9}$

$1.1602 \times 10^{-11}$

$1.8850 \times 10^{-10}$
2400

20.00

40.00

60.00
$9.9950 \times 10^{-1}$

$9.9925 \times 10^{-1}$

$9.2986 \times 10^{-6}$

$8.6465 \times 10^{-6}$

$8.0401 \times 10^{-6}$

$6.4560 \times 10^{-4}$

$6.4548 \times 10^{-4}$

$6.4535 \times 10^{-4}$

$1.9197 \times 10^{-5}$

$1.9193 \times 10^{-5}$

$1.9189 \times 10^{-5}$

$4.2676 \times 10^{-4}$

$4.2671 \times 10^{-4}$

$4.2665 \times 10^{-4}$

$5.0957 \times 10^{-5}$

$5.0949 \times 10^{-5}$

$5.0941 \times 10^{-5}$

$2.5097 \times 10^{-6}$

$2.5092 \times 10^{-6}$

$2.5088 \times 10^{-6}$

$9.4435 \times 10^{-6}$

$9.4424 \times 10^{-6}$

$9.4413 \times 10^{-6}$

$4.6402 \times 10^{-8}$

$4.6396 \times 10^{-8}$

$4.6389 \times 10^{-8}$

$7.0120 \times 10^{-7}$

$6.5210 \times 10^{-7}$

$6.0643 \times 10^{-7}$

Pressures of Species Present in Atmospheres
$\mathrm{A}_{2} \mathrm{O}_{3}$
0.
0.
0.
0.
$\mathrm{CaO}$
0 .
0.
0 .
0 .
0
$3.1171 \times 10^{-6}$
$3.1170 \times 10^{-6}$
$3.1169 \times 10^{-6}$
$3.1168 \times 10^{-6}$
$\mathrm{O}_{2}$
$1.3109 \times 10^{-7}$
$1.3108 \times 10^{-7}$
1. $3107 \times 10^{-7}$
1. $3106 \times 10^{-7}$
A1
$2.6754 \times 10^{-6}$
$2.6756 \times 10^{-6}$
$2.6757 \times 10^{-6}$
$2.6758 \times 10^{-6}$
A10
$4.0321 \times 10^{-7}$
$4.0322 \times 10^{-7}$
$4.0323 \times 10^{-7}$
$4.0323 \times 10^{-7}$
$\mathrm{AlO}_{2}$
2. $3264 \times 10^{-8}$
2. $3264 \times 10^{-8}$
$2.3263 \times 10^{-8}$
2. $3263 \times 10^{-8}$
$\mathrm{Al}_{2} \mathrm{O}$
$9.5332 \times 10^{-8}$
$9.5338 \times 10^{-8}$
$9.5343 \times 10^{-8}$
$9.5348 \times 10^{-8}$
$\mathrm{Al}_{2} \mathrm{O}_{2}$
$5.1926 \times 10^{-10}$
$5.1927 \times 10^{-10}$
$5.1929 \times 10^{-10}$
$5.1930 \times 10^{-10}$
$\mathrm{Ca}$
$5.760 \times 10^{-9}$
$5.3581 \times 10^{-9}$
$4.9838 \times 10^{-9}$
$4.6355 \times 10^{-9}$ 
As vaporization proceeds, the concentration of $\mathrm{CaO}$ in the meit decreases and this results in a lowering of the Ca vapor pressures. It should be noted that for each time interval the moles (and mole fractions) of the liquid components are treated as if they are constant throughout that interval. Since allowance is not made for liquid concentration changes within each time interval, it is necessary to choose time intervals small enough such that the liquid concentration changes between intervals are relatively small. The use of computer calculations minimizes the inconvenience of using such sequential steps.

Step approximations, dependent upon time, are not encountered in calculations for gas systems since these systems are functions only of total volume or pressure. Gases associated with contained gas systems are in constant equilibrium with the condensed phase, while gases evaporating into vacuum can be in equilibrium with the condensed phase only at the moment of evaporation.

In the above example the CaO vaporization rate may be too rapid if one wishes to control the level of the CaO doping. The chemical equilibria, however, can be shifted to inhibit the rates of vaporization by use of a constant low oxygen pressure surrounding the melt. If one chooses the oxygen pressure to be $10^{-5}$ atm. We still maintain near Knudsen flow conditions and can continue to calculate vaporization rates using the knudsen equation. For these calculations we can conveniently assign $\mathrm{Al}_{2} \mathrm{O}_{3}(1)$ and $\mathrm{CaO}(1)$ as components and use a $\mathrm{P}_{0}$ of $10^{-5}$ atm. The 
purification rates as indicated by the $\mathrm{CaO}(1)$ concentrations are shown in Figure 1 , both for the case of $P_{0}$ equal to $10^{-5} \mathrm{~atm}$. and for the case of self-developed oxygen (as tabulated above). It is seen that an oxygen pressure of $10^{-5} \mathrm{~atm}$. significantly inhibits the rate of vaporization.

It is clear that many modifications in oxidation or reduction conditions can be used to achieve desired vaporization goals. 


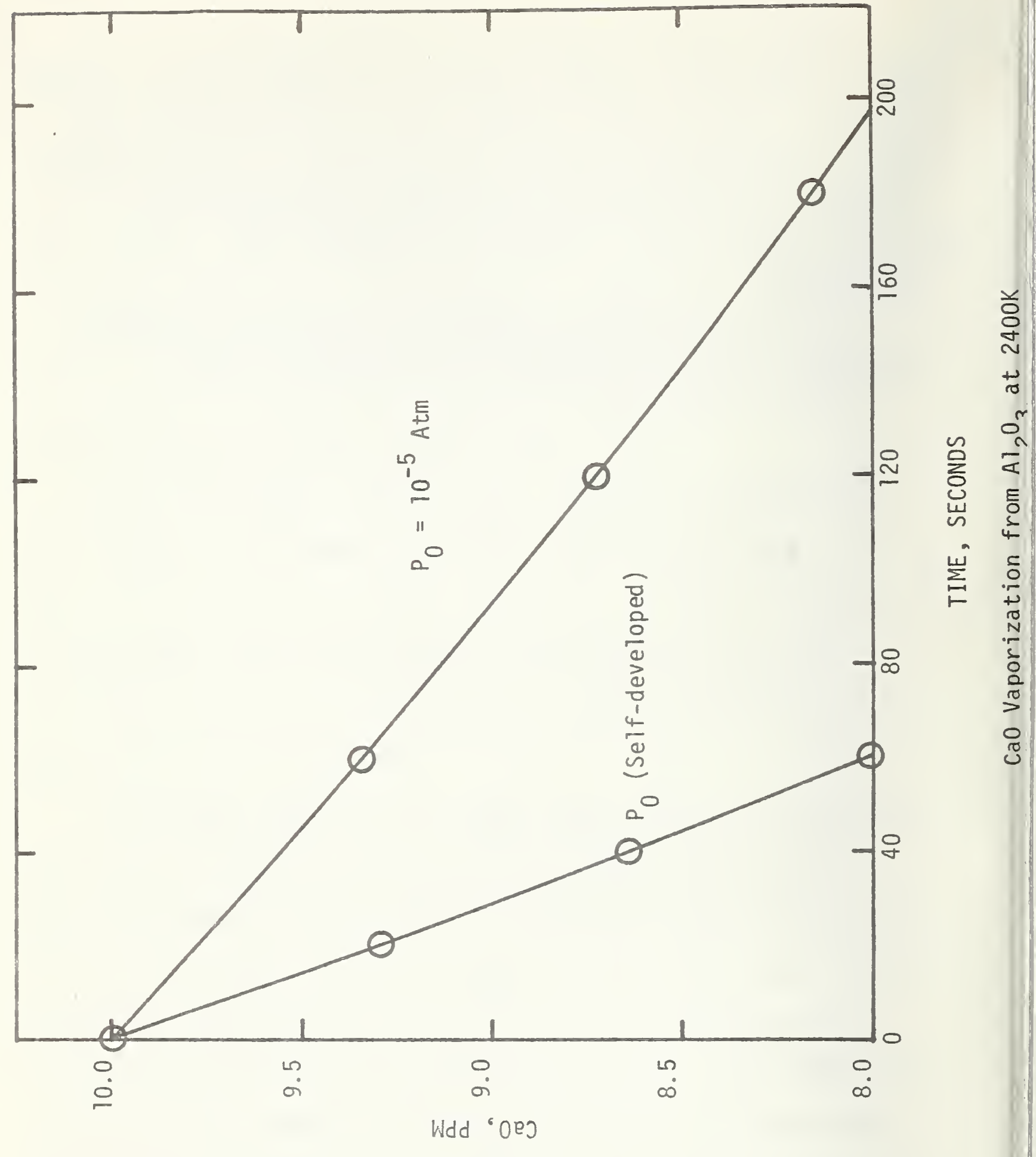


The author would like to thank Dr. John B. Wachtman, Jr. for his original suggestion and his aid in modifying vaporization equations to describe evaporative purification from mixed melts. The author is also indebted to Dr. Ernest R. Plante for many helpful suggestions and for use of a computer program from which our modified programs were written.

Financial support provided by NASA under contract $W-13,475$ \#1, is grateful1y acknowledged.

\section{REFERENCES}

1. Kandiner, H. J., and Brinkley, S. R., Ind. Eng. Chem., 42, 850 (1950).

2. White, W. B., Johnson, S. M., and Dantzig, G. B., J. Chem. Phys., 28, 751 (1958).

3. Gordon, S., and McBride, B. J., NASA, SP-273 (1971).

4. Feldmann, H. F., Simons, W. H., and Bienstock, D., U. S. Bur. of Mines, RI-7257 (1969).

5. Zeleznik, F. J., and Gordon, S., Ind. Eng. Chem., 60, 27 (1968).

6. Van Zeggeren, F., and Storey, S. H., The Computation of Chemical Equi]ibria, Cambridge University Press, 1970.

7. K1ein, M., Physical Chemistry, Vol 1/Thermodynamics, Chapter 7, edited by Eyring, H. E., Jost, W., and Henderson, D., Academic Press, New York, 1971.

8. Margenau, H., and Murphy, G. M., The Mathematics of Physics and Chemistry, 2nd.ed., page 492, D. Van Nostrand Company, Princeton, Ne's Jersey, 1956.

9. Hildebrand, F. B., Advanced Calculus for Engineers, page 353, Prentice-Ha11, New York, 1949.

10. JANAF Thermochemical Tables, Dow Chemical Co., Midland, Mich., Toose-leaf, 1972. 


\section{DETERMINATION OF THE NUMBER OF COMPONENTS}

Kandiner and Brinkley (1) have developed a convenient method for determining the number of independent components. The method is based on forming equations for the production of each chemical species from the elements and then determining the number of independent equations within the total system. Kandiner and Brinkley construct a table with column headings determined by the elements present, and row headings determined by the chemical species present. The table entries are the numbers of atoms present in each chemical species. The number of independent components is equal to the order of the largest non-zero determinant that can be formed from the table, or the rank of the matrix. For the simple $\mathrm{Al}_{2} \mathrm{O}_{3}$ system we have a matrix of rank two.

$\begin{array}{rrr}A T_{2} O_{3}(1) & 2 & 3 \\ A 1(g) & 1 & 0 \\ 0(g) & 0 & 1\end{array} \quad\left|\begin{array}{ll}2 & 3 \\ 1 & 0\end{array}\right|=-3$

If the chemical system contains only $\mathrm{Al}_{2} \mathrm{O}_{3}(\mathrm{l}) \rightarrow \mathrm{Al}_{2} \mathrm{O}_{3}(\mathrm{~g})$ or $\mathrm{KCl}(\mathrm{g}) \rightleftarrows \mathrm{K}_{2} \mathrm{Cl}_{2}(\mathrm{~g})$ we would have matricies of rank one and therefore only single components.

A1 0

$\mathrm{Al}_{2} \mathrm{O}_{3}(1)$

$\mathrm{Al}_{2} \mathrm{O}_{3}(\mathrm{~g})$
23

23
3

3

$\begin{array}{rrr} & K & C l \\ K C l(g) & 1 & 1 \\ K_{2} \mathrm{Cl}_{2}(g) & 2 & 2\end{array}$




\section{Distribution:}

National Aeronautics and Space Administration Washington, D. C. 20546

Dr. J. H. Bredt

Dr. I. Weinberg
Code MTL

Code RWM
4 copies

1 copy

National Aeronautics and Space Administration Manned Spacecraft Center

Houston, Texas 77058

Mr. W. E. Rice

Mr. J. P. Loftus

Mr. J. A. Mason
Code EA

Code AT

Code DA
2 copies

1 copy

1 copy

National Aeronautics \& Space Administration George C. Marshall Spaceflight Center Marshall Space Flight Center, Alabama 35812
Mr. H. P. Gierow
Code PD-MP-DIR
1 copy
Mr. K. R. Taylor
Code PD-MP-T
2 copies
Mr. B. 0. Montgomery
Code S\&E-DIR
Dr. W. G. Johnson
Code S\&E-R-DIR
Mr. R. E. Lake
Code $S \& E-R$
Mr. R. Schqinghamer
Code S\&E-ASTN-M
Dr. R. S. Snyder
Code S\&E-ASTN-MX
1 copy
1 copy
1 copy
1 copy
Code S\&E-ASTN-MM
1 copy
Mr. E. C. McKannan
Code S\&E-ASTN-MEV
1 copy
Mr. R. C. Ruff
Code S\&E-ASTN-MEV
1 copy
Dr. M. H. Johnston
$\mathrm{Mr}$. H. Wuenscher
Code S\&E-PE-DIR
1 copy
Code S\&E-PE-A
1 copy
Mr. I. C. Yates, Jr.
Code $S \& E-P E-A$
1 copy
Mr. L. H. Berge
Code $S \& E-P E-M X C$
Code S\&E-SSL-TR
Code S\&E-SSL-T
Code S\&E-SSL-TR
Code S\&E-SSL-TR
1 copy
1 copy
1 copy
Mr. G. M. Arnett
Mr. T. C. Bannister
Mr. M. C. Davidson
Code S\&E-ASTN-MCS
1 copy
1 copy
1 copy
1 copy
Mr. A. C. Krupnick

Jet Propulsion Laboratory

California Institute of Technology

4800 Oak Grove Drive

Pasadena, California 91103

Dr. C. H. Savage

Code 158-235

Dr. M. M. Saffren

Code 183-301

1 copy

1 copy

National Aeronautics and Space Administration Goddard Space Flight Center

Greenbelt, Maryland 20771

Dr. L. S. Walter

Code 644.0

1 copy 
National Aeronautics and Space Administration

Ames Research Center

Moffett Field, California 91103

Dr. J. A. Parker Code SC

1 copy

Gruman Aerospace Corporation

Bethpage, New York 11714

Dr. C. H. Li

1 copy

Jet Propulsion Laboratory

California Institute of Technology

4800 Oak Grove Drive

Pasadena, California 91103

Dr. J. W. Lucas

Code 180-700

1 copy 
FORM NBS.114A (1.71)

\section{IJ.S. DENT. OF COMM. \\ BIBLIOGRAPHIC DATA \\ SHEET

T. PIIBI.IC ATION OR RIIPOR'T NO.
NBSIR 73-402 NBSIR 73-402}

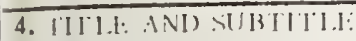

NBS Materials Science and Manufacturing in Space Research

2. Gov taccession
No.

5.

3. Recipient's Arcession $\mathrm{No}$.

5. Publication I)ite

November 1973

6. Performing Organization Code

\section{AUTHIOR(S)}

E. Passaglia and R. L. Parker

9. PI:RFORMIN(; ORGANI\%ATION NAMI! ANI) AIDIRI:SS

NATIONAL, RUREAU OI: STANI) ARISS

DIEPARTMIENT OF COMMIERCE

WASIHINGION, D.C. 20234

8. Performing Otganization

NBSIR 73-402

10. P'roject/lask/Work Init No.

12. Sponsoring Organization Name and Address

600 Independence Avenue S.W.

\section{NASA \\ FOB 10 \\ Washington, D.C. 20546}

15. SUPPL_EMENTARY NOTES

16. ABSTRACT (A 200-word or less factual summary of most significant information. If document includes a significant bibliography or literature survey, mention it here.)

This report describes NBS work for NASA in support of NASA's Materials Science and Manufacturing in Space (MS/MS) (now Space Processing) program, covering the period November 1, 1972 to October 31, 1973. The objectives of the NBS program are to perform ground-based studies of those aspects of space that could possibly provide a unique environment for making materials more perfect or more pure. The approach taken deals primarily with experimental and theoretical studies of the possible effects of the absence of gravitational forces on those materials preparation processes where the presence of gravity may be important in reducing perfection or purity. The materials preparation processes studied comprise 5 tasks in the areas of crystal growth, purification and chemical processing, and the preparation of composites.

TEY WORDS (Alphabetical order, separated by semicolons)

aterials processing; perfection; purity; space manufacturing; space processing; ero-g.

\begin{tabular}{|c|c|c|}
\hline $\begin{array}{l}\text { AVAILABILITY STATI:MI:NT } \\
\qquad \mathrm{X} \text { ] UNI.IMITEI). }\end{array}$ & $\begin{array}{l}\text { 19. NECIJRITY (I.ASS } \\
\text { (TIIS RI:PORT) } \\
\text { UNCI.ASSIIEIEI) }\end{array}$ & $\begin{array}{l}\text { 21. NO. OF PAGES } \\
127\end{array}$ \\
\hline $\begin{array}{l}\text { [IOR OIFFI IAL IOSTRIBUTION, DO NOT REI.I:ASI: } \\
\text { TO NTIS. }\end{array}$ & $\begin{array}{l}\text { 20. SI:CURITY (CI.ASS } \\
\text { (THIS PACE) } \\
\text { MNCI.ASSIIII:I) }\end{array}$ & 22. Price \\
\hline
\end{tabular}




